\title{
Individual preferences for profile attractiveness comparing two diagnostic techniques
}

Jennifer Hamilton

West Virginia University

Follow this and additional works at: https://researchrepository.wvu.edu/etd

\section{Recommended Citation}

Hamilton, Jennifer, "Individual preferences for profile attractiveness comparing two diagnostic techniques" (2007). Graduate Theses, Dissertations, and Problem Reports. 2517.

https://researchrepository.wvu.edu/etd/2517

This Thesis is protected by copyright and/or related rights. It has been brought to you by the The Research Repository @ WVU with permission from the rights-holder(s). You are free to use this Thesis in any way that is permitted by the copyright and related rights legislation that applies to your use. For other uses you must obtain permission from the rights-holder(s) directly, unless additional rights are indicated by a Creative Commons license in the record and/ or on the work itself. This Thesis has been accepted for inclusion in WVU Graduate Theses, Dissertations, and Problem Reports collection by an authorized administrator of The Research Repository @ WVU. For more information, please contact researchrepository@mail.wvu.edu. 
Individual preferences for profile attractiveness comparing two diagnostic techniques

Jennifer Hamilton, B.S., D.D.S.

A thesis submitted to the faculty of the School of Dentistry at West Virginia University in partial fulfillment of the requirements for the degree of

\author{
Master of Science \\ In \\ Orthodontics
}

\author{
Peter Ngan, D.M.D., Chair \\ Chris Martin, D.D.S., M.S. \\ Michael Bagby, D.M.D., PhD
}

\title{
Morgantown, West Virginia 2007
}

Keywords: Six Elements, Soft Tissue Cephalometric Analysis, STCA, Facial Esthetics 


\section{$\underline{\text { ABSTRACT }}$}

\section{Individual preferences for profile attractiveness comparing two diagnostic techniques}

\section{Jennifer Hamilton DDS \\ Peter Ngan DMD, Chairman}

Two analyses using soft tissue landmarks (Arnett's Soft Tissue Cephalometric Analysis, STCA and Andrews' Six Elements Diagnostic System, 6E) were compared for their ability to generate esthetic profiles in lateral repose and smiling. Photographs of 23 subjects were digitally altered to represent the STCA and 6E surgical predictions and presented to panels of professionals and lay people for rating on a visual analog scale (050). Professionals and lay people agreed that the $6 \mathrm{E}$ simulated profiles were significantly preferred to the Arnett simulated profiles in both smiling and repose. Overall the 6E profiles were rated higher (more esthetic) on the VAS compared to the Arnett profiles for both professionals (mean $\Delta 3.75 \pm 0.96$ ) and laypeople (mean $\Delta 2.33 \pm$ 0.37). These results suggest that surgical predictions using the Six Elements Diagnostic System can generate profiles that are more acceptable in smiling and repose to both professionals and lay people. 


\section{DEDICATION}

To my husband Douglas: Thanks for all the sacrifices you have made in order for me to complete 11 years of school. You are a great father and husband and I appreciate everything you do.

To my kids, Katie and Carter: You make life fun. Thanks for always being happy.

To my parents, David and Penny: Thanks for giving me the good head and knowledge base I needed to realize my dreams. You always challenged me yet kept me grounded. 


\section{ACKNOWLEDGMENTS}

Dr. Peter Ngan, for being a great teacher and chairman - always fair and kind. Your help through the years has been invaluable.

Dr. Chris Martin, for your day to day advice and help in the clinic. Thanks for your patience in teaching me the basics and letting me grow.

Dr. Tim Tremont, for all your hard work and dedication in teaching us all. You have shown us all how to practice both simply and with excellence. My attention to detail in orthodontics is because of you.

Faculty: Dr.'s Jeff Gilmore, Ned McFarland, Joe Bonello, Kerry Kirsch, John Dempsey, Mike Hazey, Anissa Anderson, for all the invaluable information you have given me over the years.

Staff: Pam and Charlotte, thanks for your patience. You taught me so much. Thanks for putting up with me while I was learning. Thanks for being great friends.

My classmates, Glenn Boyles and Spencer Hodnett, for making me look so good - just teasing. I will miss you.

My upper and lower classmates, Thomas, Joe, Jackie, Mike, Meredith, Todd, Lindsay, Nikia, Tim, Thuy, Rajia, and Mike, for making school more tolerable. You will be missed. 


\section{TABLE OF CONTENTS:}

Individual preferences for profile attractiveness comparing two

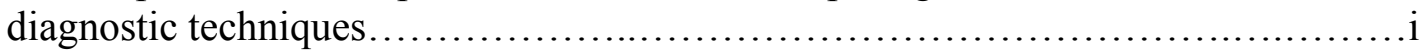

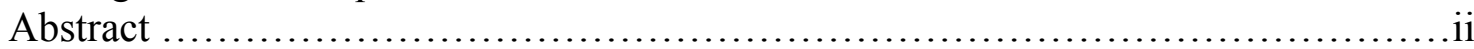

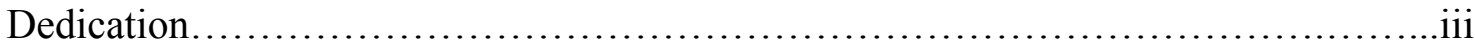

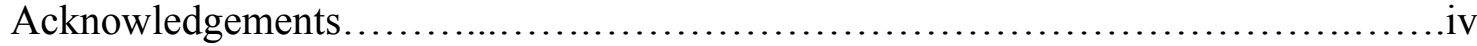

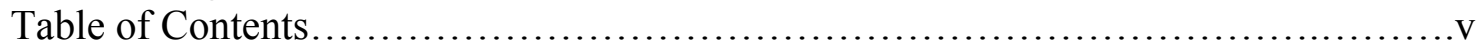

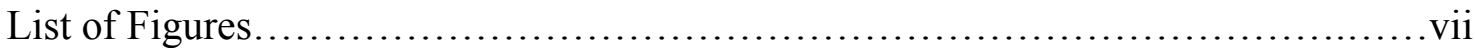

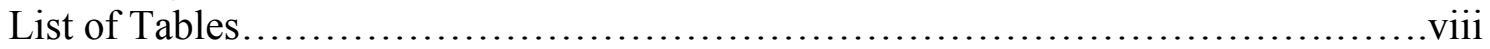

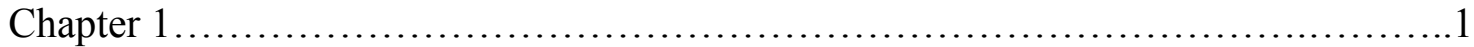

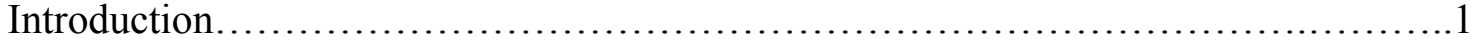

Significance of the Problem.................................................

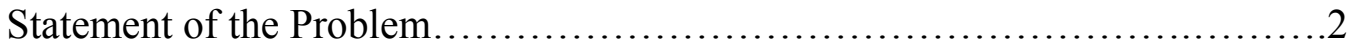

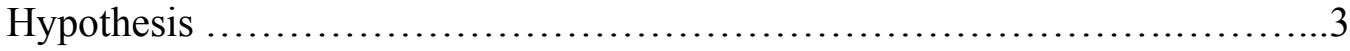

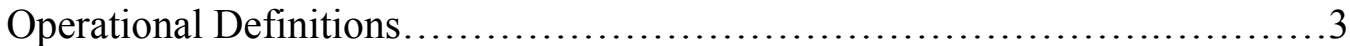

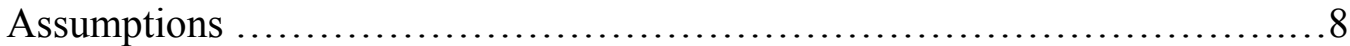

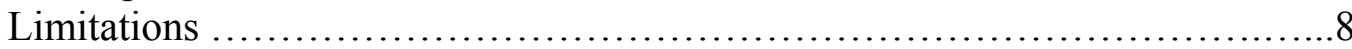

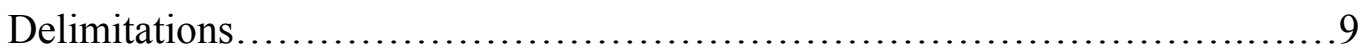

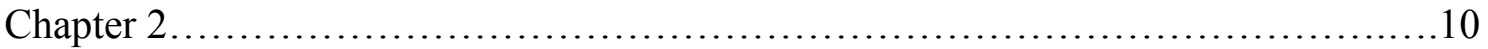

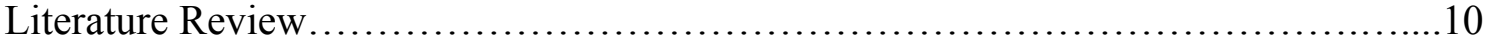

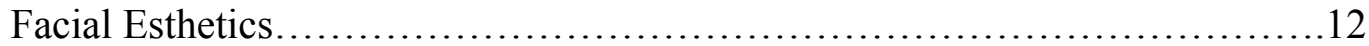

Arnett Surgical Planning............................................... 18

Arnett Soft Tissue Cephalometric Analysis (STCA) .........................26

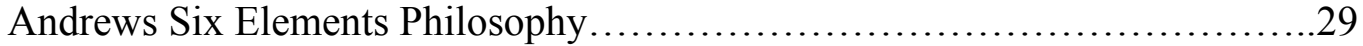

Element I: Arch Shape and Length................................ 31

Element II: AP Jaw Positions.........................................32

Element III: Buccolingual Jaw Relationships..........................35

Element IV: Superior Inferior Jaw Relationships....................36

Element V: Pogonion Prominence.................................37

Element VI: Occlusion........................................... 38

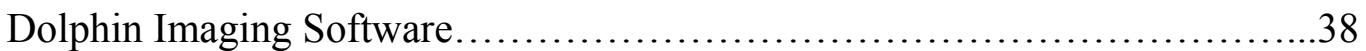

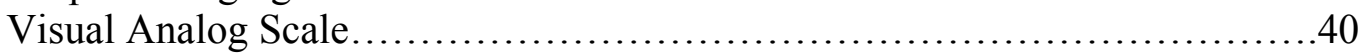

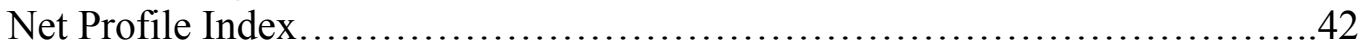

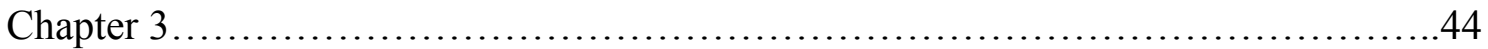

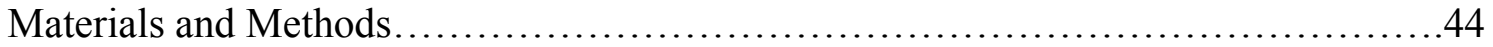

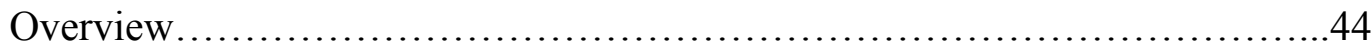

Sample Description and delimitations....................................44

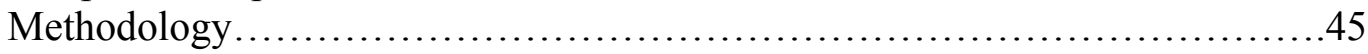

Clinical Exam.....................................................

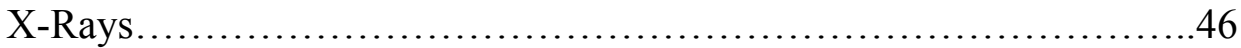

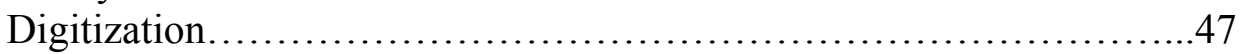

Six Elements Treatment Planning......................................48

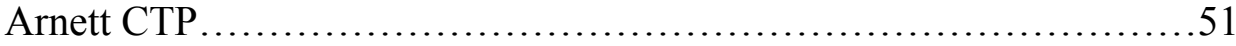

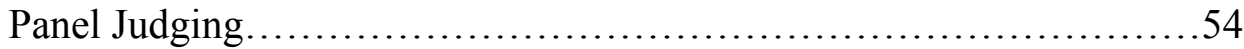

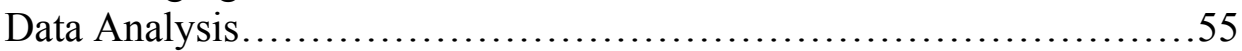




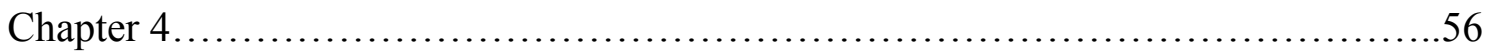

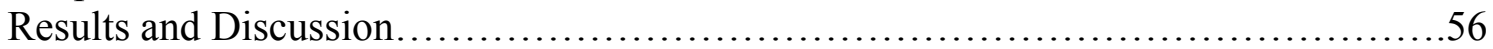

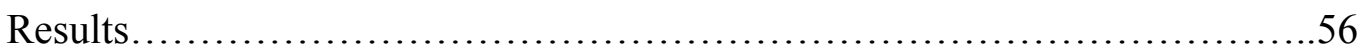

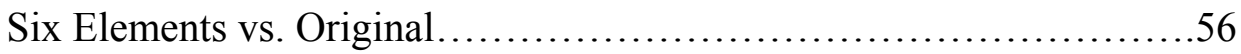

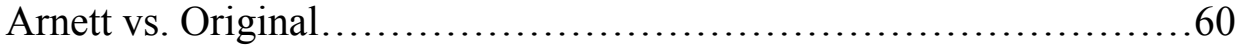

Arnett vs. Six Elements..........................................6 63

Effects of Rater Status on Profile Preferences..........................668

Effects of Subject and Rater Gender on Preferences.....................68

Intrarater Reliability ............................................69

Discussion............................................................. 70

Clinical Implications.......................................... 79

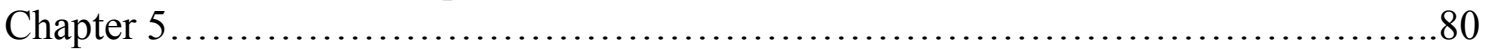

Summary and Conclusions........................................................... 80

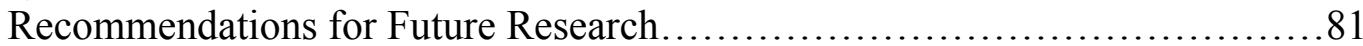

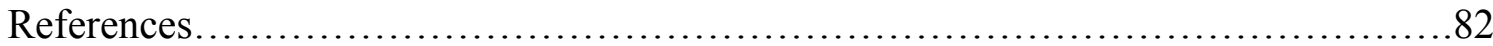

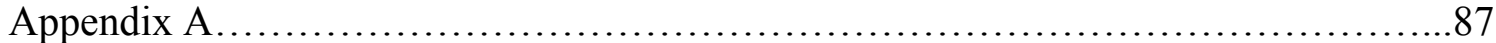

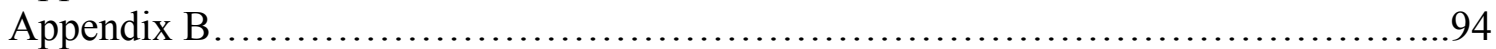

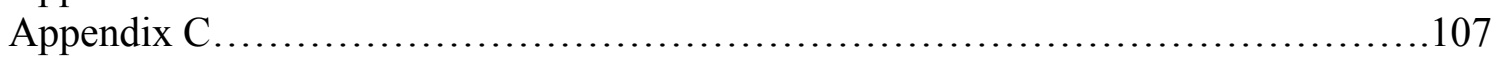

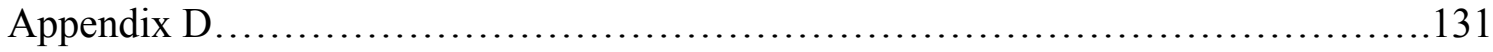

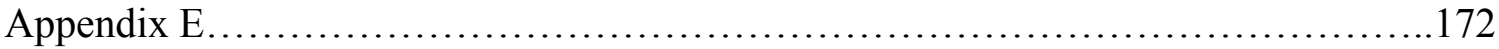




\section{LIST OF FIGURES}

Figure 1. Arnett's Clinical Exam Form.....................................22

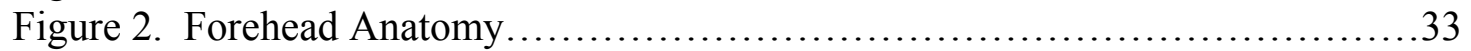

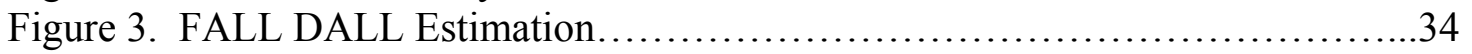

Figure 4. Forehead Inclination and the Effects on AP Jaw Positions....................35

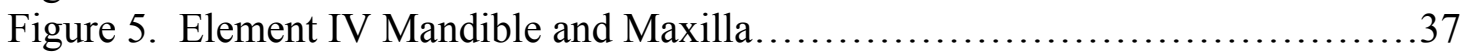

Figure 6. Visual Analog Scale............................................... 41

Figure 7. Net Profile Index................................................ 43

Figure 8. Arnett McGlaughlin Analysis on Digitized Lateral Ceph .................47

Figure 9. Six Elements Original Tracing..........................................49

Figure 10. Element I Incisors..............................................49

Figure 11. Six Elements Tracing with Element II and IV Maxilla....................50

Figure 12. Element II Mandible and Element V Pogonion...........................50

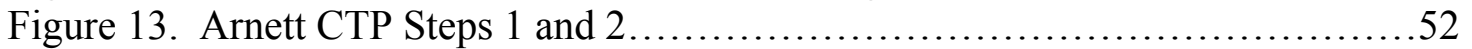

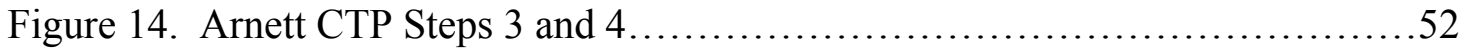

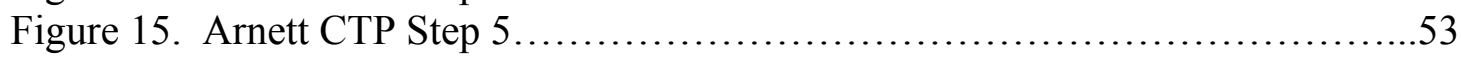

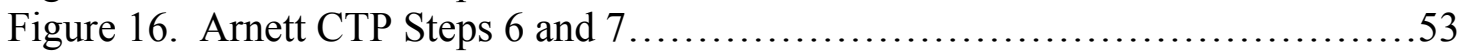

Figure 17. Comparison of 6e and Original Repose Profiles for Professionals and Laypersons......................................................58

Figure 18. Comparison of 6e and Original Smiling Profiles for Professionals and Laypersons.................................................59

Figure 19. Comparison of Arnett and Original Repose Profiles for Professionals and Laypersons........................................61

Figure 20. Comparison of Arnett and Original Smiling Profiles for Professionals and Laypersons....................................62

Figure 21. Comparison of Arnett and Six Elements Repose Profiles for Professionals and Laypersons.....................................65

Figure 22. Comparison of Arnett and Six Elements Smiling Profiles for Professionals and Laypersons. .66

Figure 23. Comparison of Arnett and Six Elements Overall Profiles for Professionals and Laypersons.

Figure 24. Example of Smiling Profile with Distorted Maxillary Incisors. 


\section{LIST OF TABLES}

Table 1. STCA means and standard deviations for males and females...............28

Table 2. Facial harmony means and standard deviations for males and females.......28

Table 3. Profile preferences of professional and layperson raters comparing Six Elements and Original...........................................57

Table 4. Profile preferences of professional and layperson raters comparing Six Elements and Original..........................................57

Table 5. Profile preferences of professional and layperson raters comparing Arnett and Original..............................................60

Table 6. Profile preferences of professional and layperson raters comparing Arnett and Original.................................................60

Table 7. Comparison of Six Elements and Arnett profiles.........................64

Table 8. Comparison of Six Elements and Arnett profiles..........................64

Table 9. Results for intrarater reliability ....................................69

Table 10. Professional and Layperson panel demographics......................... 74 


\section{CHAPTER 1 - INTRODUCTION}

Orthodontics is defined by the American Association of Orthodontists as: the area of dentistry concerned with the supervision, guidance and correction of the growing and mature dentofacial structures, including those conditions that require movement of teeth or correction of malrelationships and malformations of related structures by the adjustment of relationships between and among teeth and facial bones by the application of forces and/or the stimulation and redirection of the functional forces within the craniofacial complex(1). The "father of modern orthodontics," Edward Angle first became interested in occlusion as a prosthodontist in the late 1800's. By the 1890's, Angle's classification of malocclusions was published based on the relationship of the maxillary and mandibular first molars. Following World War II, cephalometric analyses gained widespread use in diagnosing and treatment planning (2).These analyses, such as Downs (3), Steiner(4), Tweed (5), Ricketts(6), and Jarabak (7), used internal skeletal landmarks to provide diagnostic information. Over 250 cephalometric analyses currently exist providing a multitude of normative values. In recent years more emphasis has been placed on using the facial soft tissue for diagnostic data to assist in treatment planning the so called "soft tissue paradigm (8;9)." An optimal goal would be to have the teeth in a gnathological occlusion and esthetic alignment while also having the teeth and jaws in a position to provide an esthetic face.

\section{Significance of the problem}

Treating to traditional cephalometric numbers may have adverse effects on the face(10). Orthodontics maintains as some of its principle goals (1) Function \& Occlusion, (2) Stability, (3) Periodontium and (4) Facial and Dental Esthetics (2;11;12). Some may argue that many patients seek treatment not for attainment of improved function and 
stability, but for improved facial esthetics. Currently, emphasis is being placed on treatment planning based on facial harmony of both hard and soft tissue in frontal and profile views. As expected there is significant debate about exactly what characteristics make a face harmonious or beautiful. In the last 30 years, new diagnoses have been developed with the goal of improving facial harmony and beauty. This study will look at two philosophies of treatment planning for the teeth and jaws. Both of these systems use extracranial or external landmarks to aid in diagnosis rather than internal skeletal landmarks found in traditional cephalometrics. The Arnett soft tissue cephalometric analysis (STCA) system positions the incisors and jaws based on soft tissue anteriorposterior landmarks. The Andrews' Six Elements philosophy uses the forehead as the landmark for determining the anterior posterior position of the maxillary incisor. With traditional cephalometric analyses having no universally accepted standards for facial harmony or beauty, incisor and jaw positioning is as much an art as a science. While general goals exist for the practice of orthodontics, the problem is that the specific goals may vary among orthodontists. Will the goals of the Six Elements philosophy create a more esthetic profile than that created by the Arnett system? Which of the above systems that utilize external landmarks will generate soft and hard tissue profiles that are most acceptable by professionals and laypeople?

\section{Statement of the problem}

Andrews' Six Elements philosophy relates the position of the maxillary incisor to the patient's forehead and its inclination. Arnett utilizes a soft and hard tissue analysis based on a reference plane passing vertically through soft tissue Subnasale. These two systems can generate different soft tissue profiles which may be viewed differently by 
professionals and laypeople. Which type of analysis will produce a more esthetic soft tissue profile as judged by professionals and laypeople? Hence, which landmarks, referents, and goals are better to use when diagnosing and treatment planning: Andrews' or Arnett's?

\section{$\underline{\text { Hypothesis (Null) }}$}

1. There is no significant difference in esthetic ratings between the Andrews Six Elements soft tissue profile in repose and the Arnett STCA profile in repose.

2. There is no significant difference in esthetic ratings between the Andrews Six Elements lateral smiling profile and the Arnett STCA lateral smiling profile.

3. There is no difference in the rating of the Andrews Six Elements profiles and the Arnett profiles between dental professionals and laypeople.

4. There is no difference in the rating of the Andrews Six Elements profiles and Arnett profiles based on subject or rater gender.

\section{Operational definitions and abbreviations}

Alar base point - Arnett landmark representing the deepest concavity at the nasal base

Anatomical forehead - the exposed skin from the hairline (or where the hairline once was) to glabella

Basal bone - the bone that supports the alveolar process. Clinically it is different from alveolar-process bone in that it does not atrophy after teeth are extracted Brachyfacial - short, square facial type

Centric relation (CR)- the uppermost position of the condyle in the fossa(14). 
Cheekbone point - the point of the most prominence on the cheekbone in $3 / 4$ view directly beneath the outer canthus of the eye (13)

Clinical forehead - the portion of the forehead that is oriented more with the face than the scalp. For straight foreheads, it is between trichion and glabella. For rounded or angular foreheads, it is between superion and glabella.

DALL - dentition's anterior-limit line - a line that parallels the head's frontal plane and passes through the maxillary incisor's facial axis (FA) point.

Diagnosis - definition of the patient's problem

Dolichofacial - long, narrow facial type

Element I maxillary incisor- the roots of the incisors are centered over the buccolingual borders of the basal bone, crowns inclined so they can interface correctly.

Element II - for the purpose of this study, the position of the maxilla and mandible where the FA point of the Element I maxillary incisor touches the GALL and the incisors are coupled in their Key I positions..

Facial beauty - the attractiveness of a face.

Facial harmony - when the external facial features that are indirectly within dentistry's milieu are as balanced as they can be.

FA point - incisor facial axis point - a point on the midsagittal plane of the face of the clinical crown midway between its gingival and occlusal borders.

FALL - forehead's anterior-limit line - a line that parallels the head's frontal plane and passes through the forehead's FA point.

FALL DALL - the difference between the FALL line and DALL line measured in millimeters expressed as red, green, or black. Red means the DALL is more anterior than 
the FALL. Green means the DALL and the FALL are on the same plane. Black means that the DALL is behind the FALL.

FFA point - forehead facial axis point - a point on the midsagittal plane of the forehead that is midway between the superior and inferior borders of the clinical forehead GALL - Goal Anterior Limit Line - a line that parallels the head's frontal plane and respresents the optimal anterior border for an Element I dentition. It passes through the FFA point when the cant of the forehead is 7 degrees or less. For every degree the forehead is canted more than 7 degrees, it passes through a point on the forehead that is .6 $\mathrm{mm}$ anterior to the FFA point, but never beyond glabella unless the patient demands it. Glabella - the area on the frontal bone above the nasion and between the eyebrows. In profile its most prominent portion is considered the inferior border of the clinical forehead.

Gonion - the most inferior point on the angle of the mandibular body Inclination - the faciolingual cant of the facial axis of the maxillary clinical crown when measured from a line perpendicular to the occlusal plane. Inclination is positive when the occlusal portion of the facial axis is facial to its gingival portion, negative when lingual. Key I - Interarch relationships - seven parts:

1. the mesiobuccal cusp of the maxillary first molar occludes in the mesial buccal groove of the mandibular first molar.

2. the distal marginal ridge of the maxillary first molar occludes on the mesial marginal ridge of the mandibular first molar.

3. the mesiolingual cusp of the maxillary first molar occludes in the the mandibular first molar's central fossa. 
4. the maxillary premolar buccal cusps rest in the embrasures of the mandibular premolars.

5. the maxillary premolar lingual cusps rest in the fossae of the mandibular premolars.

6. the maxillary canine rests in the embrasure of the mandibular canine and first premolar with the tip of its cusp slightly mesial to the embrasure.

7. the maxillary incisors overlap the mandibular incisors and the midlines of the arches match (15).

Nasion - the anterior point of the intersection between the nasal and frontal bones.

Natural head position - a standardized and reproducible orientation of the head in space when focusing on a distal point at eye level (16).

Menton - the most inferior point of the anterior mandible. Soft tissue menton is defined as the most inferior point on the soft tissue chin.

Mesofacial - the normal or average facial type

Morph - the computer aided alteration of a picture in size, shape, or proportions.

Neck-throat point - subjective junction of the patient's neck and throat (13)

Orbital rim marker - Arnett point on the bony portion of the orbital rim directly below the pupil when the patient is in a straight ahead gaze (13).

STCA - soft tissue cephalometric analysis - standards set forth by Arnett

Subnasale - the point at the inferior border of the nose where the upper lip begins

Subpupil point - Arnett point directly below the pupil in a straight ahead gaze place halfway between the vertical distance of the cheekbone and alar base points (13) 
Superion - the point on angular and rounded foreheads that, in profile, represents the superior boundary of the clinical forehead, that portion of the forehead that is related more to the face than to the scalp(17).

Treatment - execution of the treatment plan Treatment planning - planning changes needed to eliminate the problems based on the diagnosis

Trichion - The superior border of the anatomical forehead. Anantomically it is a line on the forehead that is, or once was, the hairline. If the hairline has receded, it can be identified by having the patient raise their eyebrows and note the line of demarcation between the smooth skin of the scalp and the furrowed skin of the forehead (17).

True Vertical Line (TVL) - the line through subnasale perpendicular to natural head position

VTO - Visual Treatment Objective - an estimation of the result of treatment used to assess how tooth and bone movement to correct the bite will impact the face (16). WALA ridge - a band of soft tissue immediately superior to the muccogingival junction in the mandible.(18)

Will's Plane - a vertical plane running through the Element I mandibular incisor's FA point perpendicular to the occlusal plane(17). 


\section{Assumptions}

Several assumptions must exist in order to perform this study. These are as follows:

1. Every person can perceive facial beauty and harmony.

2. Facial harmony can be quantified based on a visual analog scale system.

3. The Arnett true vertical line (TVL) through or approximating Subnasale is vertically parallel to the GALL line.

4. The use of different treatment plans can produce different facial profile outcomes.

5. Given computer simulation programs, these outcomes can be simulated and judged.

6. Computer generated profiles resemble the changes in patients that would actually occur with treatment.

\section{$\underline{\text { Limitations }}$}

1. Personal preferences for characteristics contributing to facial beauty and harmony may bias the panelist rating on the visual analog scale.

2. Some panel members may score based on nonorthodontic standards, for example based on quality of facial parts rather than the position of such parts.

3. Lateral cephalometric radiographs may present with indiscernible landmarks due to radiographic techniques and variables.

4. There is a certain degree of subjectivity in judging where cephalometric landmarks are located, Arnett soft tissue exam and estimating the FALL/DALL. 


\section{$\underline{\text { Delimitations }}$}

To be included in this study, all subjects must:

1) have a full set of orthodontic records including lateral cephalometric x-rays in repose and smiling, study models, FALL DALL estimation, Arnett soft tissue clinical exam, and the following photos with bared foreheads: 1) frontal repose, 2) frontal smiling, 3) lateral repose, 4) lateral smiling.

2) have lateral repose and smiling photos matching the lip and soft tissue posture of the lateral cephalometric films.

3) have lateral cephalometric films with discernable landmarks for diagnostic purposes and have radiographic markers at the FFA, glabella, superion or trichion, subnasale, cheekbone, soft tissue orbital rim, nasal base, subpupil area, and neckthroat point.

4) have relatively aligned maxillary incisors to aid in computer simulations. 


\section{CHAPTER 2 - LITERATURE REVIEW}

In the 1890's Edward Angle, the acknowledged "father of modern orthodontics" defined normal occlusion and three classes of malocclusions based on the anteriorposterior relationship of the maxillary and mandibular first molars. Class I normal occlusion has the upper first molar mesiobuccal cusp occluding in the buccal groove of the lower first molar. Class I malocclusion has a normal molar relationship, but includes malposed teeth or rotations. Class II malocclusion is also termed distocclusion and involves the lower molar distally positioned relative to the upper molar. Class III malocclusion, mesiocclusion, has the lower molar positioned anterior relative to the upper first molar(2). In order to attain this ideal Angle's occlusion, he taught that all teeth should be preserved and non-extraction theories became widespread. Facial esthetics was less emphasized due to the newfound interest in occlusion. It was not until the 1930's that facial esthetics gained emphasis and extraction treatment resumed. Heavy extraoral forces were once again used for orthopedic movement of jaws and facial esthetics generally improved with treatment (2).

After World War II, orthodontists began using intracranial structures derived from cephalometric studies as landmarks for determining skeletal growth patterns. It soon became evident that not all malocclusions were due to malpositioned teeth, but that some were due to malpositioned upper or lower jaws. Multiple analyses followed, each with different planes, lines, referents, landmarks, and angles to use to diagnose skeletal and dental malocclusions. So many existed, yet numbers rarely correlated due to the samples and standards used to define the normative values. Orthodontists who treated cases to these numbers found that often facial esthetics suffered as a result(10). Diagnosing and 
treating for facial beauty using cephalometric norms is unreliable since the hard tissue structures are not consistently related to the soft tissues of the face (19). Johnson and Smith found that the only variable that strongly predicted the esthetics of extraction patients was the office in which they were treated. This indicates that some practitioners handle extraction cases using different mechanics. These differences in treatment mechanics can create different facial outcomes. It has been shown that extraction vs. nonextraction cases are similar in esthetics if managed properly(20;21). Park and Burstone found that treatment to any given dentoskeletal standard has questionable validity in producing desirable facial esthetics or reproducible profiles following successful treatment because of the inconsistency in soft tissue thicknesses between patients (10).

As the accuracy of surgery has improved and surgeons are able to position the maxilla and mandible to within a millimeter, orthodontists as professionals must decide exactly where those jaws should be placed. No well defined or widely accepted standards for placement of jaws based on esthetics are currently being used. This makes the practice of orthodontics alone or in combination with surgery as much, if not more an art than a science.

Currently two philosophies are emerging on placement of the dentition and supporting bones in relation to esthetics. Dr. G. William Arnett, an oral surgeon based in California has devised a series of anterior-posterior measurement norms for the soft tissues of the face. On the other hand, Dr. Larry Andrews, an orthodontist also residing in California bases jaw and tooth positions on the soft tissue inclination of the clinical 
forehead. Although the two philosophies seem very different, similarities in ideal tooth and jaw positions may exist.

\section{Facial Esthetics}

With the paradigm shift in orthodontic treatment from correction of crooked teeth to treating to create esthetically pleasing faces, patients often seek treatment with a goal of having their facial appearance improved. In today's society, a high value is placed on physical attractiveness. Dion et al. found that attractive individuals are believed to be more likely to get better jobs, have more successful marriages, and to experience a happier, more fulfilling life(22). Physical attractiveness extends even into the job market, with influence on job recommendations regardless of it having no relationship to job performance or responsibility(23). Berschield and Gangestad stated "the social psychological effects of physical attractiveness are pervasive, strong, and generally uniform in nature. They are such that the physically attractive, whether male or female, old or young, black or white, or of high or low socioeconomic status, receive preferential treatment in virtually every social situation examined thus far (24)." It has been recognized that overall physical appearance, more specifically facial balance and symmetry, is an indicator of how people are perceived by others in society as well as how they perceive themselves $(25 ; 26)$. It is not surprising that many prospective orthognathic surgery patients indicate facial esthetics as a strong motivator for seeking treatment $(27 ; 28)$. A study by Vargo et al. (2003) indicated that a patient's decision to seek orthognathic surgical treatment was highly correlated to a layperson's rating of their facial attractiveness (28). 
There seems to be no exact rules governing why a face is beautiful. Professionals and artists alike have attempted to define and recreate an ideal. Although beauty may be easily recognized, objective standards useful to clinical practice are difficult to define. Perception of beauty may also have cultural and ethnic biases (29-31). Auger et al. (1999) observed that no longer is a Class I occlusion a benchmark for successful orthodontic treatment; the resultant soft tissue contours are often equally important in defining a well treated case (32). These researchers studied photos from five time periods to determine if there are any time-dependent differences in the soft tissue profiles of white females throughout the twentieth century. The study consisted of statistical analysis of linear and angular measurements of 25 photos over five time periods. No significant differences between time periods existed for the frontonasal angle, nasal tip angle, nasolabial angle, and total facial angle. However, there was a statistical difference in the interlabial angle (becoming more acute with time) and angular evaluation of lip projection (projecting more with time). In more recent studies there was a trend for fuller and more anteriorly positioned lips as well as a preference for fuller lips in female subjects (32). Other studies have been conducted that indicate the American public now prefers the more youthful appearance of fuller lips $(33 ; 34)$. Cochrane et al. found that orthodontists chose Class I profiles as most attractive, while nonorthodontists commonly chose a Class III or long face as the favored profile (35).

Nanda et al. studied soft tissue harmony and growth during orthodontic treatment. The authors developed a study in which an effort was made to find ideal combinations of facial components through a series of profiles in silhouette that would be evaluated by members of the dental profession. By varying the size of the lips, nose, chin, angle of 
facial convexity, and facial angle, it was hoped to assess the most desirable combinations as well as the least desirable. On the basis of data available on average thickness of the soft-tissue integument and its relationship to the underlying skeleton, and ideal skeletal and soft-tissue facial profile was constructed(36).

Six series of profiles varying from the ideal were generated, three series to a page. Each series consisted of seven profiles. The first series showed lips that were protruded or retruded in $2 \mathrm{~mm}$ increments from the original profile, which was the middle in the series. The second series of profiles were the same as those made for the first except that the size of the nose had been increased by $6 \mathrm{~mm}$ on all profiles. The third series was the same as the first series except that the chin size was increased by $6 \mathrm{~mm}$ on all profiles. The fourth series was based on the ideal profile with changes made in the soft-tissue facial angle in increments of \pm 1.5 degrees. The fifth series used the ideal profile and changed soft tissue A-point to change the angle of convexity in increments of 3 degrees. The sixth series was a combination of the fourth and fifth series in which changes in facial angle and convexity were incorporated(36).

A professional panel of 545 orthodontists was asked to rank in order from 1 to 7 , the most-favored to least-favored profile in each series. It was noted that for men and women the nose and chin configurations preferred were close to the constructed norms. The least-favored positions of nose and lips were the most protruded. Interestingly, seventy-five percent of the participants were able to better articulate on what they favored least than on what they favored most. Overall, a preference for a straighter profile was shown for both men and women. The study also showed that the judgment of lip protrusion/retrusion was dependent on the positions of the chin and nose (36). 
Dunlevy et al. sought to determine if dental professionals (i.e., orthodontists, oral surgeons) perceived orthognathic changes similarly, and if these professionals differ with laypersons in their perception of orthognathic procedures. A study was designed with 2 groups of 19 women with group 1 undergoing a mandibular advancement and group 2 undergoing a maxillary repositioning and advancement. Black and white pre- and postreatment frontal, oblique, and profile photographs of the patients were taken. The panels consisted of 3 groups (orthodontists, oral surgeons, and laypersons) and were asked to rank patients based on improvement in facial appearance. Each group viewed the groups of photographs and was given thirty minutes to perform the task. Millimeter changes in $\mathrm{x}$ and $\mathrm{y}$ coordinates quantified skeletal changes following surgery(37).

The results showed the trend for all three groups to rank patients similarly. However, there were some differences. For example, patients with a change of less than $5 \mathrm{~mm}$ at pogonion in both the $\mathrm{x}$ and $\mathrm{y}$ directions received higher improvement rankings from laypersons than from orthodontists. Surgeons ranked patients with a mandibular advancement higher (81\%) than orthodontists or laypersons. Interestingly, almost 25\% of the maxillary surgical cases were judged to not have improved by all three responding groups(37).

In general, all the raters seemed to correlate esthetic improvement with the amount of skeletal change required to correct jaw-size discrepancies. Thus, patients requiring large skeletal movements were more apt to be judged as having esthetic improvement by all three groups. The study was able to point out that while all three groups tended to agree on most orthognathic movements and their outcomes, differences do exist(37). Burcal et al. conducted a similar study and reported that orthodontists and 
oral surgeons focused more on the chin whereas laypersons focused more on the lips (38).

Spyropoulous and Halazonetis (2001) researched the significance of soft tissue profile on facial esthetics. Photos of twenty female patients were digitally altered to have an "average" soft tissue profile. The "average" profile was the composite of the twenty subject's profiles. The modified photos were presented with the originals for panel judging by two panels. One panel consisted of 10 laypeople and the other was a panel of 10 orthodontists. Interspersed with the original and modified photos, were three photos which were altered to be the composite average of the facial characteristics. These three photos had the one composite face with three different hairstyles. Panels rated the photos for attractiveness on a scale of 0 (least attractive) to 10 (most attractive). Good agreement was found between the judges, although the orthodontists tended to be more influenced by the profile outline than did the laypersons. The three averaged composite faces were consistently given the highest scores. The modified photos were given higher scores than the originals indicating that the overall facial attractiveness was influenced by the soft tissue outline form. However, the modified photos were never rated high enough to reach the composite images showing that factors other than the profile form may be more influential in facial esthetics(39).

A study by Czarnecki et al. found that straighter soft tissue profiles are preferred in men with a slightly convex profile considered most attractive for females. These researchers presented various silhouette combinations of noses, lips, and chin relationships with changes in facial angles and angles of convexity. Among the most unfavorable combinations, the worst were either with an extremely recessive chin or 
those with excessively convex faces. The amount of acceptable lip protrusion increased with an increased size of nose or chin. This study suggests that treatment goals with regards to facial esthetics should be based more on producing balanced and harmonious facial profiles than on rigid adherence to standard average cephalometric skeletal and dental parameters(40).

Researchers from many disciplines have studied the various aspects of facial attractiveness. Studies show that the soft tissue profile affects ratings of facial attractiveness. Studies also show that facial features affect attractiveness ratings, possibly more than profile(39). Yet, with all the research on facial beauty and harmony, we still have no universal standards. There are many who believe that the standard for a harmonious face as well as facial beauty is determined by the divine proportion. This proportion of 1: 1.618 has been found throughout history in art, architecture, fashion, flowers, birds, and the human body. Harmonious and beautiful faces, when examined, often conform in some way to the divine proportion (41). The proportion can be used for various areas of the face in frontal or profile views. Ricketts believed that organisms conforming to the divine proportion were not only considered beautiful, but also biologically healthy and fertile(42). Others support this claim noting that patients who are considered mesofacial have less medical problems than brachyfacial or dolichofacial patients. Brachyfacial patients tend to have myofascial pain and temporomandibular disorders while dolichofacial patients are more prone to upper airway obstructions (41). An important aspect of the divine proportion is symmetry. If an individual is not bilaterally symmetrical they can not be divinely proportioned. Treatment to such a standard as the divine proportion however, is not clinically relevant or attainable. 
Orthodontics has a profound effect on facial esthetics from both the frontal and profile views. Surgical advances now allow us to place the jaws precisely where we want them to improve facial attractiveness as well as function. However, the exact position where the jaws should be positioned to be the most attractive is still unknown. Although a person's ability to recognize beauty appears to be innate, the translation of this into treatment goals is difficult(43). Furthermore, the orthodontist's role in resolving the patient's dental and facial esthetic concerns is complicated by the number of factors, such as the effects of growth and aging, that one must consider. Treatment goals are even more challenged by professional bias and patient bias and desires (44). Dr. Arnett's STCA and CTP and the Andrews Six Elements philosophy currently have the most detailed descriptions for jaw placement for optimal facial esthetics. Each of these schools of thought will be further examined.

\section{Arnett Surgical Planning: Clinical Exam}

Orthodontics alone or in combination with orthognathic surgery can alter soft tissue relationships. Two outcomes may occur with treatment: the patient's soft tissue looks more harmonious or it looks less harmonious. Underlying cranial landmarks are unpredictably related to the soft tissue coverings of the face (19). Therefore, using radiographic cephalometric norms to plan surgical jaw movements is unreliable. Orthodontists and surgeons have found that treating and correcting an occlusal discrepancy does not necessarily treat or correct the underlying facial imbalance. The soft tissue covering the teeth and bone is highly variable in thickness, even more variable that the position and size of the teeth and bones (45). 
Arnett and other surgeons have focused their own research on facial esthetics to aid in surgical treatment planning. Arnett and other authors have noted that cephalometric measurements should not be the primary diagnostic tool for planning orthodontic and surgical treatments. Rather, a set of Facial Keys from a detailed clinical exam should be a major diagnostic tool. Arnett and Bergman have defined a list of 19 facial traits to examine and consider when planning for orthognathic surgery. Each should be considered to arrive at the best treatment plan for the individual. Along with the clinical exam, Arnett has developed a soft tissue cephalometric analysis (STCA) to assess the patient's soft tissue characteristics as they relate to the underlying bony tissues. This analysis includes such measurements as upper and lower lip thickness and length and a series of anterior-posterior measurements to a defined vertical line running through or near Subnasale called the True Vertical Line (TVL). Arnett bases his surgical treatment plan on both the clinical exam of the patient and the STCA.

For the clinical exam, Arnett recommends having the patient in natural head posture (NHP). This is, for most patients, the head orientation that the patient assumes naturally (43). However, patients with certain skeletal problems may assume unnatural head positions in order to camouflage the discrepancy. In these instances, the experienced clinician may decide to place the patient in a corrected natural head position (46;47). Arnett also recommends examining the patient in centric relation with relaxed lips. Typically a wax bite taken in centric relation is used to maintain the patient's jaw position while the exam is performed in the anterior-posterior, transverse, and vertical dimensions (43). 
The 19 traits are as follows and will be discussed in greater detail: outline form, facial level, midlines, facial thirds, lower facial third evaluation, incisor exposure, interlabial gap, closed lip position, smiling lip level, profile angle, nasolabial angle, maxillary sulcus contour, mandibular sulcus contour, nasal base to lip contour, nasal projection, throat length, and subnasale to pogonion (48). Refer to Figure 1 for the clinical exam form Arnett recommends using. Outline form assesses the patient's symmetry from a frontal form in a horizontal dimension comparing right and left sides. When judging the outline form it is important to keep in mind whether or not the orthodontic and/or surgical treatment plan necessary for bite correction will correct or accentuate the current facial imbalance. The most common sites for asymmetry are the chin, mandibular angles, and cheekbones (48). 
FACIAL EXAMINATION SUMMARY

Name

Age

Orthodontist

\begin{tabular}{|c|c|c|c|c|c|c|c|}
\hline 1. Vertical & Range & Patient & \multicolumn{5}{|c|}{ Possible ways to normalize vertical } \\
\hline Middle $1 / 3$ & $62-75 \mathrm{~mm}$ & & & & & & \\
\hline Overbite & $3 \mathrm{~mm}$ & & LFI & BSSO & \multicolumn{2}{|c|}{ Crown length change } & $\begin{array}{l}\text { Orthodontic crown torque } \\
\text { change }\end{array}$ \\
\hline Upper lip height (a) & $19-22 \mathrm{~mm}$ & & & & & & \multirow{2}{*}{ Lip length surgery } \\
\hline Inter-labial gap (b) & $1-5 \mathrm{~mm}$ & & \multirow{6}{*}{ LFI } & \multirow{3}{*}{ BSSO } & \multirow{3}{*}{ Overbite correction } & \multirow{2}{*}{ Lip posture change } & \\
\hline Lower lip height (c) & $42-48 \mathrm{~mm}$ & & & & & & \multirow{2}{*}{$\begin{array}{l}\text { Chin osteotomy- } \\
\text { change height }\end{array}$} \\
\hline Lower $1 / 3$ height & $62-75 \mathrm{~mm}$ & & & & & Submental lipectomy & \\
\hline Mx incisor exposure (reduced) & $1-5 \mathrm{~mm}$ & & & & \multirow{2}{*}{$\begin{array}{l}\text { Crown length } \\
\text { change }\end{array}$} & \multirow{3}{*}{ Lip length surgery } & Crown torque change \\
\hline Mx incisor exposure (smile) & 8 crown to 2 gingiva & & & & & & Gingivectomy \\
\hline Closed lip & $\begin{array}{l}\text { Strain less } \\
\text { touch }\end{array}$ & $\begin{array}{l}\text { Strain } \\
\text { redundaxy }\end{array}$ & & BSSO & Overbite correction & & \\
\hline Mx incisor height & $9.5-11.5 \mathrm{~mm}$ & & & & \multicolumn{2}{|c|}{ Crown length change } & Gingivectomy \\
\hline Upper vermillion & $6-9 \mathrm{~mm}$ & & & & \multirow{2}{*}{\multicolumn{3}{|c|}{ Lip reconstruction procedure }} \\
\hline Lower vermillion & $8-12 \mathrm{~mm}$ & & & & & & \\
\hline
\end{tabular}

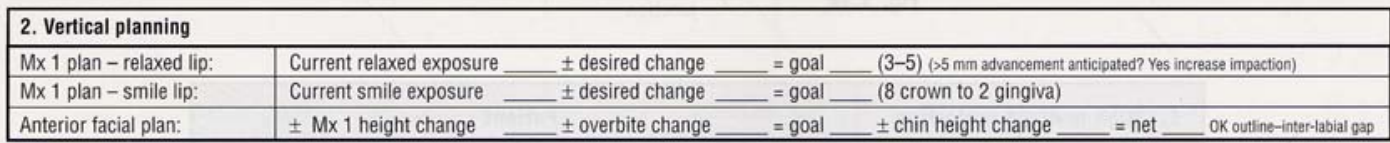

\begin{tabular}{|c|c|c|c|c|c|c|c|}
\hline 3. Midlines & \multicolumn{2}{|c|}{ Patient } & \multicolumn{5}{|c|}{ Possible ways to normalize facial midlines } \\
\hline Nasal tip & to right & to left & \multicolumn{3}{|c|}{ LFI - shorten septum } & & \\
\hline Philtrum & to right & to left & & & \multicolumn{3}{|c|}{ Dental midlines measured to philtum } \\
\hline$M \times 11$ & to right & to left & LFI & & \multirow{2}{*}{\multicolumn{2}{|c|}{ Orthodontics }} & \multirow{3}{*}{ Canine cant change } \\
\hline Md 11 & to right & to left & & \multirow{2}{*}{ BSSO } & & & \\
\hline Chin & to right & to left & & & \multicolumn{2}{|c|}{ Chin osteotomy } & \\
\hline
\end{tabular}

\begin{tabular}{|c|c|c|c|c|c|}
\hline 4. Facial levels & \multicolumn{2}{|c|}{ Patient } & & \multicolumn{2}{|c|}{ Possible ways to normalize facial levels } \\
\hline Eyes & R down & L down & Visualize cant $Y \quad N$ & \multicolumn{2}{|c|}{ None } \\
\hline Mx canines & $R$ down & L down & Visualize cant $Y \quad N$ & LFI-skeletal & \multirow[t]{2}{*}{ Orthodontics-dental } \\
\hline Md canines & $R$ down & L down & Visualize cant $Y \quad N$ & \multirow{3}{*}{ BSSO-skeletal } & \\
\hline Md body level & $R$ down & L down & Visualize cant $Y \quad N$ & & Heat treated $\mathrm{HA}$ augmentation \\
\hline Chin level & R down & L down & Visualize cant $Y \quad N$ & & Chin osteotomy \\
\hline
\end{tabular}

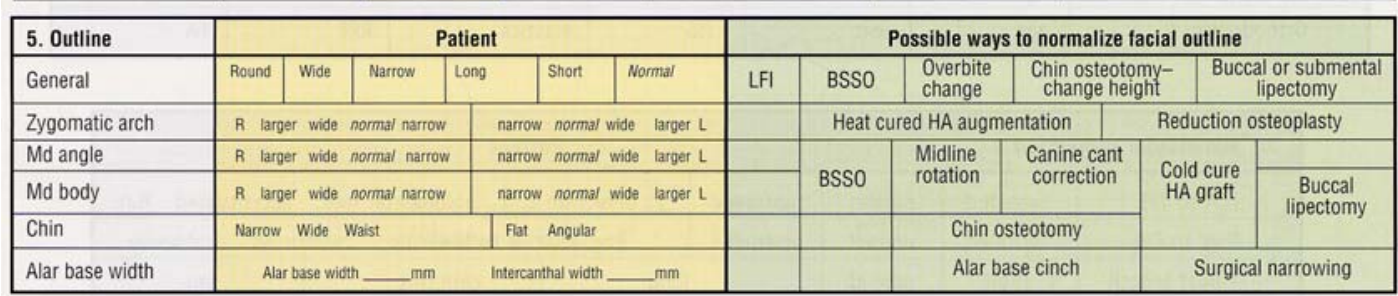




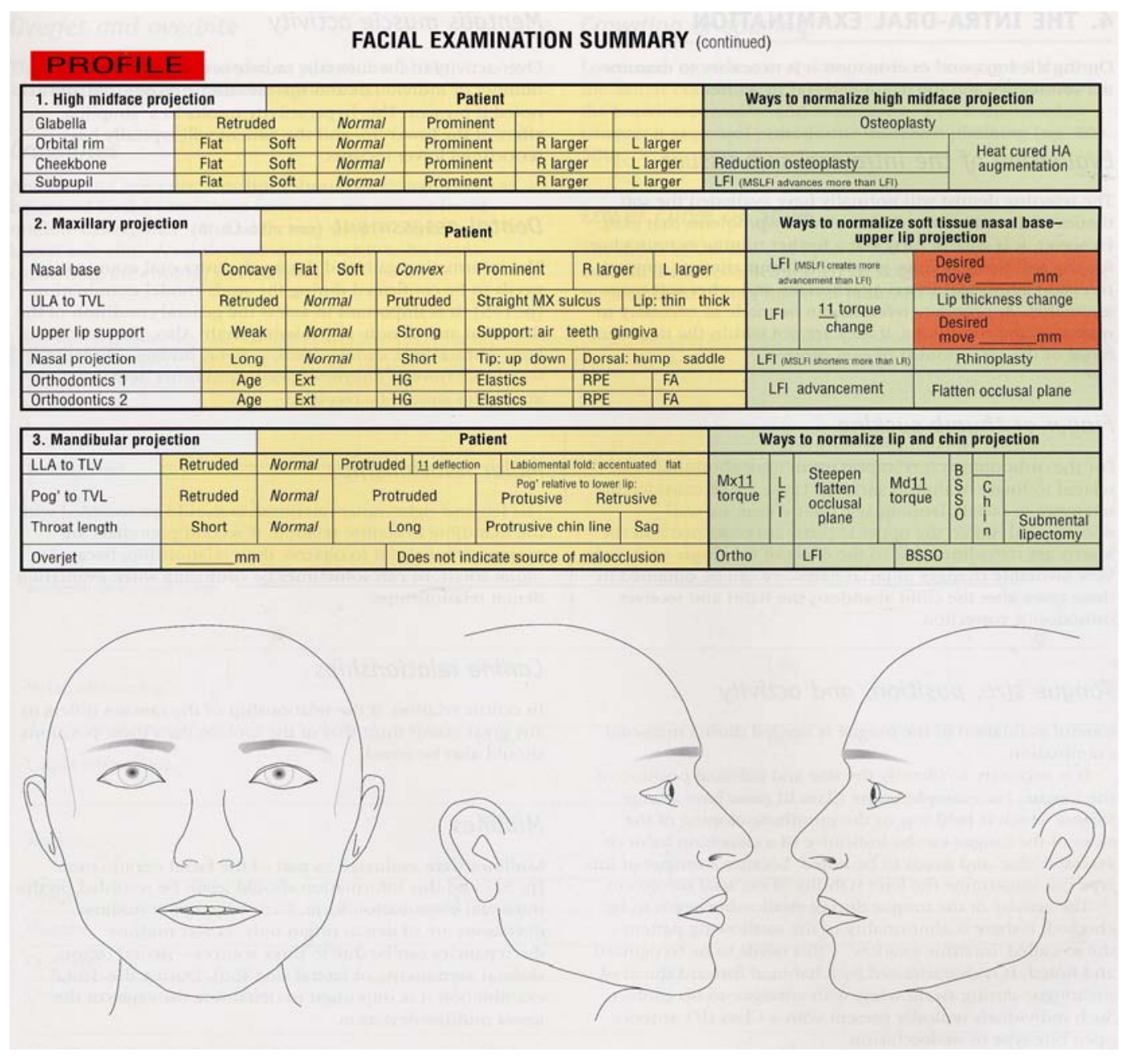

Figure 1: Arnett's Clinical Exam Form

Facial levels are examined from the frontal view. This is also an assessment for symmetry, however, in a vertical dimension. The patient's eyes, maxillary and mandibular canines, mandibular body level and chin level should be assessed comparing sides. For example, a note may be made that the right eye is lower on the face than the left eye or that there is a cant to the maxilla that is visualized clinically $(46 ; 48)$. Midlines are assessed and noted to be off to the right or left. It is absolutely necessary to have the 
patient in first tooth contact, in centric relation, with relaxed lip posture for midline examination. The nasal tip, philtrum, maxillary and mandibular central incisors and chin should all be examined to determine if they are positioned correctly to the facial midline $(46 ; 48)$.

For assessment of the facial one thirds, the face is divided into vertical thirds from hairline to midbrow, midbrow to subnasale, and subnasale to soft tissue menton. Arnett believes that the equality of the lower and middle facial thirds is not as important as the appearance of the landmarks within the lower one third such as incisor exposure and interlabial gap (48). Also he notes that the middle and lower thirds are rarely equal as some other clinicians believe (46). The lower one third evaluation is the major part of Arnett's vertical examination from the frontal perspective. It includes vertical measurements of the upper and lower lips, interlabial gap, maxillary incisor exposure at rest and on smiling, maxillary incisor height, and upper and lower vermillion heights. Also, an evaluation of the closed lip position is performed. According to Arnett, when the lips and skeletal lengths are balanced, the lips should ideally be able to close from a relaxed, separated position without lip, mentalis, or alar base strain (48). The upper lip measured from subnasale to the inferior border of the lip should be approximately half the length of the lower lip measured from the superior border of the lower lip to soft tissue menton. These two measurements combined with the interlabial gap length make up the vertical height of the lower third of the face. Arnett defines the normal range for maxillary incisor exposure at rest to be $1-5 \mathrm{~mm}$, and $8 \mathrm{~mm}$ of crown to $2 \mathrm{~mm}$ of gingival when the patient smiles. Since excessive gingival exposure can be caused by a combination of factors such as a short upper lip, vertical maxillary excess, or short 
clinical crowns, care should be taken when planning surgical impaction of the maxilla. Maxillary impaction is indicated when excessive gingival exposure is found with an increased interlabial gap, increased tooth exposure, and increased lower facial height with or without mentalis strain. More emphasis should be placed on the relaxed lip maxillary incisor exposure than the amount of incisor or gingiva exposed during smiling to prevent the premature aging of the patient's face due to surgical moves $(46 ; 48)$.

To begin the patient's profile examination, the profile angle is assessed by connecting the points glabella, subnasale, and soft tissue pogonion on the patient's left side. The profile angle typically ranges from 165-175 degrees. Arnett notes that the profile angle is the most important key to assess the need for anteroposterior surgical correction. Profile angles outside this range are usually caused by skeletal disharmony rather than soft tissue thickness differences (48). The nasolabial angle should measure in the esthetically pleasing range of 85-105 degrees. This angle changes considerably with surgical and orthodontic movements because it is based on both hard tissue placement and soft tissue thicknesses which can be affected by muscle pull and healing following surgery (48). The maxillary and mandibular sulci are subjectively assessed as flat, having an accentuated curve or a gentle curve. These sulci normally present as a gentle curve leading to the lip vermillion borders. Flaccid lips will present with more accentuated curves. As lip tension increases, the sulcus contour flattens. This is important to note since flaccid lips move less with surgical and orthodontic hard tissue movements than tense lips which move more posteriorly and less anteriorly (46;48).

The patient's orbital rim is assessed in relation to the globe of the eye. Typically the globe is $2-4 \mathrm{~mm}$ anterior to the orbital rim when viewing the patient's profile. The 
orbital rim is subjectively described as normal, flat, soft, or protruded and is an anteroposterior indicator of the maxillary position. The cheekbone contour is an anteriorly curved line starting just anterior to the ear and extending to the point on the maxilla adjacent to the nasal alar base. It is divided into three areas: zygomatic arch, middle contour area, and subpupil areas. The nasal base-lip contour extends inferiorly from the nasal base point to a point just below and inferior to the mouth commissure. In patients with skeletal harmony, the cheekbone-nasal base-lip contour should be a continuous gently curving line with no interruptions. Breaks in this line may aid in diagnosing maxillary retrusion or mandibular protrusion $(46 ; 48)$.

Nasal projection is measured from subnasale to the nasal tip anteroposteriorly in the profile view. Arnett notes that nasal projections below the normal range of $16-20 \mathrm{~mm}$ may contraindicate maxillary advancement since the nasal tip would be superiorly positioned from the surgical procedure (48). The patient's throat length from the neckthroat point to soft tissue menton should be subjectively assessed as being short, normal, or long, and any sag in the area should be noted. This facial characteristic may affect surgical treatment planning. A patient with a short, sagging throat length may not be a good candidate for a mandibular setback (48). The subnasale-pogonion line is used to assess the projections of the upper and lower lips. According to Burstone, the upper lip should be anterior to this line by approximately $3.5 \mathrm{~mm}$ and the lower lip should be anterior to the line by approximately $2.2 \mathrm{~mm}(49)$. 


\section{Arnett Soft Tissue Cephalometric Analysis (STCA)}

The STCA is to be used along with the detailed soft tissue clinical exam to aid in surgical diagnosis and treatment planning. To develop the STCA, Arnett selected forty-six adult Caucasian models to comprise the database. All models were selected by Arnett as being reasonably facially balanced with Class I occlusions. Quality of facial parts was disregarded as selection criteria. Only the balance and position of facial parts was used for inclusion in the database. The models were first examined clinically in natural head position, with seated condyles, and with passive lips using the process described in the above paragraphs (13).

In preparation for digitization and cephalometric analysis, metallic beads were placed for markers on the model's midface in four areas: orbital rim, cheekbone, subpupil and alar base(13). The orbital rim marker is placed directly over the osseous orbital rim directly under the pupil of the eye with the patient looking straight ahead. The cheekbone marker is placed by viewing the patient from the $3 / 4$ and frontal views. In the $3 / 4$ view the right malar (or cheekbone) height of contour is marked with ink. Then the frontal view is used to place the metallic marker at this height directly in line with the outer canthus of the eye. The alar base marker is placed in the deepest depression at the alar base of the nose. The subpupil marker is placed directly below the pupil with the patient looking straight ahead at a vertical height one half the distance between the orbital rim and alar base markers(46). In addition to these midface markers, the clinician also placed a marker at the subjective junction of the patient's neck and throat(13). The cephalometric film was then taken with the model in NHP, centric relation and with passive lips. Arnett then established the True Vertical Line (TVL) which was placed 
through subnasale and perpendicular to the patient's NHP. This line typically falls approximately 9-13 $\mathrm{mm}$ anterior to glabella. In patients with maxillary retrusion as judged clinically, the TVL is moved anterior 1-3 mm. The STCA was completed, with different norms developed for males and females. The STCA includes both horizontal and vertical measurements based on the patient's TVL in NHP. The numbers can be used to diagnose the patient in five different areas: dentoskeletal factors, soft tissue components, facial lengths, TVL projections and harmony of facial parts. Harmony values are based on horizontal differences between points calculated from the TVL. These values do not change based on the placement of the TVL (13). Table 1 shows the STCA means and standard deviations for males and females. Table 2 shows the facial harmony means and standard deviations for males and females (46). Although statistically significant differences do not exist for all values, enough exist to warrant different male and female normative values $(13 ; 46)$.

Arnett's Cephalometric Treatment Planning (CTP) involves seven steps to plan the surgical moves needed to place a patient's STCA values within the normal range to optimize the occlusal and facial results. The first step is to correct the mandibular incisor axial inclination to within the normative range to the mandibular occlusal plane. The second step is to correct the maxillary incisor axial inclination to the maxillary occlusal plane. Once these two steps are completed, the true skeletal overjet is revealed. The third step is setting the maxillary incisor position to a correct vertical position with 3$5 \mathrm{~mm}$ of incisor exposed beneath the relaxed lip. 


\begin{tabular}{|c|c|c|c|}
\hline & Mean \pm SD Females & Mean $\pm S D$ Males & Female to male difference signifiant when $>.05$ \\
\hline \multicolumn{4}{|l|}{ Dentoskeletal factors } \\
\hline Mx occlusal plane & $95.6 \pm 1.8$ & $95.0 \pm 1.4$ & .1789 \\
\hline Mx1 to Mx occlusal plane & $56.8 \pm 2.5$ & $57.8 \pm 3.0$ & .2585 \\
\hline Md1 to Md nocclusal plane & $64.3 \pm 3.2$ & $64.0 \pm 4.0$ & .7764 \\
\hline Overjet & $3.2 \pm .4$ & $3.2 \pm .6$ & .6371 \\
\hline Overbite & $3.2 \pm .7$ & $3.2 \pm .7$ & .7481 \\
\hline \multicolumn{4}{|l|}{ Soft tissue structure } \\
\hline Upper lip thickness & $12.6 \pm 1.8$ & $14.8 \pm 1.4$ & 3.388-E05 \\
\hline Lower lip thickness & $13.6 \pm 1.4$ & $15.1 \pm 1.2$ & .0004 \\
\hline Pogonion-Pogonion' & $11.8 \pm 1.5$ & $13.5 \pm 2.3$ & .0086 \\
\hline Menton-Menton' & $7.4 \pm 1.6$ & $8.8 \pm 1.3$ & .0019 \\
\hline Nasolabial angle & $103.5 \pm 6.8$ & $106.4 \pm 7.7$ & .1937 \\
\hline Upper lip angle & $12.1 \pm 5.1$ & $8.3 \pm 5.4$ & .0197 \\
\hline \multicolumn{4}{|l|}{ Facial length } \\
\hline Nasion'-Menton' & $124.6 \pm 4.7$ & $137.7 \pm 6.5$ & $8.916 \mathrm{E}-09$ \\
\hline Upper lip length & $21.0 \pm 1.9$ & $24.4 \pm 2.5$ & $1.024 \mathrm{E}-05$ \\
\hline Interlabial gap & $3.3 \pm 1.3$ & $2.4 \pm 1.1$ & .0214 \\
\hline Lower lip length & $46.9 \pm 2.3$ & $54.3 \pm 2.4$ & $2.158 \mathrm{E}-13$ \\
\hline Lower $1 / 3$ of face & $71.1 \pm 3.5$ & $81.1 \pm 4.7$ & $3.170 \mathrm{E}-09$ \\
\hline Overbite & $3.2 \pm .7$ & $3.2 \pm .7$ & .7481 \\
\hline Mxl exposure & $4.7 \pm 1.6$ & $3.9 \pm 1.2$ & .0417 \\
\hline Maxillary height & $25.7 \pm 2.1$ & $28.4 \pm 3.2$ & .0026 \\
\hline Mandibular height & $48.6 \pm 2.4$ & $56.0 \pm 3.0$ & $8.573 \mathrm{E}-11$ \\
\hline \multicolumn{4}{|l|}{ Projections to TVL } \\
\hline Glabella & $-8.5 \pm 2.4$ & $-8.0 \pm 2.5$ & .5246 \\
\hline Orbital rims & $-18.7 \pm 2.0$ & $-22.4 \pm 2.7$ & $1.060 \mathrm{E}-05$ \\
\hline Cheek bone & $-20.6 \pm 2.4$ & $-25.2 \pm 4.0$ & $7.405 \mathrm{E}-05$ \\
\hline Subpupil & $-14.8 \pm 2.1$ & $-18.4 .0 \pm 1.9$ & $2.266 \mathrm{E}-07$ \\
\hline Alar base & $-12.9 \pm 1.1$ & $-15.0 \pm 1.7$ & $6.054 \mathrm{E}-05$ \\
\hline Nasal projection & $16.0 \pm 1.4$ & $-17.4 \pm 1.7$ & .0052 \\
\hline Subnasale & 0 & 0 & 0 \\
\hline A point' & $-.1 \pm 1.0$ & $-.3 \pm 1.0$ & .6629 \\
\hline Upper lip anterior & $3.7 \pm 1.2$ & $3.3 \pm 1.7$ & .3836 \\
\hline $\mathrm{M} \times 1$ & $-9.2 \pm 2.2$ & $-12.1 \pm 1.8$ & $1.064 \mathrm{E}-05$ \\
\hline Mdl & $-12.4 \pm 2.2$ & $-15.4 \pm 1.9$ & $1.312 \mathrm{E}-05$ \\
\hline Lower lip anterior & $1.9 \pm 1.4$ & $1.0 \pm 2.2$ & .1065 \\
\hline B point' & $-5.3 \pm 1.5$ & $-7.1 \pm 1.6$ & .0004 \\
\hline Pogonion' & $-2.6 \pm 1.9$ & $-3.5 \pm 1.8$ & .1294 \\
\hline
\end{tabular}

Table 1: STCA means and standard deviations for males and females.

\begin{tabular}{lccc}
\hline & Mean \pm SD Females & Mean $\pm S D$ Males & Female to male difference significant when $>.05$ \\
\hline Intramandibular relations & & & \\
Mdl-Pogonion' & $9.8 \pm 2.6$ & $11.9 \pm 2.8$ & .0076 \\
Lower lip anterior-Pogonion' & $4.5 \pm 2.1$ & $4.4 \pm 2.5$ & .8915 \\
B point'-Pogonion' & $2.7 \pm 1.1$ & $3.6 \pm 1.3$ & .0192 \\
Throat length (neck throat point to Pog') & $58.2 \pm 5.9$ & $61.4 \pm 7.4$ & .1213 \\
Interjaw relations & & & .1191 \\
Subnasale'-Pogonion' & $3.2 \pm 1.9$ & $4.0 \pm 1.7$ & .0010 \\
A point'-B point' & $5.2 \pm 1.6$ & $6.8 \pm 1.5$ & .1236 \\
Upper lip anterior-lower lip anterior & $1.8 \pm 1.0$ & $2.3 \pm 1.2$ & \\
Orbit to jaws & & & \\
Orbital rim'-A point' & $18.5 \pm 2.3$ & $22.1 \pm 3$ & .0009 \\
Orbital rim'-Pogonion' & $16.0 \pm 2.6$ & $18.9 \pm 2.8$ & .05 \\
Full facial balance & & & .9609 \\
Facial angle & $169.3 \pm 3.4$ & $169.4 \pm 3.2$ & .4609 \\
Glabella'-A point' & $8.4 \pm 2.7$ & $7.8 \pm 2.8$ & .0511 \\
Glabella'-Pogonion' & $5.9 \pm 2.3$ & $4.6 \pm 2.2$ & \\
\hline
\end{tabular}

Table 2: Facial harmony means and standard deviations for males and females. 
The maxillary incisor is then positioned in an anteroposterior direction based on both clinical exam and STCA findings, such as midface projection and contours, nasal projection, clinical upper lip support and cephalometric upper lip angle, projection and thickness $(13 ; 46)$. Arnett notes that the maxilla, and therefore the maxillary incisors, should be surgically advanced if the nose is long, midface structures are flat, the upper lip lacks incisor support, the upper lip is thick or retrusive, or the angle of the upper lip is upright (46). Step four is to auto-rotate the mandible to $3 \mathrm{~mm}$ of incisal overbite. Step five is to move the mandible to the newly positioned maxilla so that there is $3.2 \mathrm{~mm}$ incisal overjet and overbite and $1.5 \mathrm{~mm}$ first molar cusp tip overbite. At this point the lower lip usually needs re-posturing to touch the upper incisors without altering its thickness. Maxillary occlusal plane alteration is step six. Rotation of the maxillarymandibular complex to alter the occlusal plane angle should be performed to place it in the normative range to the TVL in order to optimize profile esthetics in particular the projection of the chin. Care should also be taken to maintain the chin to TVL in the normative range while gaining the appropriate facial changes at the alar base. Step seven is to position the chin anteroposteriorly and vertically to normative values by a sliding chin osteotomy or adjusting the occlusal plane angulation to the TVL $(13 ; 46)$. These steps can be performed manually or prompted by the Dolphin Imaging 9.0 software Arnett module.

\section{Andrews Six Elements Philosophy}

Dr. Andrews began studying "ideal" non-treated orthodontic study models in the early 1960's looking for characteristics of occlusion that could be emulated through orthodontic treatment (17). Collecting study models from dentists and orthodontists, he 
discovered 120 casts of patients considered to have good to excellent occlusion. Six characteristics were found common to all casts, which he termed the Six Keys of Optimal Occlusion(15). Although the individual keys were not entirely new, they were valuable together as a complete set of indicators of optimal occlusion judged from tangible landmarks. The keys include: Key I - interarch relationship, Key II - crown angulation, Key III - crown inclination, Key IV - rotations, Key V - tight contacts, Key VI - curve of spee (17). From these keys and study models as well as his past work, Andrews developed the Straight-Wire Appliance System (SWA) in $1970(15 ; 18)$. The SWA is a system in which the bracket is built to a certain prescription including inclination, angulation, and prominence specific to each tooth and treatment plan, so that use of straight wires will give a treatment result similar to the optimal occlusions Andrews studied $(15 ; 18)$.

Although surgical methods had evolved to give a more precise jaw placement, there was no set of guidelines for jaw placement based on facial harmony and beauty. The only guidelines with widespread acceptance were the cephalometric norms. These norms were based on samples from what was considered a "normal" population of Caucasian males and females and were to serve as guidelines to a "normal" face. The studies producing the norms used various cephalometric techniques. Some used lateral repose and some had the patients with closed lips regardless of lip competence. Cephalometric norms were based on internal landmarks with a large range of positions and many orthodontists do not locate the landmarks alike on the headfilms (17). Andrews and others believed that these norms could produce varied soft tissue and esthetic outcomes. During the 1980's Andrews began examining photos of models, 
actors, and other people from magazines. He felt that with society being the ultimate judge of beauty, some common characteristics may exist among the photos that could aid in orthodontic and surgical diagnosis and treatment planning. Andrews did find commonalities in the group of photos and from this began the Six Elements philosophy $(15 ; 18)$. Andrews concluded that orthodontists should consider the following six areas when diagnosing and treatment planning a case: 1) Arch shape and length, 2) Anterior-posterior jaw positions, 3) Buccolingual jaw widths, 4) Vertical jaw measurements, 5) Poginion prominence, and 6) occlusion (15;18). The Six Elements diagnostic method uses landmarks (a point or line representing unique and positionally correct anatomy that can be used to measure the quality of the position of the teeth and jaws) and referents (a point or line that represents anatomy that may or may not be positionally correct). Use of the Six Elements diagnostic method should, according to Andrews, produce a treatment plan for each individual that is unique to their face, not based on norms, but on facial beauty and harmony (50). The Six Elements of Orofacial Harmony are "universal" meaning that they should work equally well for patients regardless of race, age, or gender (17). Dr. Andrews believes that if the Six Elements are met, the soft tissue features will be optimal and unique for each patient. The following is the diagnostic method.

\section{ELEMENT 1: ARCH SHAPE AND LENGTHS}

The goals of Element I are for the roots of maxillary and mandibular teeth to be centered over basal bone with the crowns inclined for optimal occlusion. The depth of the core line should be between 0 and $2.5 \mathrm{~mm}$. From the occlusal perspective, the FA points should approximate the WALA ridge within a range of .1-2.2 $\mathrm{mm}$ depending on 
the tooth. The landmark for the maxillary core line shape is dictated by the mandibular core line established by the WALA ridge (18).

Element I is achieved using dental casts, photos and radiographs. The core discrepancy (CD) is first calculated by comparing the mesiodistal diameter of the corrected arch's core line to the mesiodistal diameters of all the teeth in the arch. This is basically the arch's dental crowding or spacing. Core line changes based on ideal placement of the teeth superior-inferiorly, anteroposteriorly, and buccolingually are summed with the core discrepancy to give the interim core discrepancy or ICD. This is the arch's total core line discrepancy with all the teeth in their Element I positions (18).

\section{ELEMENT II: AP JAW POSITIONS}

The maxilla is in its Element II position when the maxillary incisor is Element I with the FA point touching the Goal Anterior Limit Line (GALL). The mandible is Element II if it is in Key I occlusion with an Element II maxilla. To determine the Element II position of the jaws, clinical and radiographic data must be examined. The forehead is used to find the GALL for several reasons. Dr. Andrews found from his study of individuals with facial harmony that there is a correlation between the prominence and inclination of the forehead and the anterior positions of the teeth and jaws. Also, the AP relationship of the maxillary incisor to the forehead remains unchanged throughout the patient's life. First the patient's forehead is classified as round, straight, or angular to aid in determining the forehead's FA point (FFA). The FFA point is the midpoint of the clinical forehead. For straight foreheads, the clinical and anatomical foreheads are the same, therefore, the FFA is the midpoint between trichion and glabella. For angular and round foreheads, the clinical forehead (superion to 
glabella) is different from the anatomical forehead (trichion to glabella). In this case, the FFA is the midpoint between superion and glabella (Figure 2).

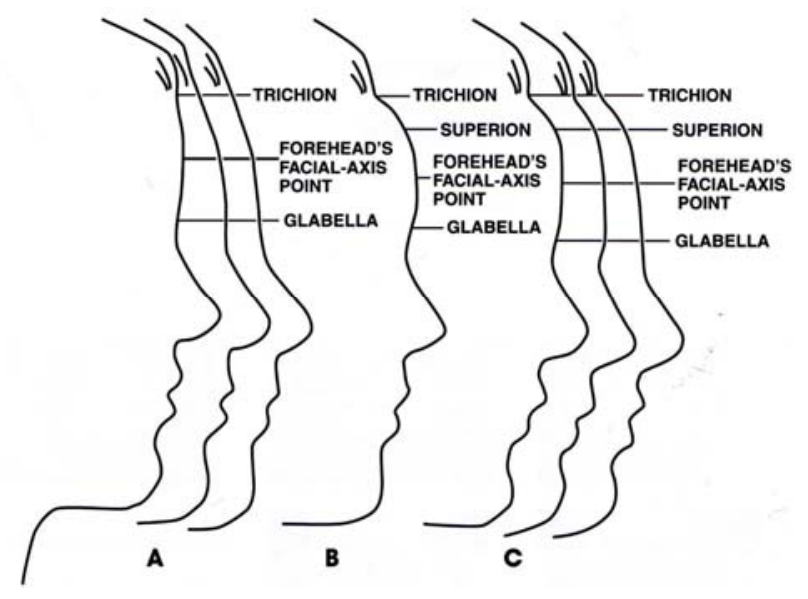

Figure 2: Forehead anatomy A: Straight; B: Rounded; C: Angular

(From Andrews Journal of Orthodontics and Orofacial Harmony vol. 1 no. 2, 2001)

After determining the FFA point, the FALL/DALL estimation can be done. This is the distance between the FALL (the line parallel to the head's frontal plane running through the forehead's FA point) and the DALL (the line parallel to the head's frontal plane running through the maxillary incisor's FA point) (Figure 3). For this estimation, the distance between the FALL and DALL should be judged in millimeters and noted in the patient's chart. For example, if the DALL is $3 \mathrm{~mm}$ behind the FALL, the FALL/DALL would be expressed as $-3 \mathrm{~mm}$. If the DALL is $3 \mathrm{~mm}$ anterior to the FALL, the FALL/DALL would be expressed as $+3 \mathrm{~mm}$. The patient's clinical forehead inclination is used to determine the GALL. For every degree the forehead is canted more than 7 degrees, the GALL passes through a point on the forehead that is $0.6 \mathrm{~mm}$ anterior 
to the FFA point, but never beyond glabella (Figure 4). Dr. Andrews uses a specific nomenclature for expressing the jaw positions in relation to the GALL. Jaws with Element I incisors on the GALL are said to be "green." Jaws with Element I incisors behind the GALL are said to be "black" (B). Jaws with Element I incisors anterior to the GALL are said to be "red" (R). Furthermore, a millimeter measurement of the incisor's FA point to the GALL can be added. For example, a maxilla with the Element I incisor's FA point $4 \mathrm{~mm}$ posterior to the GALL is called a B4 maxilla. Using an acetate paper tracing, the maxilla and Element I incisor are positioned with the incisor's FA point on the GALL. The traced mandible with an Element I incisor are then placed in a Key I relationship. This places the maxilla and mandible in the Element II positions. If anterior or posterior movement is necessary to position the jaws in an Element II position, the same movement would be necessary surgically. The movement of the acetate template represents the surgical moves needed to place the jaws in their Element II positions.

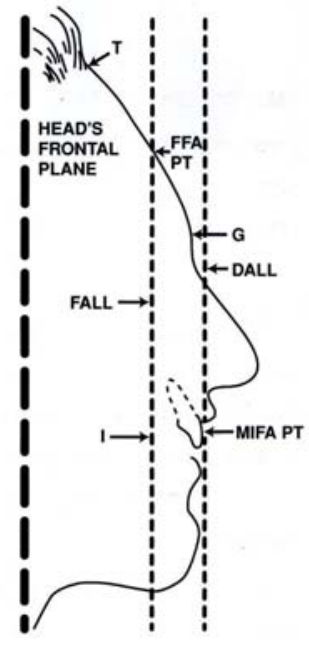

Figure 3: FALL DALL estimation 

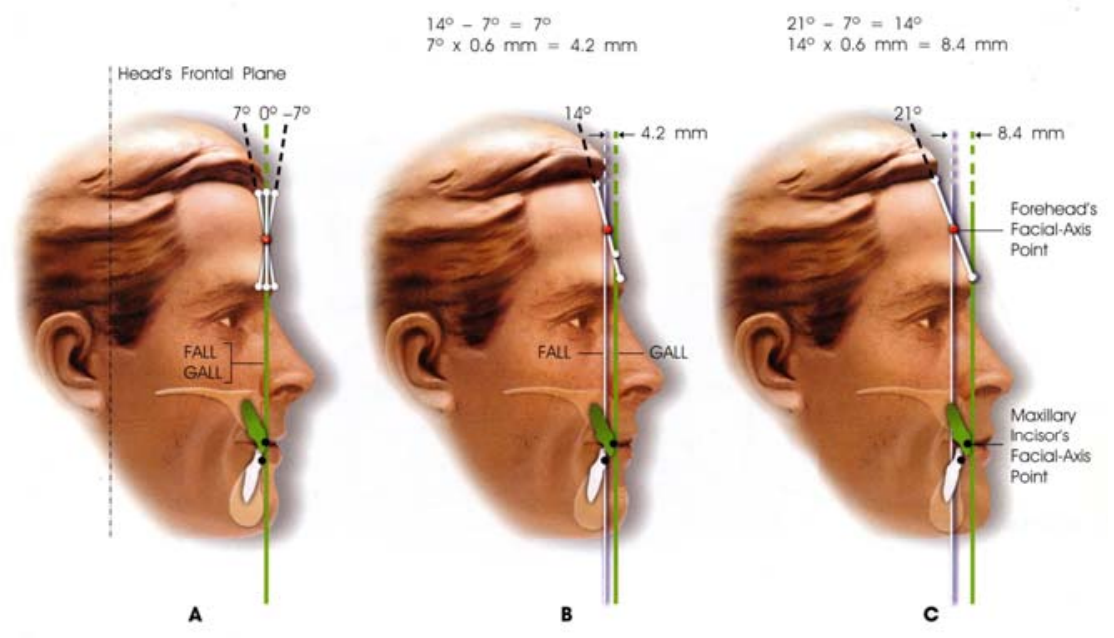

Figure 4: Forehead inclination and the effects on AP jaw positions. A: Straight forehead with inclination of 7 degrees or less, GALL passes through the FFA point. B and C: Forehead inclination of more than 7 degrees. For every degree of forehead inclination more than 7 degrees, the GALL passes through a point on the forehead $0.6 \mathrm{~mm}$ more anterior the the FFA point. The anterior limit for the GALL is glabella. (From Andrews Journal of Orthodontics and Orofacial Harmony vol. 1 no. 2, 2001).

\section{ELEMENT III: BUCCOLINGUAL JAW RELATIONSHIPS}

The mandibular basal bone is naturally Element III. It will be unchanged throughout treatment. The FA points of the Element I mandibular molars serve as the landmarks for assessment of maxillary basal bone width. The maxilla is Element III when the maxillary and mandibular arches are Element I and the teeth are in a cusp fossa relationship buccolingually. When measuring from the FA points of the Element I teeth, the Element III maxillary arch is several millimeters wider than the Element III mandibular arch (17). Clinically this relationship is assessed from measurements on the 
dental casts. A buccolingual deficiency is noted as a space discrepancy when calculating the ICD and, therefore, the total space deficiency or crowding.

\section{ELEMENT IV：SUPERIOR INFERIOR JAW RELATIONSHIPS}

Element IV has been divided into four parts with specific goals and objectives for the anterior and posterior parts of the maxilla and mandible. The anterior maxilla is Element IV when the FA point of the Element I maxillary incisor is at the same level as the inferior border of the upper lip in repose. The anterior mandible is Element IV when the distance measured from the FA point of the Element I mandibular incisor to hard tissue menton is approximately half the distance from the condyle's superior surface to hard tissue gonion(Figure $5 \mathrm{~A}$ ). For the posterior maxilla and mandible to be Element IV the distances between 1) glabella to subnasale, 2) subnasale to menton, and 3) the external auditory meatus to soft tissue gonion should all be approximately equal and there should be no posterior open bite when the anterior maxilla and mandible are Element IV and in occlusion (Figure $5 \mathrm{~B})(17)$. Element IV is assessed from a series of measurements made from the headfilm tracing. The vertical heights of the maxilla and mandible are controlled by movements of the acetate paper templates. The movements of the acetate templates simulate the surgical moves necessary to achieve Element IV. Not only is the maxillo-mandibular complex movable in a straight vertical direction, but the entire complex can also be rotated around the Element IV anterior maxilla altering the inclination of the occlusal plane and anterior posterior prominence of hard tissue pogonion. These are important movements to consider before planning surgical moves. Dr. Andrews feels that the ideal inclination of the occlusal plane is 7 degrees from the GALL if achievable while creating an Element IV vertical jaw relationship (18). 

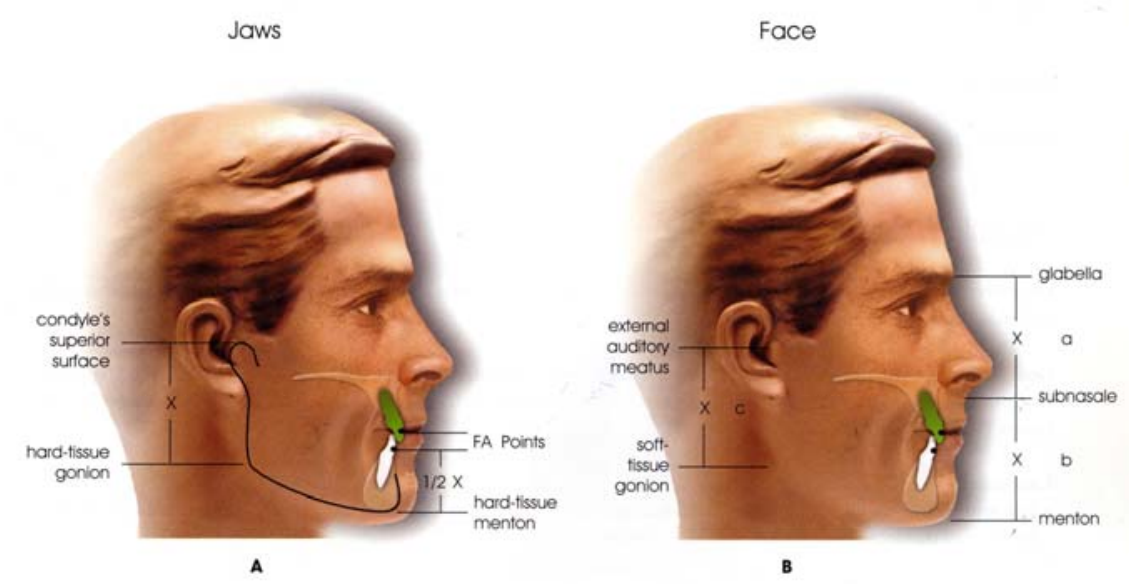

Figure 5: A: For the Element IV anterior mandible, the distance from the Element I incisor FA point to hard tissue menton should be approximately half the distance from the condyle's superior surface to hard tissue gonion. B: for the Element IV posterior maxilla and mandible, the distances for $a, b$, and c should be approximately equal. (From Andrews Journal of Orthodontics and Orofacial Harmony vol. 1 no. 2, 2001).

\section{ELEMENT V: POGONION PROMINENCE}

The prominence of hard tissue pogonion should be unique for each individual. Will's Plane is a line perpendicular to the occlusal plane passing through the FA point of the Element I mandibular incisor. The anteroposterior prominence of pogonion should match the anteroposterior position of Will's Plane to be Element V. The patient is described as having a B3 pogonion if its AP position is $3 \mathrm{~mm}$ posterior to Will's Plane. An R3 pogonion would be $3 \mathrm{~mm}$ anterior to Will's Plane (17). This is assessed from the radiographic headfilm tracing using a template. 


\section{ELEMENT VI: OCCLUSION}

Element VI is achieved when the patient's occlusion meets the Six Keys to Optimal Occlusion when the condyles are in centric relation. Again, the Six Keys are: Key I - interarch relationship, Key II - crown angulation, Key III - crown inclination, Key IV - rotations, Key V - tight contacts, Key VI - curve of spee. Dr. Andrews' study of naturally occurring good occlusions found specific relationships of correctly positioned teeth. Angulations and inclinations have a normal range and vary according to each tooth. There is also a specific pattern of occlusion with cusps being related to fossa or marginal ridges. Dental casts are needed for this assessment (17).

\section{Dolphin Imaging Software}

Dolphin Imaging 9.0 is one of the leading orthodontic imaging softwares. It is available to orthodontists and oral surgeons for treatment planning and presentation purposes as well as for basic imaging needs. Using the software, a lateral cephalogram can be digitized rather than manually traced. The analysis to be run can be chosen by the user and varied as needed. In addition to the STCA, Dr. Arnett has a CTP module in the Dolphin software which prompts users to perform surgical steps to fall within the norms for STCA standards. Landmarks are identified by moving the mouse to the area and pointing and clicking. Magnification tools aid the user in identifying obscure landmarks. The 9.0 version allows the patient's photographic image and digitized ceph to be superimposed and linked so that planned surgical or orthodontic movements can be visualized with a photo image. Typically these altered photos are used in case presentations for patients considering orthognathic surgery to give them some idea of 
what they may look like after undergoing the surgical procedure. However, the accuracy of such computer simulations has been questioned.

Researchers have been interested in how accurate imaging softwares are in predicting the soft and hard tissue changes associated with orthognathic surgery. Smith et al. (2004) compared the accuracy of five imaging software programs. Panels judged the similarity of morphed images with the actual treatment outcome photos of patients. Dolphin Imaging version 8.0 was chosen to most resemble the actual treatment results $10 \%$ of the time. Only Dentofacial Planner Plus version 2.5 was found to be more accurate with panels finding these images to most resemble the actual treatment outcomes $79 \%$ of the time. Other software programs including Quick Ceph, Vistadent and OrthoPlan were found to most resemble treatment outcomes in less than $5 \%$ of cases. Retouching the soft tissue points improved the average ranking for the Dolphin Imaging software (51).

Power et al. (2005) studied Dolphin Imaging version 8.0 for accuracy. Results showed manual tracings to be more accurate for identification of most landmarks including SNA, SNB, SNMx, and MxMd. Dolphin 8.0 was found to be more accurate for U1Mx and L1Md which are used for the Arnett McGlaughlin analysis. Comparison of actual outcome and software generated predictions for 26 orthognathic cases demonstrated clinically significant differences for all measurements. This study found that software errors may result in miscalculations due to radiographic magnification when using linear measurements (52). No studies have been done on the accuracy of the current software version 9.0 which became available in mid 2005 . 
Dolphin version 9.0 allows the user to define the soft tissue changes associated with the planned hard tissue movements in surgical simulations. The default settings are based on opinions of Arnett and McGlaughlin. For surgical treatment planning, the user may choose the Arnett module and CTP which prompts and autocorrects most movements according to Arnett's STCA standards. Rather than using the Arnett module, the user can also do movements they prescribe by entering data in the corresponding fields. Soft tissue can be retouched by using automatic or manual techniques in the program.

\section{Visual Analog Scale}

Preferably a scoring system for facial esthetics must be simple, applicable in clinical practice, and should lead to quantitative data (8). These scales can be set to a certain length with the two endpoints or bipolar points having different descriptors such as "most attractive" or "least attractive". The rater is asked to make a mark on the scale to indicate the perceived facial attractiveness of the subject. This mark can then be measured by the investigator to come up with an exact number or score representing the facial attractiveness of the subject judged by the rater (Figure 6). Phillips et al. designed a study with a visual analog scale $100 \mathrm{~mm}$ in length having the bipolar points of "very unattractive face" $(0 \mathrm{~mm})$ and "very attractive face" $(100 \mathrm{~mm})(53)$. Tedesco et al. used a rank order with 1 being "very attractive" and 5 being "very unattractive (54). Visual analog scales have several advantages. Ratings can be given quickly and the scores can be measured as continuous measures. The rating scores can detect differences in overall perception of facial attractiveness between panels of raters and yet be used for the mean scores of all raters. 


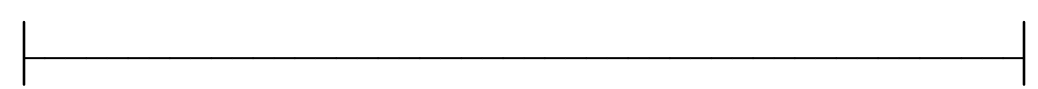

Figure 6: Visual analog scale (VAS). This scale is exactly $100 \mathrm{~mm}$ in length. The mark placed by the rater can be measured at a specific distance on the scale. A mark at $46 \mathrm{~mm}$ would indicate a score of 46 on the VAS. This number can then be tallied or averaged as needed for statistical purposes.

In all most all cases, panel assessments have been used to evaluate facial esthetics. Much attention has been paid to the makeup of such panels. Researchers have been interested in finding out if the perception of facial esthetics is related to professional background, age, gender, or socioeconomic class of the judges. Research in this field has reported conflicting results. Peerlings et al. (1995) and other researchers found no effect of panel composition (55-57). Spyropoulos and Halazonetis (2001) and others reported professionals to be less critical $(39 ; 58)$, while Kerr and O’Donnell (1990) found professionals to be more critical than laymen (59). In a more recent study, Kiekens et al. (2005), found that a laymen panel with a high socioeconomic class such as those who may more often seek orthodontic care, had no different perceptions of facial esthetics than the professional panel. The professional panel did rate the subjects slightly lower 
overall in facial attractiveness (were more critical), but not a statistically significant amount (57). Howells and Shaw (1995) have shown that a close relationship exists between judgements of facial esthetics on live stimuli and single color photos (60). Phillips et al. (1992) found that presentation of multiple views may even improve this relationship (61).

\section{$\underline{\text { Net Profile Index }}$}

A net profile index is an expansion of the visual analog scale concept. This can be used to sum the combined overall improvement or decline of facial attractiveness of a morphed smiling or repose profile as compared with the original. Figure 7 shows a series of photos for a patient. Figure 7 A represents the original repose photo. Figure 7 B shows the patient's image digitally altered to the Arnett standards in repose. Figure $7 \mathrm{C}$ represents the original smiling photo. Figure 7D shows the patient's image altered to the Arnett standards smiling. The VAS score for 7A is 40 . The VAS score for 7B is 50 . The VAS score for $7 \mathrm{C}$ is 45 . The VAS score for $7 \mathrm{D}$ is 30 . Therefore the overall change in attractiveness is the sum of the change, $(50-40)+(30-45)=(10)+(-15)=-5$. Therefore, the net profile index is -5 . This indicates a net decline in perceived facial attractiveness. If the same photos and VAS are presented using the Andrews Six Elements profiles, a similar net profile index can be tallied. This will allow the two standards to be compared. If the Arnett net profile index is -5 and the net Six Elements net profile index is +10 , it could be concluded that the Six Elements profile changes were preferred and statistical analysis could be done using these NPIs. 

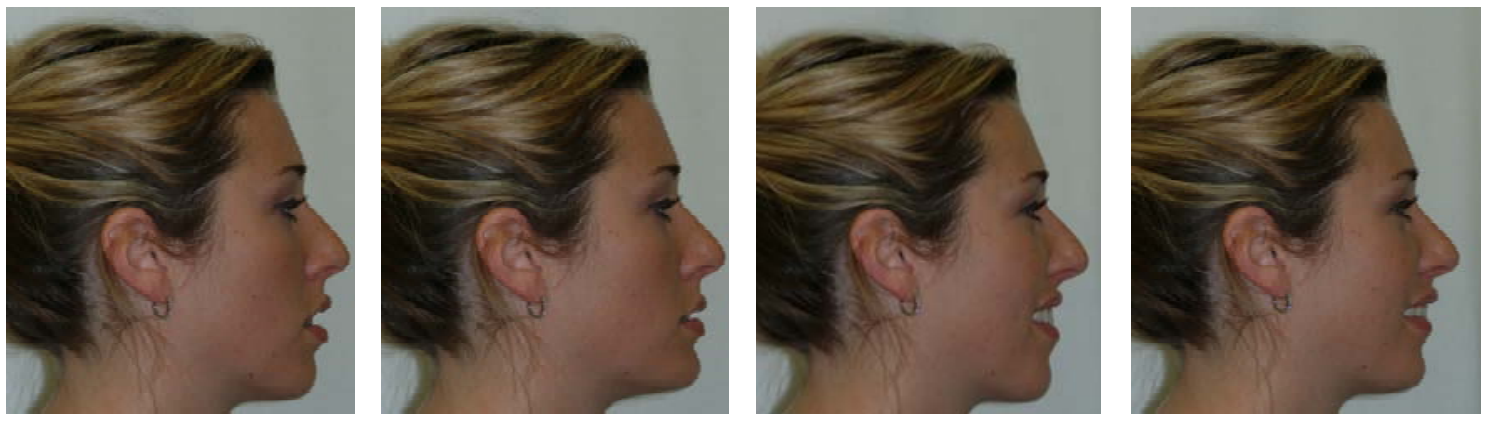

A

$\mathrm{B}$

$\mathrm{C}$

$\mathrm{D}$

Figure 7: Net profile index. A Original Repose, B Arnett Repose, C Original Smiling, D Arnett Smiling. The VAS score for 7A is 40. The VAS score for $7 \mathrm{~B}$ is 50 . The VAS score for $7 \mathrm{C}$ is 45 . The VAS score for $7 \mathrm{D}$ is 30 . Therefore the overall change in attractiveness is the sum of the change, or $(50-40)+(30-45)=(+10)+(-15)=-5$. Therefore, the net profile index for the Arnett sample is -5 meaning that there was an overall decline in perceived facial attractiveness. 


\section{CHAPTER 3 - MATERIALS AND METHODS}

\section{$\underline{\text { Overview }}$}

The methods and materials outlined in this study were submitted to and approved by the Institutional Review Board. Subjects participating in the study were chosen based on their maxillary incisor alignment and facial characteristics. Patients with characteristics which are most suitable for computer imaging and enhancement were selected for participation in the study. These characteristics included relatively aligned maxillary incisors and limited facial hair. Photos of these patients in lateral repose and smiling were computer simulated to meet the Arnett STCA standards and the Andrews Six Elements standards using Dolphin 9.0 Imaging software. These digitally altered photos along with the unaltered original photos were then presented to two panels. One panel represented the professionals and was made up of orthodontists in attendance at the WV Dental Association meeting. The layperson panel consisted of a group of Pharmacy students at the WVU Health Sciences Center who had no training in dentistry. Each panel member rated the photos on a visual analog scale ranging from a score of 0 being "least attractive" to 50 being "most attractive." A net profile index representing a composite score was tallied for each patient. This net profile index represents a total increase or decrease in score relative to the unaltered original photos for both the Arnett and Six Elements profiles. Data were analyzed using matched pairs student t-tests, least squares means, and Cronbach's Alpha.

\section{$\underline{\text { Sample description and delimitations }}$}

Twenty three sample subjects were selected from the West Virginia University Orthodontics Clinic. Selection criteria included patients with relatively aligned maxillary 
incisors or who had undergone previous orthodontic treatment. Patients with facial hair were excluded from the study since this adversely affects the digital alteration of photos. Patients meeting these requirements were approached at screening and debonding appointments to determine willingness to participate in the study. Those patients agreeing to participate signed the appropriate consent forms and were scheduled for the clinical and radiographic exam appointment. The sample was composed of five males and 18 females ranging in age from 10 to 36. Three subjects were African American, 20 were Caucasian.

\section{Methodology}

\section{CLINICAL EXAM:}

Each records visit lasted approximately one hour in length and included x-rays, photos and an exam. The clinical exam included features of both the Arnett soft tissue exam and Andrews Six Elements clinical exam as described in their articles and books. An Arnett facial features analysis was done in both frontal and profile views. This was done using the form shown in Figure 1 according to methods detailed in his surgical treatment planning text. A Six Elements FALL DALL estimate was done and agreed upon by at least two clinicians. During the estimation, Barium sulfate radiopaque markers were placed on the forehead's FA point, trichion or superion, and glabella.

Each subject was manipulated into centric relation (CR) to check for $\mathrm{CR}$ and $\mathrm{CO}$ discrepancies. None of the subjects had a CR - CO discrepancy. The subject was checked for mentalis muscle strain while in the repose position to ensure proper lip positioning for photos and cephs. Photos were taken with the condyles in CR and in natural head position (NHP). Lateral smiling and repose and frontal smiling and repose photos were 
taken without lip strain. Care was taken to position the camera at eye level in order to aid in the accuracy of computer simulation.

\section{X-RAYS:}

Lateral cephalograms were taken in both smiling and repose. Care was taken to place the patient in a similar manner as described for the photos (CR and NHP). Barium sulfate radiopaque markers were placed to indicate glabella, the forehead's FA point, superion or trichion, subnasale, cheekbone point, neck-throat point, alar base, and subpupil point. The lateral cephalometric head films were then scanned for use with Dolphin 9.0 Imaging software. 


\section{DIGITIZATION:}

The scanned lateral cephs were digitized according to the Arnett McGlaughlin cephalometric analysis. This default analysis has all the necessary points for the Arnett STCA and CTP. After all intracranial and extracranial landmarks were identified the TVL was adjusted as indicated by the Arnett soft tissue exam. For patients who were found to be maxillary deficient by soft tissue indicators during the clinical exam, the TVL was moved anterior by 1-3 mm. This was occasionally indicated. Figure 8 shows an example of a digitized ceph with the Arnett McGlaughlin analysis. Numbers are shown in colors representing the variance from normative values (black $=1 \mathrm{SD}$, green $=2 \mathrm{SD}$, blue $=3 \mathrm{SD}$, and red $=3+\mathrm{SD}$ from the norms).

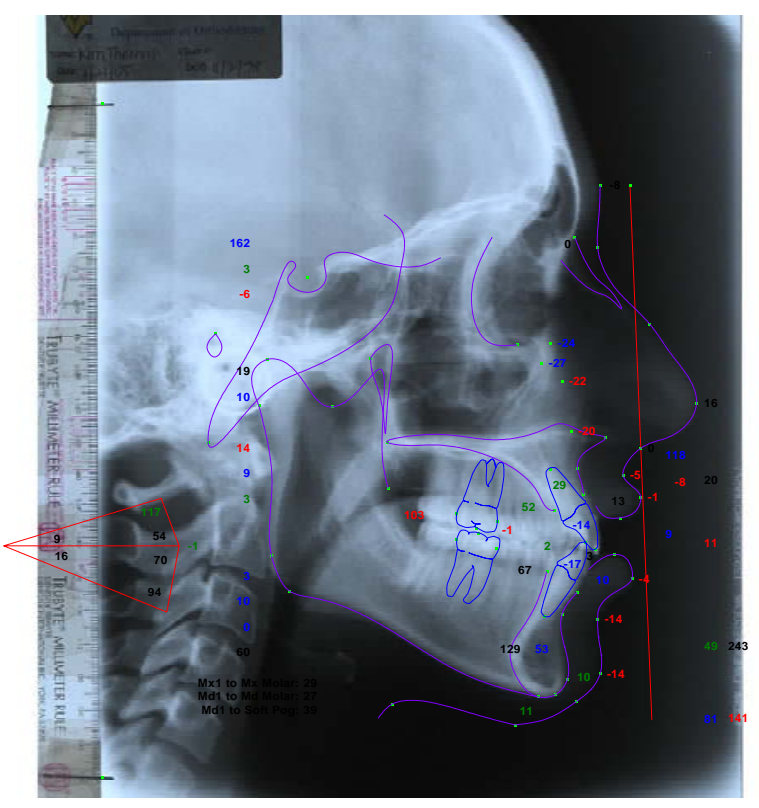

Figure 8: Arnett McGlaughlin analysis on digitized lateral ceph (black $=1 \mathrm{SD}$, green $=2$ $\mathrm{SD}$, blue $=3 \mathrm{SD}$, and red $=3+\mathrm{SD}$ from the norms). 


\section{SIX ELEMENTS TREATMENT PLANNING:}

In addition to the computer tracing, an acetate tracing was performed for the Six Elements diagnosis and treatment planning procedure. Steps were performed as detailed in the literature review of the Six Elements philosophy. Although each patient's surgical prediction and treatment plan were different, the basic procedure is as follows. First the lateral ceph landmarks were traced on acetate paper. This included the soft tissue outline, marked points, incisors, molars, occlusal plane, and maxilla and mandible including the condyle (Figure 9). The Element I incisors were then traced with the maxilla and mandible and occlusal plane on movable acetate templates (Figure 10). The FALL DALL was drawn and the GALL calculated and drawn to determine the Element II AP jaw positions. The maxillary template was moved to its Element II and Element IV (vertical) position by placing the maxillary incisor FA point on the GALL at the inferior border of the upper lip (Figure 11). The mandibular template was then autorotated to first tooth contact. The distal segment of the mandible was advanced and rotated as necessary to achieve the Key I occlusion with the Element II and IV maxillary template (Figure 12). The hard tissue chin was assessed for Element V. If necessary, a genioplasty was planned to advance the hard tissue pogonion to its Element V position at Will's Plane. At this point the soft tissue was retraced according to the predicted hard tissue movements. The movements were recorded for entrance into the Dolphin Imaging surgical treatment planning module. 


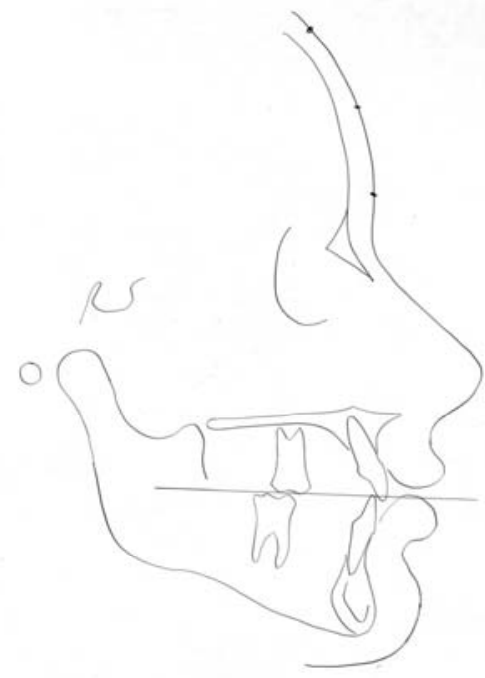

Figure 9: Six Elements original tracing with incisors, molars, and occlusal plane.

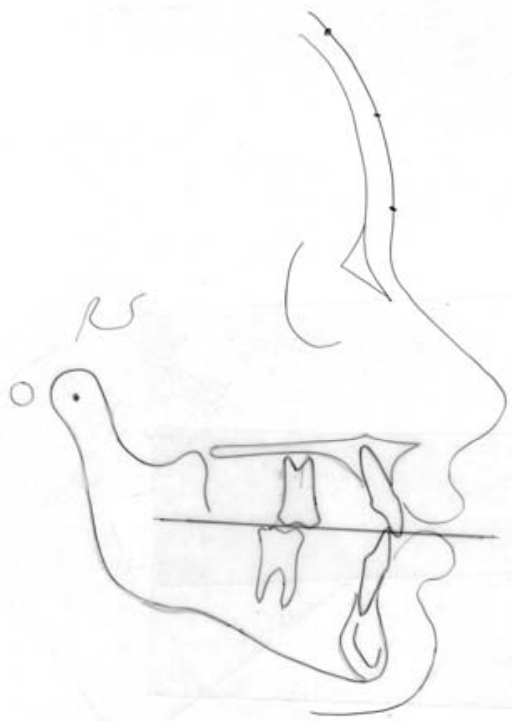

Figure 10: Element I incisors centered over basal bone. 


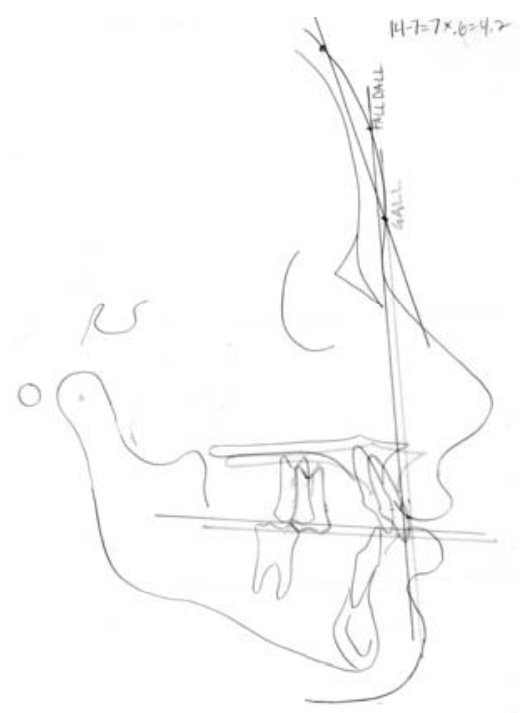

Figure 11: Six Elements tracing with Element II and IV maxilla. Maxillary template was moved to position the Element I incisor's FA point to the inferior border of the upper lip and to the GALL. This resulted in a $4 \mathrm{~mm}$ anterior and $2 \mathrm{~mm}$ inferior movement which would be necessary surgically.

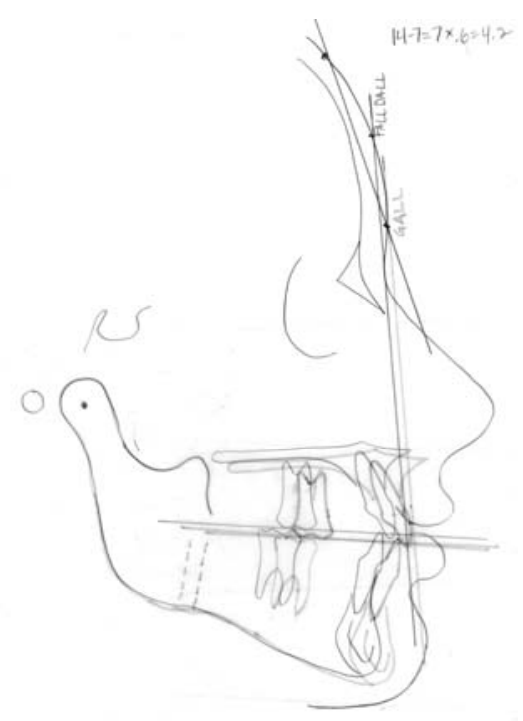

Figure 12: Element II mandible and Element V pogonion. Distal mandibular template advanced to Key I relationship with Element II and IV maxillary template. Pogonion is assessed from Will's plane and is Element V. 
Before any surgical treatment planning movements were made on the computer, the patient's photo image and digitized ceph were superimposed and linked. After this was completed, the predicted Six Elements movements were entered in the Dolphin program and the patient's images were altered. These same movements were performed on the lateral repose and smiling images. In order to accurately compare the morphed photos, all soft tissue default values were left the same for both Arnett and Six Elements. Completion of these steps produced the Six Elements repose and smiling altered photos.

\section{ARNETT CTP:}

After superimposing and linking the photos and digitized cephs, the Arnett CTP was done as detailed in the literature review. The following figures depict the steps of the CTP procedure (Figures 13-16). Again, the exact procedure was unique to each individual. Little to no photo retouching was done to eliminate any possible operator bias. At the conclusion of these steps, the Arnett repose and smiling altered photos were completed yielding all the photos necessary for panel judging. 


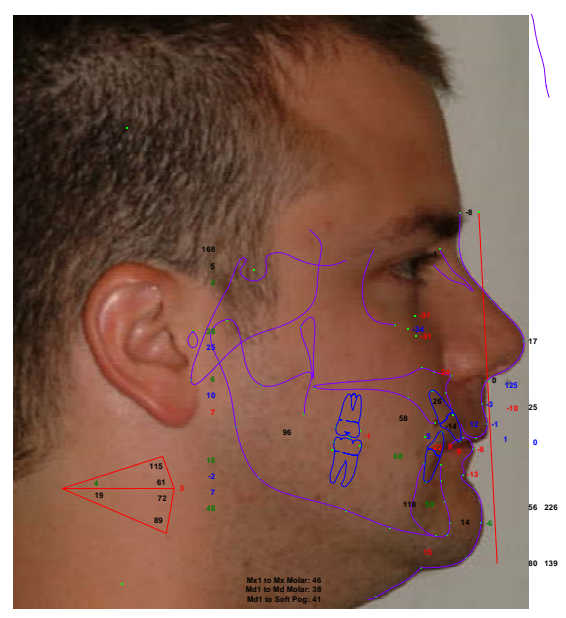

A

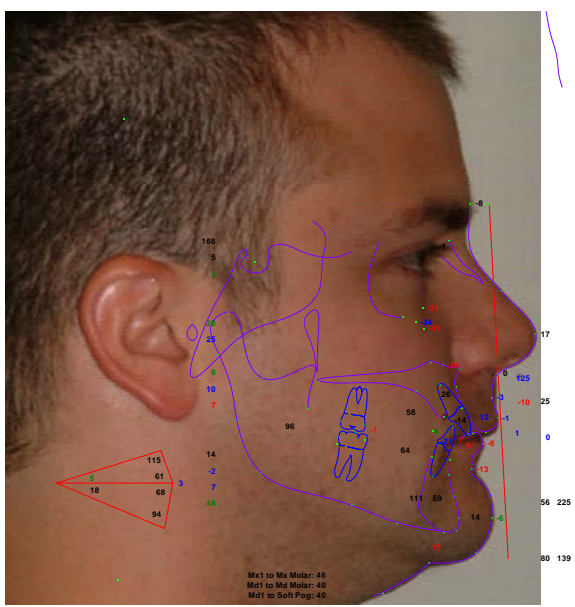

B

Figure 13: A: Correction of maxillary incisor inclination to occlusal plane. B:

Correction of mandibular incisor to occlusal plane.

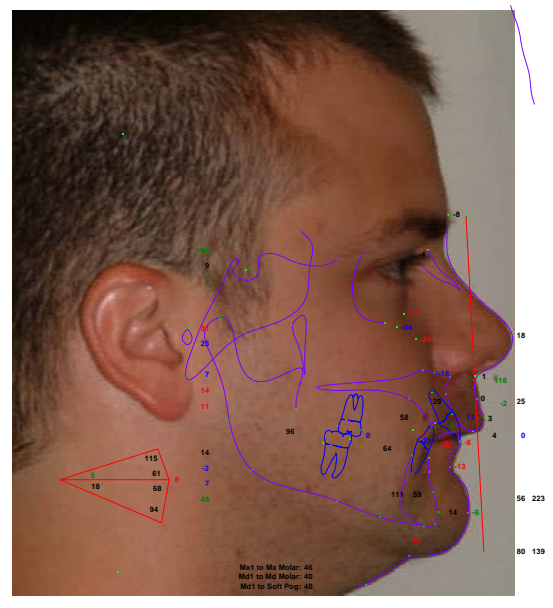

A

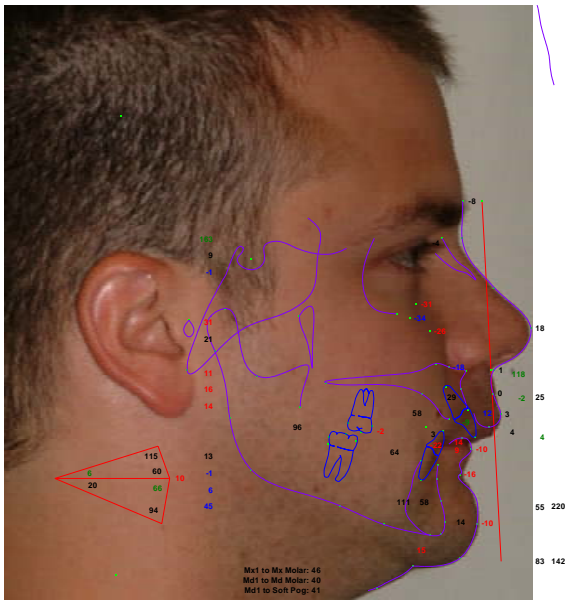

B

Figure 14: A: Position maxilla to TVL. B: Autorotate mandible to correct overbite. 


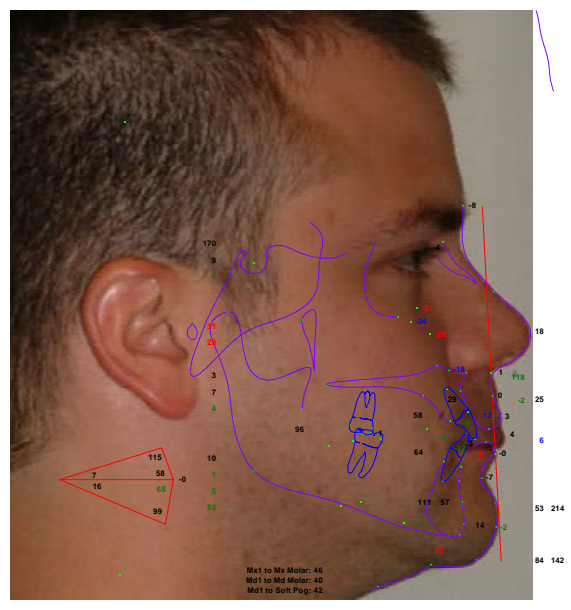

A

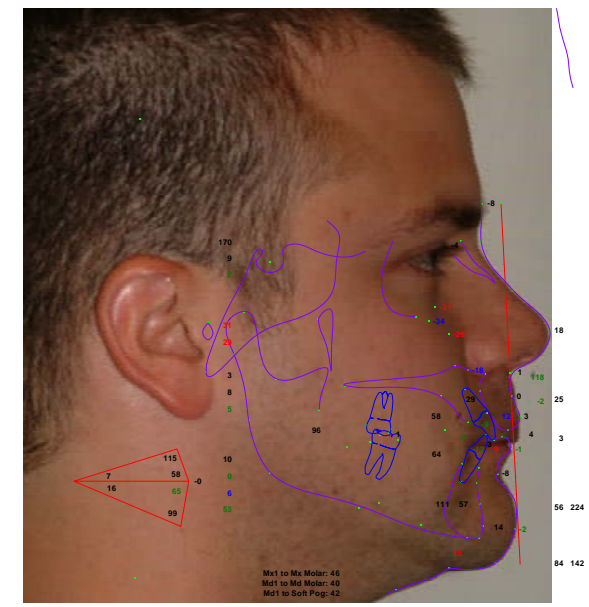

B

Figure 15: A: BSSO to correct overjet and molar overbite. B: Reposture lower lip maintaining thickness.

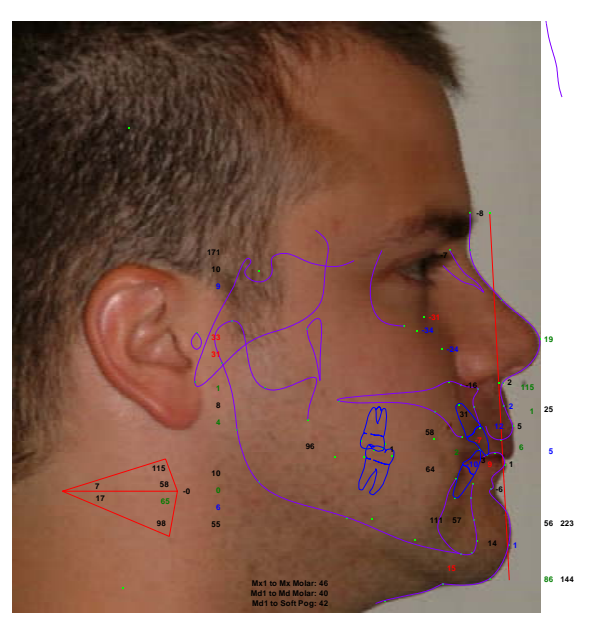

A

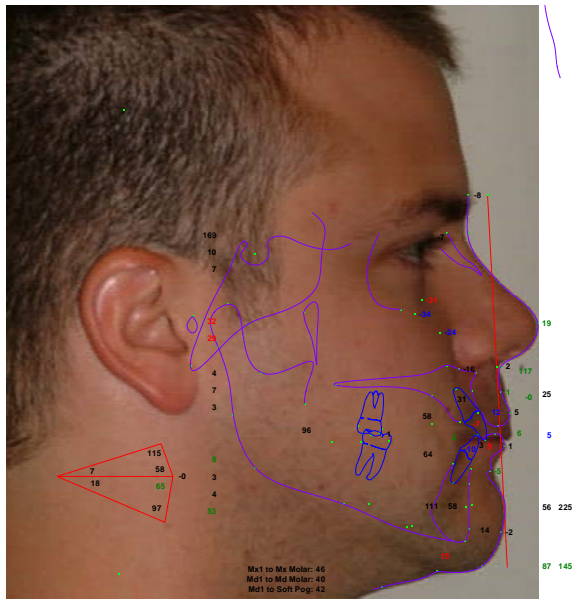

B

Figure 16: A: Move maxilla and mandible for necessary alar base changes.

B: Genioplasty to correct pogonion projection and final lip and soft tissue recontouring. 


\section{PANEL JUDGING:}

The six photos (original lateral smiling and repose, Arnett morphed smiling and repose, and Six Elements morphed smiling and repose) were assembled with corresponding visual analog scales for judgment by panels. In order create a double blind experiment, photos were arranged randomly in a presentation using Microsoft Powerpoint 2003. Neither the primary researcher nor panel members had any indication of the morphed or original photos. Panel members were given no information on the purpose of the study. Panel members were told to focus their attention on the position of parts rather than the beauty of parts such as hair or eye color, etc. The VAS extended from 0 ("least attractive") to 50 ("most attractive") and was $50 \mathrm{~mm}$ in length. The laymen panel consisted of 82 students in a pharmacy class. The professional panel consisted of 17 orthodontists attending the WV Dental Association meeting. To test intrarater reliability, three subjects photos were presented at two timepoints in random order. VAS ratings were measured. A mark on the line at $34 \mathrm{~mm}$ along the scale was written as a score of 34. A net profile index was tallied for each photo line up giving one composite score each per subject for the Arnett and Six Elements profiles for a total of 2 NPIs per rater per subject. The NPIs could then be used to statistically compare the overall preferences for Six Elements or Arnett profiles. 


\section{DATA ANALYSIS:}

Data were analyzed by matched pairs student t-test, least squares means, and Cronbach's Alpha. Data were analyzed to determine the following. 1) Is there a panel preference for the smiling profile between the Six Elements and Arnett standards? 2) Is there a panel preference for the lateral repose profile between the Six Elements and Arnett standards? 3) Are there differences in preferences for repose and smiling views based on subject or rater gender? 4) Is there a determinable panel preference for the morphed Six Elements or Arnett profiles? 5) Are there differences in preferences for repose and smiling views based on rater status of professional or non-professional? 


\section{CHAPTER 4: RESULTS AND DISCUSSION}

\section{$\underline{\text { Results }}$}

Data were analyzed to compare the preferences of the panels on the profiles generated using either the Six Elements (6e) or the Arnett STCA systems. Comparisons were made to evaluate differences in preferences for the Arnett and 6e profiles from the Originals and each other. Smiling and repose profiles were analyzed separately for both professional (Pro) and layperson (Non-Pro) panels. The overall preferences (smiling and repose) represented by the NPI composite scores were also analyzed separately for professional and layperson panels.

\section{SIX ELEMENTS VS. ORIGINAL:}

Comparisons between the preferences of the Six Elements (6e) profiles to the Originals were performed using the matched pairs student t-test. The difference between the mean rating of the 6e and the mean rating of the Original was calculated (M). Positive values of $\mathrm{M}$ indicate a preference for 6e profiles while negative values indicate a preference for the Original. Results are summarized in Tables 3 and 4. In repose, the professional raters preferred the $6 \mathrm{e}$ profile to the Original $(\mathrm{M}=4.02 \pm 0.68, \mathrm{p}<0.0003)$ (Figure 17). Layperson raters preferred the 6e repose profile to the Original also $(\mathrm{M}=0.90 \pm 0.26$, $\mathrm{p}=0.0003$. Professional raters preferred the $6 \mathrm{e}$ smiling profile to the Original profile $(\mathrm{M}=1.32 \pm 0.60, \mathrm{p}=0.01)$. Layperson raters had no significant preference between the 6e and Original smiling profiles $(\mathrm{M}=-0.02 \pm 0.24, \mathrm{p}=0.92)$ (Figure 18). 


\begin{tabular}{|c|ccr|lrr|}
\hline & \multicolumn{3}{|c|}{ Professsionals } & \multicolumn{3}{c|}{ Laypersons } \\
Profiles & Mean & SD & Sig & Mean & SD & Sig \\
\hline Repose & 4.02 & 0.68 & $\mathrm{p}<0.0003$ & 0.90 & 0.26 & $\mathrm{p}=0.0003$ \\
\hline Smiling & 1.32 & 0.60 & $\mathrm{p}=0.01$ & -0.02 & 0.24 & $\mathrm{p}=0.92$ \\
\hline
\end{tabular}

Table 3: Profile preferences of professional and layperson raters comparing Six Elements (6e) and Original.

\begin{tabular}{|l|l|l|}
\hline Profiles & Professionals & Laypersons \\
\hline Repose & $6 \mathrm{e}$ & $6 \mathrm{e}$ \\
\hline Smiling & $6 \mathrm{e}$ & No preference \\
\hline
\end{tabular}

Table 4: Profile preferences of professional and layperson raters comparing Six Elements (6e) and Original. 
Matched Pairs Rstatus=LAYPERSONS

Difference: 6E REP-ORIG REP

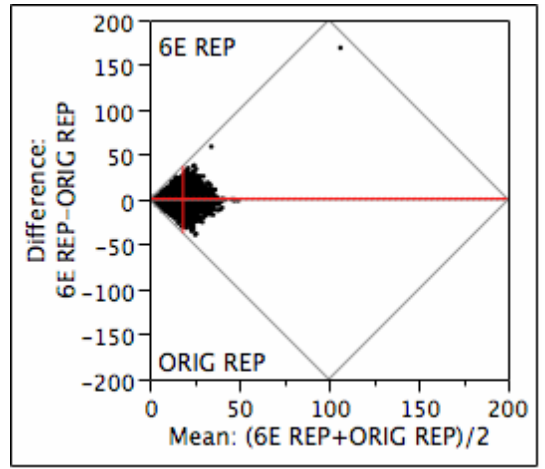

6E REP
ORIG REP
Mean Difference
Std Error
Upper $95 \%$
Lower $95 \%$
N
Correlation

19.1733

18.2695

t-Ratio

0.90377

0.26219

Prob $>|t|$

3.446958

1880

0.0006

Prob $>t$

$\odot .0003$

1.418

Prob $<\mathrm{t}$

$\odot .9997$

Correlation

1881

0.3241

A

Matched Pairs Rstatus=PROFSSIONAL

Difference: 6E REP-ORIG REP

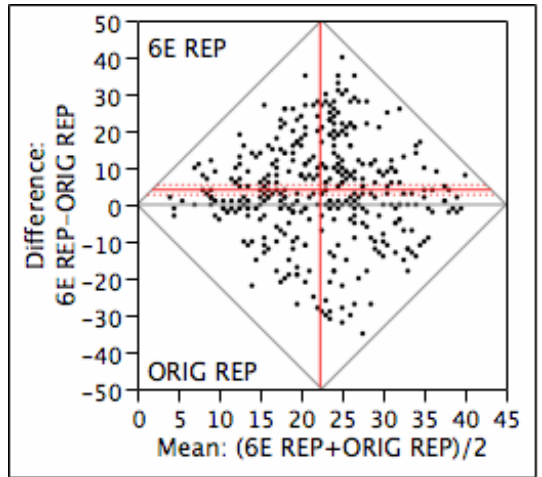

6E REP
ORIG REP
Mean Difference
Std Error
Upper $95 \%$
Lower $95 \%$
$\mathrm{~N}$
Correlation

24.3248
20.3043
4.02046
0.68496
5.36714
2.67378
391
0.06935

B

Figure 17: Comparison of 6e and Original repose profiles for Professionals and

Laypersons. 
Matched Pairs Rstatus=LAYPERSON

Difference: 6E SM-ORIG SM

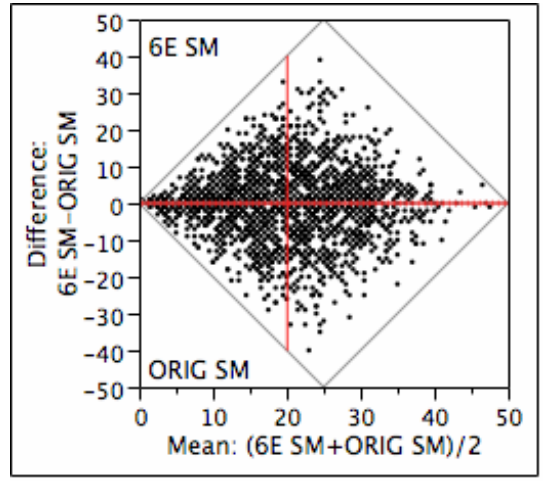

6E SM
ORIG SM
Mean Difference
Std Error
Upper $95 \%$
Lower95\%
N
Correlation

20.0579

t-Ratio

$-\odot .09471$

20.0807

DF

1883

$-0.0228$

Prob $>|\mathrm{t}|$

0.9246

$\odot .24098$

Prob $>t$

$\odot .5377$

$\odot .44979$

Prob $<\mathrm{t}$

0.4623

Correlation

\begin{abstract}
1884
\end{abstract}
$\bullet .45336$

A

Matched Pairs Rstatus=PROFESSIONAL

Difference: 6E SM-ORIG SM

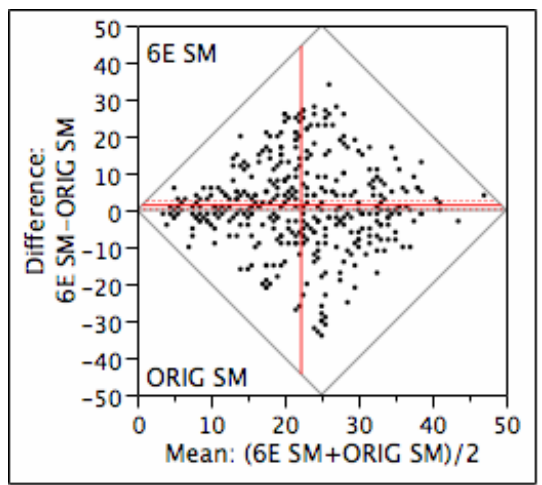

$\begin{array}{lrlr}\text { 6E SM } & 22.8951 & \text { t-Ratio } & 2.194199 \\ \text { ORIG SM } & 21.5729 & \text { DF } & 390 \\ \text { Mean Difference } & 1.32225 & \text { Prob }>|\mathrm{t}| & 0.0288 \\ \text { Std Error } & 0.60261 & \text { Prob }>\mathrm{t} & 0.0144 \\ \text { Upper95\% } & 2.50703 & \text { Prob < t } & 0.9856 \\ \text { Lower95\% } & 0.13748 & & \\ \text { N } & 391 & & \\ \text { Correlation } & & & \end{array}$

Figure 18: Comparison of 6e and Original smiling profiles for Professionals (B) and

Laypersons(A). 


\section{ARNETT VS. ORIGINAL:}

Comparisons between the preferences of the Arnett profiles to the Originals were

performed using the matched pairs student t-test. The difference between the mean rating of the Arnett and the mean rating of the Original was calculated (M). Positive values of $\mathrm{M}$ indicate a preference for Arnett profiles while negative values indicate a preference for the Original. Results are summarized in Tables 5 and 6. In repose, professional raters preferred the Arnett profile to the Original $(\mathrm{M}=1.90 \pm 0.68, \mathrm{p}=0.002)$. Layperson raters had no significant preference between the two $(M=-0.27 \pm 0.25, \mathrm{p}=0.29)$ (Figure 19). For smiling profiles, layperson raters preferred the Original to the Arnett $(\mathrm{M}=-1.23 \pm$ $0.24, \mathrm{p}<0.0001)$. No significant preference was found between the Original and Arnett smiling profiles for professiona raters $(\mathrm{M}=-0.32 \pm 0.65, \mathrm{p}=0.63)$ (Figure 20).

\begin{tabular}{|l|llr|rrr|}
\hline & \multicolumn{3}{|c|}{ Professionals } & \multicolumn{3}{c|}{ Laypersons } \\
Profiles & Mean & SD & Sig & Mean & SD & Sig \\
\hline Repose & 1.90 & 0.68 & $\mathrm{p}=0.002$ & -0.27 & 0.25 & $\mathrm{p}=0.29$ \\
\hline Smiling & -0.32 & 0.65 & $\mathrm{p}=0.63$ & -1.23 & 0.24 & $\mathrm{p}<0.0001$ \\
\hline
\end{tabular}

Table 5: Profile preferences of professional and layperson raters comparing Arnett and Original.

\begin{tabular}{|l|l|l|}
\hline Profiles & Professionals & Laypersons \\
\hline Repose & Arnett & No preference \\
\hline Smiling & No preference & Original \\
\hline
\end{tabular}

Table 6: Profile preferences of professional and layperson raters comparing Arnett and Original. 
Matched Pairs Rstatus=LAYPERSON

Difference: ARN REP-ORIG REP

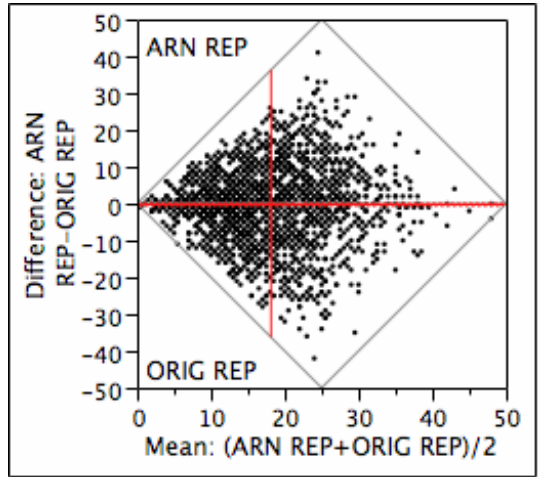

ARN REP
ORIG REP
Mean Difference
Std Error
Upper $95 \%$
Lower $95 \%$
N
Correlation

18. 0037

t-Ratio

DF

$-1.05547$

1884

18.2716

Prob $>|t|$

0.2913

$-0.2679$

Prob $>t$

0.8543

0.2299

Prob $<t$

$\odot .1457$

Correlation

$$
1885
$$

0.31819

A

Matched Pairs Rstatus=PROFESSIONAL

Difference: ARN REP-ORIG REP

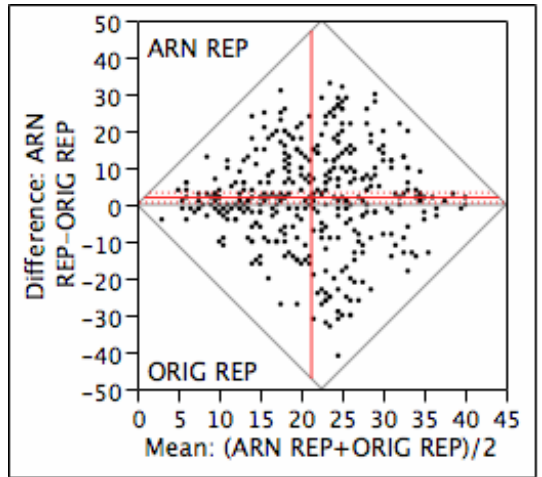

$\begin{array}{lr}\text { ARN REP } & 22.2123 \\ \text { ORIG REP } & 20.3043 \\ \text { Mean Difference } & 1.90793 \\ \text { Std Error } & 0.68269 \\ \text { Upper95\% } & 3.25014 \\ \text { Lower95\% } & 0.56571 \\ \text { N } & 391 \\ \text { Correlation } & 0.09736\end{array}$

t-Ratio

DF

Prob $>|t|$

Prob $>t$

Prob $<t$

09736

B

Figure 19: Comparison of Arnett and Original repose profiles for Professional and

Layperson (A) raters. 
Matched Pairs Rstatus=LAYPERSON

Difference: ARN SM-ORIG SM

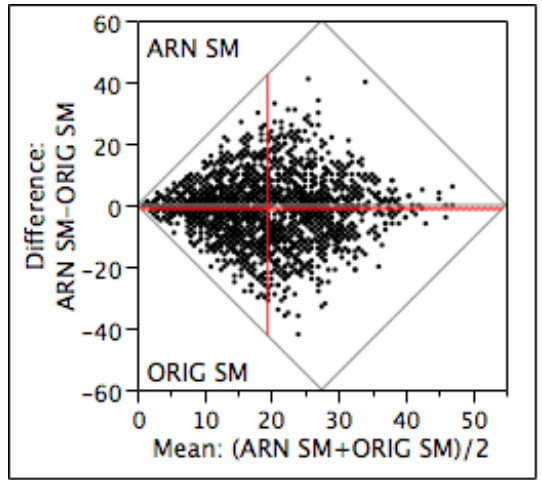

ARN SM
ORIG SM
Mean Difference
Std Error
Upper $95 \%$
Lower $95 \%$
N
Correlation

18.843

20.0828

$-1.2398$

0.24513

$-0.759$

$-1.7205$

1885

0.42821
t-Ratio

DF

Prob $>|t|$

Prob $>t$

Prob $<\mathrm{t}$
$-5.05772$
1884
$<.0001$
1.0000
$<.0001$

A

Matched Pairs Rstatus=PROFESSIONAL

Difference: ARN SM-ORIG SM

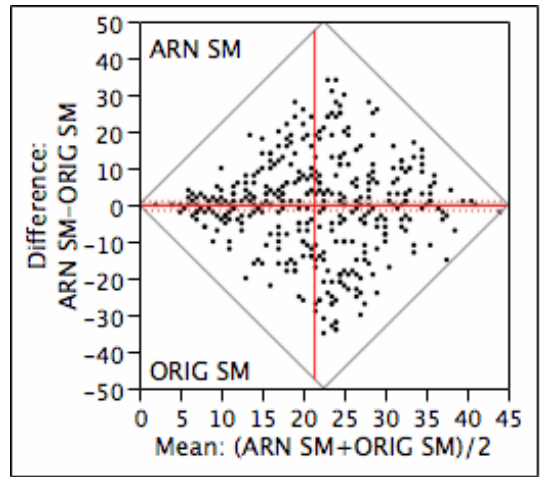

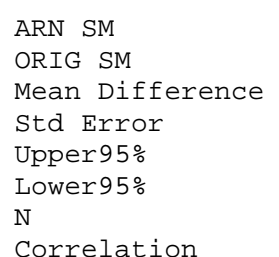

ARN SM

Std Error

Correlation
21.2558
21.5729
$-0.3171$
$\odot .65988$
$\odot .98023$
$-1.6145$
391
๑ . 21311

t-Ratio

DF

Prob $>|\mathrm{t}|$

Prob $>\mathrm{t}$

Prob $<\mathrm{t}$

$$
\begin{array}{r}
-0.4806 \\
390 \\
0.6311 \\
0.6845 \\
0.3155
\end{array}
$$

$\mathrm{B}$

Figure 20: Comparison of Arnett and Original smiling profiles for Professional (B) and Layperson (A) raters. 


\section{ARNETT VS. SIX ELEMENTS:}

Comparisons between the preferences of the Arnett profiles to the Six Elements were performed using the matched pairs student t-test. The difference between the mean rating of the Arnett and the mean rating of the Six Elements was calculated (M). NPI composite scores were used to compare the overall (combined smiling and repose profiles) preferences for $6 \mathrm{e}$ or Arnett. Positive values of $\mathrm{M}$ indicate a preference for $6 \mathrm{e}$ profiles while negative values indicate a preference for the Arnett profiles. Results of panel preferences for smiling and repose profiles comparing the 6e and Arnett analyses are summarized in Tables 7 and 8. Professional raters preferred the 6e to Arnett profiles in repose $(\mathrm{M}=2.11 \pm 0.71, \mathrm{p}<0.0001)$. Layperson raters also preferred the $6 \mathrm{e}$ repose to Arnett profiles $(\mathrm{M}=1.18 \pm 0.26, \mathrm{p}<0.0001)$ (Figure 21). Similar results were found with the smiling profiles, with 6e being preferred to Arnett for both professional $(\mathrm{M}=1.63 \pm$ $0.59, \mathrm{p}=0.003)$ and layperson $(\mathrm{M}=1.21 \pm 0.23, \mathrm{p}<0.0001)$ raters (Figure 22).

Consequently, when comparing the overall preference (combined smiling and repose) represented by the NPIs both professional $(\mathrm{M}=3.75 \pm 0.96, \mathrm{p}<0.0001)$ and layperson $(\mathrm{M}=2.33 \pm 0.37, \mathrm{p}<0.0001)$ panels preferred 6e to Arnett (Figure 23). 


\begin{tabular}{|c|crr|lrr|}
\hline & \multicolumn{3}{|c|}{ Professionals } & \multicolumn{3}{c|}{ Laypersons } \\
Profiles & Mean & SD & Sig & Mean & SD & Sig \\
\hline Repose & 2.11 & 0.71 & $\mathrm{p}<0.0001$ & 1.18 & 0.26 & $\mathrm{p}<0.0001$ \\
\hline Smiling & 1.63 & 0.59 & $\mathrm{p}=0.003$ & 1.21 & 0.23 & $\mathrm{p}<0.0001$ \\
\hline NPI (Overall) & 3.75 & 0.96 & $\mathrm{p}<0.0001$ & 2.33 & 0.37 & $\mathrm{p}<0.0001$ \\
\hline
\end{tabular}

Table 7: Comparison of Six Elements (6e) and Arnett profiles. Panel preferences for smiling, repose, and overall (NPI) profiles for professional and layperson raters.

\begin{tabular}{|l|l|l|}
\hline Profiles & Professionals & Laypersons \\
\hline Repose & $6 \mathrm{e}$ & $6 \mathrm{e}$ \\
\hline Smiling & $6 \mathrm{e}$ & $6 \mathrm{e}$ \\
\hline NPI & $6 \mathrm{e}$ & $6 \mathrm{e}$ \\
\hline
\end{tabular}

Table 8: Comparison of Six Elements (6e) and Arnett profiles. Panel preferences for smiling, repose, and overall (NPI) profiles for professional and layperson raters. 
Matched Pairs Rstatus=LAYPERSON

Difference: 6E REP-ARN REP

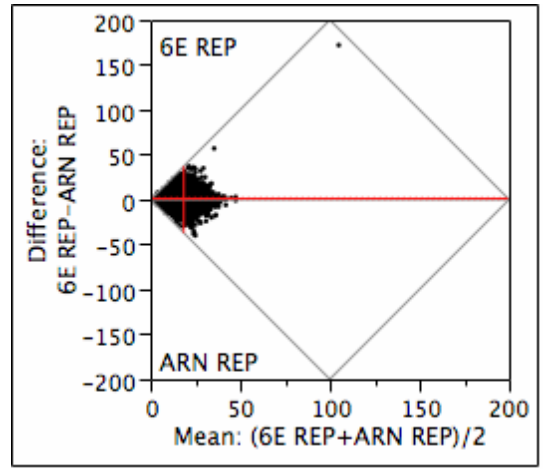

$\begin{array}{lrlr}\text { 6E REP } & 19.1733 & \text { t-Ratio } & 4.472571 \\ \text { ARN REP } & 17.9894 & \text { DF } & 1880 \\ \text { Mean Difference } & 1.18394 & \text { Prob }>|t| & <.0001 \\ \text { Std Error } & 0.26471 & \text { Prob }>\mathrm{t} & <.0001 \\ \text { Upper95\% } & 1.70311 & \text { Prob < t } & 1.0000 \\ \text { Lower95\% } & 0.66478 & & \\ \mathrm{~N} & 1881 & & \\ \text { Correlation } & 0.33204 & & \end{array}$

A

Matched Pairs Rstatus=PROFESSIONAL

Difference: 6E REP-ARN REP

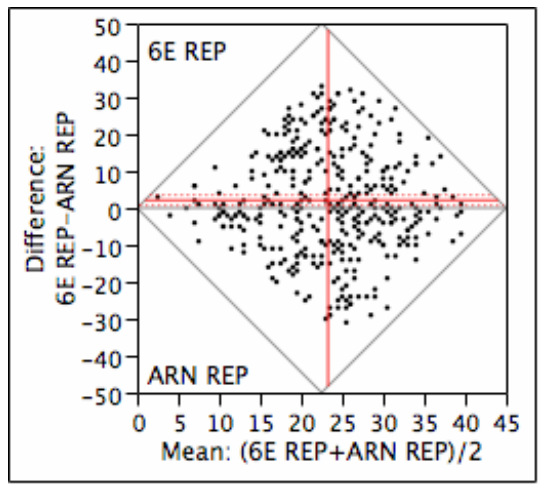

$\begin{array}{lrlr}\text { 6E REP } & 24.3248 & \text { t-Ratio } & 2.959409 \\ \text { ARN REP } & 22.2123 & \text { DF } & 390 \\ \text { Mean Difference } & 2.11253 & \text { Prob > It } & 0.0033 \\ \text { Std Error } & 0.71384 & \text { Prob }>\text { t } & 0.0016 \\ \text { Upper95\% } & 3.51598 & \text { Prob }<\text { t } & 0.9984 \\ \text { Lower95\% } & 0.70908 & & \\ \text { N } & 391 & & \\ \text { Correlation } & & & \end{array}$

Figure 21: Comparison of Arnett and Six Elements (6e) repose profiles for Professional and Layperson (A) raters. 
Matched Pairs Rstatus=LAYPERSON

Difference: 6E SM-ARN SM

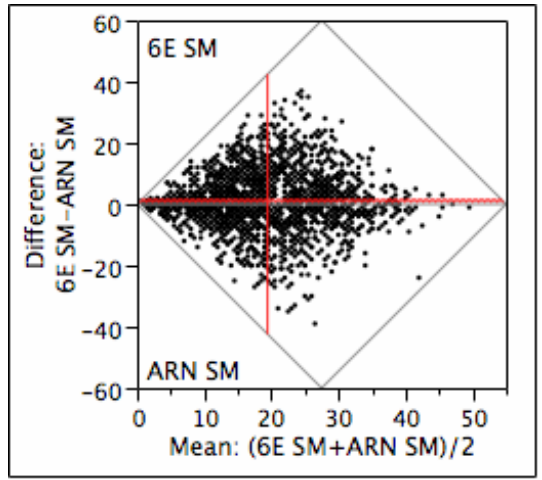

6E SM
ARN SM
Mean Difference
Std Error
Upper $95 \%$
Lower $95 \%$
$\mathrm{~N}$
Correlation

20.0579

18.8392

t-Ratio

DF

Prob $>|t|$

1.21868

Prob $>\mathrm{t}$

1883

$<.0001$

$<.0001$

1.67714

Prob $<\mathrm{t}$

1.0000

Correlation

0.76023

A

Matched Pairs Rstatus=PROFESSIONAL

Difference: 6E SM-ARN SM

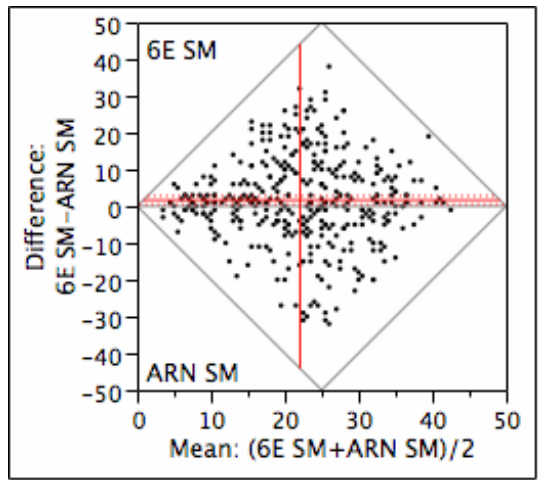

6E SM
ARN SM
Mean Difference
Std Error
Upper95\%
Lower $95 \%$
$\mathrm{~N}$
Correlation

$\begin{aligned} 22.8951 & \text { t-Ratio } \\ 21.2558 & \text { DF } \\ 1.63939 & \text { Prob }>\quad t \mid \\ 0.59718 & \text { Prob }>\mathrm{t} \\ 2.81349 & \text { Prob }<\mathrm{t} \\ 0.46529 & \\ 391 & \\ 0.34762 & \end{aligned}$

2.745199

390

0.0063

0.0032

0.9968

B

Figure 22: Comparison of Arnett and Six Elements (6e) smiling profiles for Professional

(B) and Layperson (A) raters. 
Matched Pairs Rstatus=LAYPERSON

Difference: 6E NPI-Arnett NPI

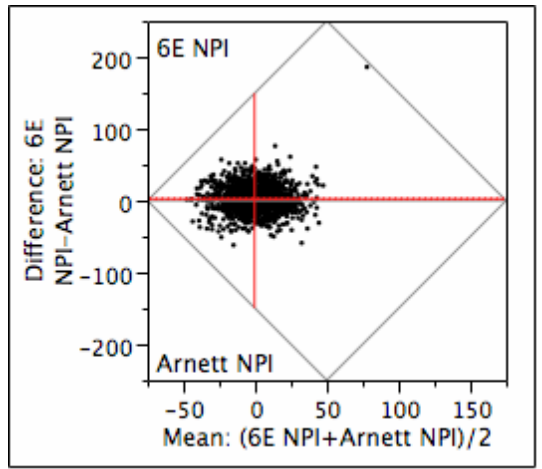

6E NPI
Arnett NPI
Mean Difference
Std Error
Upper95\%
Lower95\%
N
Correlation

$\begin{aligned} 0.82503 & \text { t-Ratio } \\ -1.5069 & \text { DF } \\ 2.33192 & \text { Prob }>|\mathrm{t}| \\ 0.37754 & \text { Prob }>\mathrm{t} \\ 3.07235 & \text { Prob }<\mathrm{t} \\ 1.59148 & \\ 1886 & \\ 0.45654 & \end{aligned}$

6.176655

1885

$<.0001$

$<.0001$

1.0000

Correlation

A

Matched Pairs Rstatus=PROFESSIONAL

Difference: 6E NPI-Arnett NPI

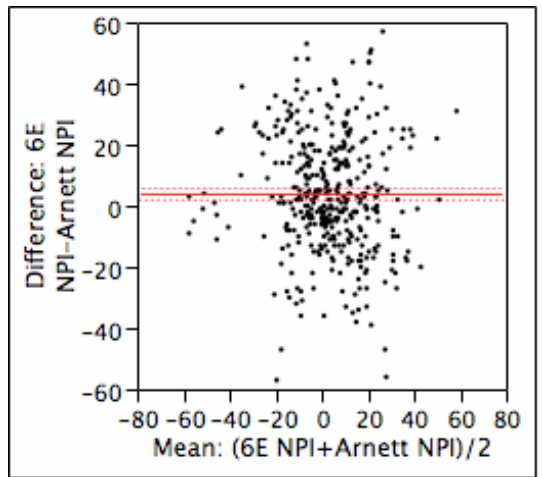

6E NPI
Arnett NPI
Mean Difference
Std Error
Upper $95 \%$
Lower95\%
N
Correlation

$\begin{aligned} 5.34271 & \text { t-Ratio } \\ 1.59079 & \text { DF } \\ 3.75192 & \text { Prob }>|t| \\ 0.96499 & \text { Prob }>\mathrm{t} \\ 5.64916 & \text { Prob }<\mathrm{t} \\ 1.85468 & \\ 391 & \\ 0.54932 & \end{aligned}$

3.88802

390

0.0001

$<.0001$

$\odot .9999$

B

Figure 23: Comparison of Arnett and Six Elements (6e) overall (NPI) profiles for

Professional (B) and Layperson (A) raters. 


\section{EFFECTS OF RATER STATUS ON PROFILE PREFERENCES:}

Least squares means was used to determine any statistical significance of rater status (professional or layperson) on profile preferences. No significant difference was found in preferences for 6 e repose or smiling profiles ( $\mathrm{p}=0.12$ and $\mathrm{p}=0.44$ respectively) compared to Arnett based on rater status.

\section{EFFECTS OF SUBJECT AND RATER GENDER ON PROFILE PREFERENCES:}

Least squares means was used to determine any statistical significance that subject and rater gender may have on profile preferences. No significant difference was found due to rater gender in preferences for of 6 e repose and smiling profiles $(p=0.75$ and $p=0.74$ respectively) compared to Arnett. No significant difference was found due to subject gender in preferences for 6 e repose and smiling profiles $(p=0.23$ and $p=0.84$ respectively) compared to Arnett. 


\section{INTRARATER RELIABILITY:}

During the panel presentation, raters were presented with three subject's photos at two timepoints in random order to assess the intrarater reliability of VAS scores. Cronbach's Alpha indicated that the VAS scores were most reliable for Subject 20, followed by Subject 11, and lastly Subject 1 . Overall reliability was satisfactory. Results are summarized in Table 9.

\begin{tabular}{|l|l|l|}
\hline & & Cronbach's Alpha \\
\hline Subjects $1,11,20$ & Original & 0.60 \\
\hline Subjects $1,11,20$ & Arnett & 0.69 \\
\hline Subjects $1,11,20$ & 6e & 0.62 \\
\hline Subject 1 & Original & 0.44 \\
\hline Subject 1 & Arnett & 0.51 \\
\hline Subject 1 & 6e & 0.53 \\
\hline Subject 11 & Original & 0.59 \\
\hline Subject 11 & Arnett & 0.76 \\
\hline Subject 11 & 6e & 0.57 \\
\hline Subject 20 & Original & 0.71 \\
\hline Subject 20 & Arnett & 0.72 \\
\hline Subject 20 & 6e & 0.71 \\
\hline
\end{tabular}

Table 9: Results for intrarater reliability from T1 to T2 using Cronbach's Alpha. VAS scores were most reliable for Subject 20, followed by Subject 11 and Subject 1. Overall reliability is satisfactory. 


\section{$\underline{\text { Discussion }}$}

When comparing the 6e and Original in repose, professionals and laypersons alike preferred the Six Elements (6e) profiles. While professional raters also preferred the 6e smiling profile to the Original, layperson raters had no statistically significant preference between the two. Several possible explanations may exist. Orthodontists undoubtedly have a more trained eye, with maxillary incisor positions being routinely assessed. Dolphin Imaging 9.0 is not commonly used to morph or digitally alter smiling photos. In some instances, mainly for subjects with larger maxillary anterior-posterior movements, the maxillary incisors appeared distorted by the software (Figure 24). One possible explanation for the differences in preferences for smiling profiles is that while professional raters may have been able to overlook this distortion, laypersons, being unfamiliar with the software capabilities, may have been distracted.

Another possible explanation is that unlike professionals, laypeople were less receptive to the anterior-posterior change of the maxillary incisors (or maxilla). This is contradictory to findings of Romani et al., who found that both orthodontists and laypeople were similarly sensitive to small horizontal changes in maxillary position and nearly identically sensitive to changes of $3 \mathrm{~mm}$ or more. Schlosser et al. had judges rate the attractiveness of smiling photos with the maxillary incisor position moved anterior or posterior in one millimeter increments. Results showed that laypeople and orthodontists agreed that the normal to protrusive incisor positions were most attractive while the $4 \mathrm{~mm}$ retrusive photo was significantly less desirable than the norm. 


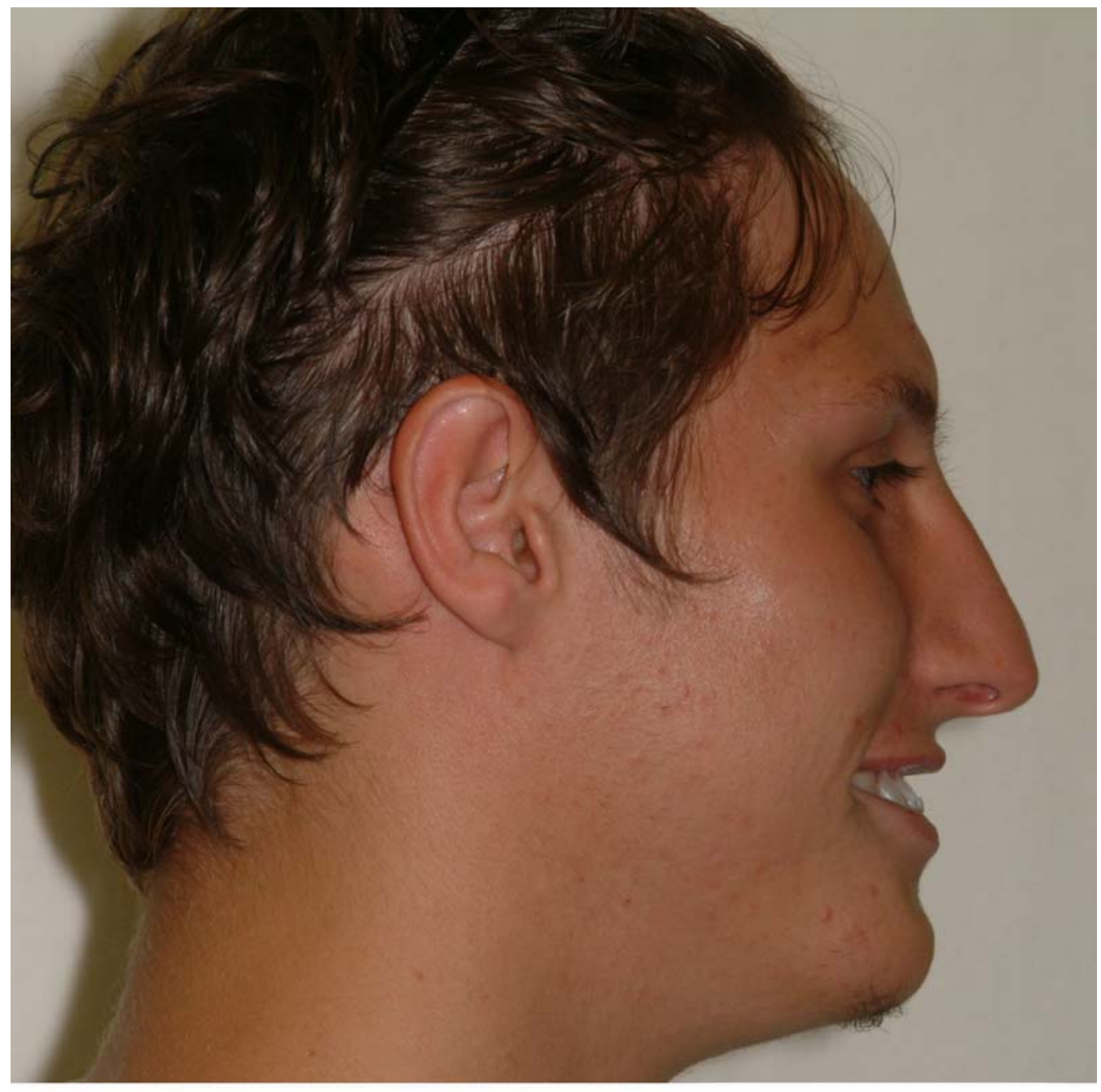

Figure 24: Example of a morphed smiling profile with distorted maxillary incisors which may have cause distraction of raters. 
When comparing Arnett and Original in repose, professional raters preferred Arnett, while layperson raters had no preference. Due to training in profile assessment professional raters judged the Arnett profiles as having more harmonious jaw positions than the Originals. Past research supports this finding. The Original repose photos had patients with varying skeletal patterns. In a study comparing the perception of facial attractiveness between orthodontists, oral surgeons and laypeople, Burcal et al. found that professionals focused more on the chin and nose in the soft tissue outline while laypeople focused more on the lip projection(38). Riedel suggested that there were perceived differences in profile attractiveness for professionals and laypeople. He found that, in general, orthodontists preferred a flatter profile whereas laypeople preferred a more convex soft tissue outline (62). In the Arnett profiles, the chin projection typically changed by correction of the skeletal imbalance while the lips had little change. This change in chin projection may have been more preferred for professional raters while the layperson raters focused more on the convex appearance of the Original profile with little to no change in lip projection in the Arnett morphed profile. However, it is interesting to note that while the chin projection also changed in the 6e profiles while maintaining lip posture laypeople and professionals both preferred the 6e repose to Original.

Spyropoulos found good general agreement between orthodontists and laypeople in rating profile attractiveness, but noted that orthodontists seemed more influenced by profile outline while factors other than a harmonious profile may be more influential on overall facial attractiveness ratings(39).

For smiling profiles, layperson raters significantly preferred the Original profile. Professional raters had no statistically significant preference for smiling profiles. As 
previously discussed, for smiling profiles laypeople may have been distracted by the distortion of the maxillary incisors influencing their ratings on the VAS. It is logical to speculate that more distortion of the maxillary incisor occurred with the Arnett smiling profile than the Original or 6e smiling because of the increased inclination of the maxillary incisor in the CTP. The first step in Arnett's CTP is to correct the inclination of the maxillary incisor (Mx1) to the maxillary occlusal plane (MxOP). According to Arnett the optimal inclination for Mx1 $-\mathrm{MxOP}$ is $54.3-59.3^{\circ}(46)$. For the Six Elements the optimal maxillary incisor inclination to $\mathrm{MxOP}$ is $65^{\circ}(18)$. The smaller the angle of $\mathrm{Mx} 1-\mathrm{MxOP}$, the more proclined the incisors are. This increased inclination of the Arnett maxillary incisor may have added to the distortion of the morphed smiling photo causing the layperson raters to prefer the Original smiling to Arnett. Since professional raters preferred the Arnett repose but had no preference for the Arnett smiling, it is reasonable to speculate that placing the soft tissue in a more esthetically pleasing position in repose may not create a more esthetically pleasing smiling profile. Professional raters preferred the 6e profile to the Original in both smiling and repose. Therefore, it may be more predictable to place the hard tissue (maxillary incisors) in a more esthetically pleasing position and have the soft tissue profile in repose also appear improved.

Varied results regarding differences between orthodontist and layperson perceptions have been noted in past research $(34 ; 35 ; 39 ; 59)$. It is reasonable to speculate that professionals are more sensitive to profile outlines than are laypeople due to differences in education and training $(38 ; 62)$. This is one potential reason for studies to use profile outline drawings rather than photographs. With outline drawings, extrinsic factors such as complexion, hair color, and eye color can be excluded from influencing 
VAS scores(63). Since the present study used photos rather than profile outline drawings, it is a reasonable assumption that laypeople may have evaluated subjects on both profile outline and beauty of parts. This may contribute to some of the differences in preferences found between laypeople and professionals.

It is also important to note that the professional raters were considerably older than the layperson raters. The majority of professional raters were in the age range of 5160 years old while most layperson raters were in the 18-25 year old range (Table 10). This may also have contributed to some differences in preferences between laypeople and professionals.

\begin{tabular}{|c|c|}
\hline Age Range & \# Professionals \\
\hline $25-30$ & 2 \\
\hline $31-40$ & 3 \\
\hline $41-50$ & 1 \\
\hline $51-60$ & 9 \\
\hline $61-70$ & 2 \\
\hline
\end{tabular}

\begin{tabular}{|l|l|}
\hline Age Range & \# laypersons \\
\hline $18-25$ & 69 \\
\hline $26-30$ & 11 \\
\hline $31-35$ & 0 \\
\hline $36-40$ & 1 \\
\hline $41-50$ & 0 \\
\hline Over 51 & 1 \\
\hline
\end{tabular}

\begin{tabular}{|l|l|l|}
\hline & Professionals & laypersons \\
\hline $\mathrm{M}$ & 35 & 16 \\
\hline $\mathrm{F}$ & 47 & 1 \\
\hline
\end{tabular}

Table10: Professional and Layperson panel demographics 
In all instances, repose, smiling and overall (NPI), 6e profiles were significantly preferred when compared to Arnett profiles for both professional and layperson raters (Tables 7 and 8). There were no significant differences based on rater status (professional vs. layperson) or rater or subject gender. One explanation is that some feature of the 6e profile is overwhelmingly preferred to the Arnett profile. In general, differences exist in the anterior-posterior placement of the maxilla, mandible, and pognion between the two diagnostic methods. While both use a vertical reference plane to determine the anterior-posterior position of the maxillary incisor, the location of the reference plane is different. Arnett's TVL is drawn through Subnasale perpendicular to NHP which is typically $5-10 \mathrm{~mm}$ anterior of Glabella (46). The Six Elements GALL is at or behind a vertical line through Glabella based on the patient's unique forehead inclination (18). In Arnett's CTP the maxilla and incisor are positioned to TVL while attention is given to the soft tissue thickness of the upper lip. The thicker the upper lip soft tissue, the further posterior the maxilla will be placed relative to the TVL. Preference is given to the soft tissue in repose as compared to the maxillary incisor in repose(46). In contrast, the Six Elements philosophy emphasizes the placement of the maxillary incisor in repose (and smiling) when compared to the soft tissue. That is, Dr. Andrews believes that if the maxillary incisor is placed in the proper anterior-posterior position the soft tissue will also appear harmonious or esthetically acceptable (18).

The present study seems to confirm Dr. Andrews' theory. While both Pro and Non-Pro raters preferred 6e in repose, both panels liked 6e in smiling at least as much as the Original smiling. This indicates that placing the maxillary incisor in a unique anterior-posterior position created an esthetically pleasing profile in both repose and 
smiling. However, though the Arnett profile in repose was preferred by professionl raters, layperson raters actually preferred the Original smiling to the Arnett profile. So it would seem that placing the repose soft tissue in an acceptable position did not necessarily correlate with an esthetically pleasing smiling profile. Arnett and other researchers agree that there is a wide range in variability of soft tissue thickness overlying the hard tissue structures(10;43). It is reasonable to assume that there would also be a wider range of acceptability in placement of these soft tissue structures than in the placement of a more precise landmark such as the maxillary incisors. The present study supports this theory since professional raters preferred the 6e profile in smiling and repose yet preferred the Arnett profile only in repose (and not smiling) when compared to the Original. So while both were considered improved compared to the Original in repose, only the system which emphasizes anteroposterior placement of the maxillary incisor in smiling created a more esthetic profile during smiling. The goals of the two diagnostic and treatment planning systems are different, creating different facial outcomes which accounts for the differences in profile preferences.

Other possible explanations exist for preferences of the 6e profiles to Arnett by both professional and layperson raters. When examining the morphed profiles, some generalities could be noted. Often the Arnett profiles had more pronounced chin projections and deeper mentolabial folds (soft tissue concavity between the lower lip and chin). Some of this may be attributed to the increased inclination of the mandibular incisors (Md1) to the mandibular occlusal plane (MdOP). In the Arnett CTP, the inclination of the optimal Md1 - MdOP is $61.1-67.5^{\circ}(46)$. The Six Elements optimal incisor inclination is approximately $76^{\circ}(18)$. A smaller angle for Md1-MdOP creates a 
more proclined incisor. Increased inclination of the mandibular incisor can cause a more pronounced mentolabial fold. The increased chin projection in some of the Arnett profiles could also have caused the maxillary incisors to appear more retruded. Multiple researchers have concluded that the retruded maxillary appearance is much less attractive than the normal or protruded appearance regardless of rater status (professional or layperson) (40;64).

Still another possible explanation for the preferences for 6e over the Arnett profiles is the sample selection for the development of each system. Dr. Andrews selected his sample population for the development of the Six Elements system from people society judged to be attractive. He collected photos of models and celebrities of all ages and ethnicities from magazines and other published works to determine any similarities in appearance which may explain their perceived attractiveness. It was from this research that he discovered the relationship of the maxillary incisor to the patient's unique forehead inclination and devised the GALL. Therefore, his sample was judged by him and society as being attractive (regardless of their occlusion)(17). Arnett, on the other hand, chose a sample of 46 Caucasian patients with untreated Class I occlusions which were judged by him to be "reasonably facially balanced." From this sample he created the STCA and CTP module for Dolphin Imaging 9.0. The preference for 6e compared to Arnett could potentially be linked to the sample selection criteria. Results from this study seem to corroborate Dr. Andrews' philosophy of what society judges as facial harmony. This theory on sample selection could also explain why there was no effect of subject or rater gender or rater status on the preference of the 6e profiles to the Arnett profiles. 
While these results have been determined to be statistically significant, whether or not they are clinically significant is unknown. The mean ratings of the 6e, Arnett, and Original profiles are shown in Figures 17-23. The mean ratings are similar in most instances. The large amount of data collected, mainly the large number of individuals on the panels, created statistically significant results though not necessarily clinically significant. A mean difference of 2 when rated on a scale from 0 to 50 may be below the level of clinical significance. The slight clinical improvement in appearance, unless the disharmony is pronounced, may not be worth the additional cost and risk associated with orthognathic surgery.

It is important to note that the primary researcher in this study has attended an introductory Six Elements philosophy course, but has never attended a course by Dr. Arnett on the STCA and CTP. The steps for the STCA and CTP were performed as described in Dr. Arnett's text book and as prompted by the Dolphin 9.0 imaging software Arnett STCA and CTP module. Every attempt was made to eliminate any bias based on researcher training. 


\section{CLINICAL IMPLICATIONS:}

The present study poses multiple clinical implications:

1. It is more important when diagnosing and treatment planning to place the incisors and hard tissue structures in an ideal location rather than emphasizing the placement of the overlying soft tissue structures.

2. Placement of the hard tissue structures to generate an esthetically pleasing soft tissue outline in repose does not necessarily create an esthetically pleasing smiling profile.

3. Placement of the maxillary incisor in a unique anterior-posterior position as described by the Six Elements philosophy will generate esthetically pleasing profiles in both smiling and repose.

4. The profiles generated by principles of the Six Elements philosophy are more esthetically pleasing than those profiles created by the Arnett STCA and CTP.

5. Preference for the Six Elements profiles was not influenced by subject or rater gender or rater status (professional or layperson).

6. The Six Elements tracing can be done quickly and inexpensively compared to the Arnett STCA and CTP and creates more esthetic results. 


\section{CHAPTER 5: SUMMARY AND CONCLUSIONS}

The purpose of this study was to examine the Six Elements and Arnett STCA standard profiles in smiling and repose. The goal was to determine which type of diagnosis and treatment plan would produce a more esthetic overall result as judged by professionals and laypeople? To date, no researchers have investigated differences in profile attractiveness comparing these two diagnostic techniques.

Professional and layperson panels were asked to judge smiling and repose profiles based on position of facial parts rather than attractiveness of facial features. Ratings of profiles were done on visual analog scales and composite scores for both smiling and repose photos were tallied (NPIs) for statistical analysis. Statistical analysis using matched pairs student t-tests, least squares means and Cronbach's alpha was performed to determine profile preferences and intrarater reliability. Data were analyzed to determine differences in preferences for laypeople and professionals.

The Six Elements (6e) profiles were statistically preferred in smiling, repose, and overall for professional and layperson panels when compared to the Arnett profiles. The only Arnett profile that was preferred was the repose as compared to the Original for professional raters only. Differences exist between the Six Elements philosophy and Arnett STCA and CTP systems based on sample selection, goals, landmarks, and referents. Results from this study suggest that the placement of the maxilla and mandible and associated dental structures as detailed in the Six Elements philosophy will create esthetic profiles in smiling and repose. Profiles created by treatment to the goals of the Six Elements philosophy will be more esthetic than those that would be created by treatment with the Arnett STCA and CTP. The Six Elements is an inexpensive, effective 
method of diagnosing and treatment planning which will create facially and dentally esthetic results.

\section{RECOMMENDATIONS FOR FUTURE RESEARCH:}

1. In the present study the primary researcher did not attend an Arnett STCA and CTP course. It may be beneficial for a researcher trained in both areas to conduct and reproduce the present study using knowledge obtained at both courses.

2. In the present study, subjects were chosen mainly from patients undergoing post-treatment records. None of these patients had significantly malpositioned jaws. It may be interesting to reproduce this study using subjects with more pronounced physical deformities.

3. The patient pool at West Virginia University is not as diverse in ethnicity as may be found elsewhere. It would be interesting to conduct this study on subjects of varying ethnicities. 
1. Glossary of dentofacial orthopedic terms. St. Louis, American Association of Orthodontists; 1996.

2. Proffit WR, Fields HW. Contemporary Orthodontics. 3 edn. St. Louis, Mosby; 2000.

3. Downs WB. The role of cephalometrics in orthodontics case analysis and diagnosis. Am J Orthod 1952; 38: 162-82.

4. Steiner CC. Cephalometrics for you and me. Am J Orthod 1953; 39: 729-55.

5. Tweed CH. The Frankfort-mandibular incisor angle (FMIA) in orthodontic diagnosis, treatment planning and prognosis. Angle Orthod 1954; 24: 121-69.

6. Jacobson. Radiographic cephalometry. Chicago, Quintessence Publishing Co.; 1995.

7. Jarabak JR, Fizzel JA. Technique and treatment with light-wire edgewise appliance. St. Louis, Mosby; 1972.

8. Ackerman JL, Proffit WR, Sarver DM. The emerging soft tissue paradigm in orthodontic diagnosis and treatment planning. Clinical Orthodontic Research 1999; 2: 49-52.

9. Proffit WR. The soft tissue paradigm in orthodontic diagnosis and treatment planning: a new view for a new century. J Esthet Dent 2000; 12: 46-9.

10. Park YC, Burstone CJ. Soft-tissue profile--fallacies of hard-tissue standards in treatment planning. Am J Orthod Dentofacial Orthop 1986; 90: 52-62.

11. McLaughlin RP, Bennett JC. Orthodontic management of the dentition with the preadjusted appliance. 3rd edn. Oxford, Isis Medical Media Ltd; 1997.

12. Bishara SE. Textbook of Orthodontics. Philadelphia, W.B. Saunders Co.; 2001.

13. Arnett GW, Jelic JS, Kim J, Cummings DR, Beress A, Worley CM, Jr. et al. Soft tissue cephalometric analysis: diagnosis and treatment planning of dentofacial deformity. Am J Orthod Dentofacial Orthop 1999; 116: 239-53.

14. Dawson PE. Optimum TMJ condyle position in clinical practice. Int J Periodont Restor Dent 1985; 3: 11-31.

15. Andrews LF. Straight Wire: The Concept and Appliance. L.A. Wells Co.; 1989. 
16. Arnett GW, Gunson MJ. Facial planning for orthodontists and oral surgeons. Am J Orthod Dentofacial Orthop 2004; 126: 290-5.

17. Andrews, L. F. Six elements orthodontics. Andrews J Orthod and Orofac Harmony 1(1). 2000.

Ref Type: Journal (Full)

18. Andrews LF. Syllabus of philosophy and techniques. 2001.

19. Arnett, G. W., Gunson, M. J., and McLaughlin, R. P. The essence of beauty. 2002.

Ref Type: Unpublished Work

20. James RD. A comparative study of facial profiles in extraction and nonextraction treatment. Am J Orthod Dentofacial Orthop 1998; 114: 265-76.

21. Bishara SE, Jakobsen JR. Profile changes in patients treated with and without extractions: assessment by lay people. Am J Orthod Dentofacial Orthop 1997; 112: 639-44.

22. Dion KK, Berschield E, Walster E. What is beautiful is good. J Pers Soc Psychol 1972; 24: 285-90.

23. Cash TF, Gillen B, Burns DS. Sexism and "beautyism" in personal consultant decision making. J Appl Psychol 1996; 8: 189-92.

24. Berschield E, Gangestad S. The social psychological implications of physical attractiveness. Clin Plast Surg 1982; 9: 289-96.

25. Phillips C, Bennett ME, Broder HL. Dentofacial disharmony: psychological status of patients seeking treatment consultation. 68 1998; 556.

26. Giddon DB. Orthodontic applications of psychological and perceptual studies of facial esthetics. Semin Orthod 1995; 1: 82-93.

27. Bell R, Kiyak HA, Joondeph DR. perceptions of facial profile and their influence on the decision to undergo orthognathic surgery. Am J Orthod 1985; 88: 323-32.

28. Vargo JK, Gladwin M, Ngan P. Association between ratings of facial attractivess and patients' motivation for orthognathic surgery. Orthod Craniofac Res 2003; 6: 63-71.

29. Polk MS, Farman AG, Yancey JA, Gholston LR, Johnson BE, Regennitter FJ. Soft tissue profile: a survey of African American preferences. Am J Orthod Dentofacial Orthop 1995; 108: 90-101. 
30. Mantzikos T. Esthetic soft tissue profile preferences among the Japanese population. Am J Orthod Dentofacial Orthop 1998; 114: 1-7.

31. Maganzini AL, Tseng JY, Epstein JZ. Perception of facial esthetics by native Chinese participants by using manipulated digital imagery techniques. Angle Orthod 2000; 70: 393-9.

32. Auger TA, Turley PK. The female soft tissue profile as presented in fashion magazines during the 1900's: a photographic analysis. Int J Adult Orthodon Orthognath Surg 1999; 14: 7-18.

33. Peck H, Peck S. A concept of facial esthetics. Angle Orthod 1970; 40: 284-318.

34. Foster EJ. Profile preferences among diversified groups. Angle Orthod 1973; 43: $34-40$.

35. Cochrane SM, Cunningham S, Hunt N. Perceptions of facial appearance by orthodontists and the general lay public. J Clin Orthod 1997; 31: 164-8.

36. Nanda R, Joydeep G. Facial soft tissue harmony and growth in Orthodontic treatment. Semin Orthod 1995; 1: 67-81.

37. Dunlevy HA, White RP, Turvey TA. Professional and lay judgement of facial esthetic changes in orthognathic surgery. Int J Adult Orthodon Orthognath Surg 1987; 3: 151-8.

38. Burcal RG, Laskin DM, Sperry TP. Recognition of profile changes after simulated orthognathic surgery. J Oral Maxillofac Surg 1987; 45: 666-73.

39. Spyropoulos MN, Halazonetis DJ. Significance of the soft tissue profile on facial esthetics. Am J Orthod Dentofacial Orthop 2001; 119: 464-71.

40. Czarneki ST, Nanda R, Currier GF. Perceptions of a balanced facial profile. Am J Orthod Dentofacial Orthop 1993; 104: 180-7.

41. Jefferson Y. Facial beauty--establishing a universal standard. Int J Orthod Milwaukee 2004; 15: 9-22.

42. Ricketts RM. The biologic significance of the divine proportion and Fibonacci series. Am J Orthod 1982; 81: 351-70.

43. Arnett GW, Bergman RT. Facial keys to orthodontic diagnosis and treatment planning. Part I. Am J Orthod Dentofacial Orthop 1993; 103: 299-312.

44. Adams TB. Optimal dental and facial esthetics in orthodontics--a multifaceted challenge. Tex Dent J 2002; 119: 1019-31.

45. Burstone CJ. The integument profile. Am J Orthod 1958; 44: 1-25. 
46. Arnett GW, McLaughlin RP. Facial and Dental Planning for Orthodontists and Oral Surgeons. Mosby; 2004.

47. Lundstrom A, Lundstrom F. The Frankfort horizontal as a basis for cephalometric analysis. Am J Orthod Dentofacial Orthop 1992; 101: 244-7.

48. Arnett GW, Bergman R. Facial keys to orthodontic diagnosis and treatment planning - Part II. Am J Orthod Dentofacial Orthop 1993; 103: 395-411.

49. Burstone CJ. Lip posture and its significance in treatment planning. Am J Orthod 1967; 53: 262-84.

50. Andrews LF. Article 2: Six element diagnostic record. Andrews J Orthod and Orofac Harmony 2001; 2: 15-20.

51. Smith JD, Thomas R, Proffit WR. A comparison of current prediction imaging programs. Am J Orthod Dentofacial Orthop 2004; 125: 527-36.

52. Power G, Breckon J, Silveira AM, McDonald F. Dolphin Imaging Software: an anlysis of the accuracy of cephalometric digitization and orthognathic prediction. Int J Oral and Maxillofacial Surgery 2005; 34: 619-26.

53. Phillips C, Trentini C, Douvartzidis N. The Effect of Treatment on Facial Attractiveness. J Oral Maxillofac Surg 1992; 50: 590-4.

54. Tedesco L, Albino J, Cunat J, Green L, Lewis E, Slakter M. A dental-facial attractiveness scale. Am J Orthod Dentofacial Orthop 1983; 83: 38-46.

55. Peerlings RH, Kuijpers-Jagtman AM, Hoeksma JB. A photographic scale to measure facial esthetics. European Journal of Orthodontics 1995; 17: 101-10.

56. Lines PA, Lines RR, Lines CA. Profilemetrics and facial esthetics. Am J Orthod 1978; 73: 648-57.

57. Kiekens RMA, Martha JC, Van't Hof MA, Kuijpers-Jagtman AM. A measuring system for facial esthetics in caucasian adolescents: reproducibility and validity. European Journal of Orthodontics 2005; 27: 579-84.

58. Giddon DB, Sconzo R, Kinchen JA, Evans CA. Quantitative comparison of computerized discrete and animated profile preferences. Angle Orthod 1996; 66: 441-8.

59. Kerr WJS, O'Donnell JM. Panel perception of facial attractiveness. British Journal of Orthodontics 1990; 17: 299-304.

60. Howells DJ, Shaw WC. The validity and reliability of ratings of dental and facial attractiveness for epidemiological use. Am J Orthod 1985; 88: 402-8. 
61. Phillips C, Tulloch C, Dann C. Rating of facial attractiveness. Community Dentistry and Oral Epidemiology 1992; 20: 214-20.

62. Riedel R. Esthetics and its relationship to orthodontic therapy. Angle Orthod 1950; 20: 168-78.

63. Shelley A, Southard T, Southard K, Casko J, Jakobsen J, Fridrich K. Evaluation of profile esthetic change with mandibular advancement surgery. Am J Orthod Dentofacial Orthop 2000; 117: 630-7.

64. Schlosser JB, Preston CB, Lampasso J. The effects of computer-aided anteroposterior maxillary incisor movement on ratings of facial attractiveness. Am J Orthod Dentofacial Orthop 2005; 127: 17-24. 


\section{APPENDIX A IRB FORMS}




\section{West VirginiaUniversity \\ Office of Research Compliance}

DATE: November 18, 2005

This research will be monitored for re-approval annually.

APPROVAL PERIOD: October 12, 2005 to October 11, 2006

NOTICE OF APPROVAL FOR PROTOCOL: IRB \#16710

TO: Jennifer Hamilton

Peter Ngan, Chris Martin, \& Michael Bagby

TITLE: Attractiveness of Repose and Lateral Smiling Profiles using the Arnett and Andrews' Soft Tissue Diagnostic Standards

AGENCY : N/A

The Institutional Review Board for the Protection of Human Research Subjects (IRB) has approved the project described above. Approval was based on the descriptive material and procedures you submitted for review. Should any changes in your protocol/consent form be necessary, prior approval must be obtained from the IRB.

According to the Code of Federal Regulations, Section 312.32, investigators are required to notify the FDA and the study sponsor of any adverse experience associated with the use of an investigational drug that is serious and unexpected. A serious adverse experience is considered any event that is fatal or lifethreatening, is permanently disabling, requires inpatient hospitalization, or is a congenital anomaly, cancer, or overdose. An unexpected adverse experience is an event that is not identified in nature, severity, or frequency in the current investigator brochure. Any experience reportable to FDA and the sponsor must also be reported immediately to the IRB. If the study is funded, initiation of the protocol may not begin until the contract is finalized. 
Date: November 18, 2005

Page -2-

Hamilton

IRB \#16710

A consent form* $\mathrm{X}$ is__ is not required of each subject.

An assent form $\mathrm{X}$ is__ is not required of each subject.

A recruitment ad has__ has not_ $\mathrm{X}$ been approved.

A consent form waiver has__ has not_ $\mathrm{X}$ been approved.

An authorization form to use PHI has_ $\mathrm{X}$ has not__ been approved.

A PHI waiver has has not $\mathrm{X}$ been approved.

Only copies of the consent and/or assent form with the IRB's approval stamp may be used with human subject research. It is the responsibility of the investigator to submit a revised consent form for the IRB's approval should funding be obtained. This stamped consent form must then be used for subjects enrolled. A copy of each subject's signed Consent/Assent Form must be retained by the investigator and accessible to federal regulatory authorities for at least three years after the study is completed.

Senior Program Coordinator for Research Compliance

LAA/clg 


\title{
WestVurginiaUniversity
}

Radiation SAFetY SerVices

\section{Memorandum}

\author{
To: IRB Committee \\ Sponsored Program \\ 202 CRRB \\ 886 Chestnut Ridge Rd \\ POBox 6845 \\ From: \\ Director and Radiation Safety $O$ fficer $V$ \\ Date: $\quad 9 / 19 / 2005$ \\ Re: Attractiveness of Repose and Lateral Smiling Profiles using the Arnett \\ and Andrews' soft Tissue Diagnostic Standards
}

I have completed my review of the radiation safety aspects of the research protocol entitled, "Attractiveness of Repose and Lateral Smiling Profiles using the Arnett and Andrews' soft Tissue Diagnostic Standards" In the study the points I want to reiterate are:

- The subject shall not be pregnant or breast feedings

- Although there are no patients dose limits, the amount of patient radiation exposure should always be optimized to the minimum amount required to achieve the medical objective of the procedure. Therefore, typically, the patient doses from diagnostic examination (cephalometric), effective dose per examination should be $1.7 \mathrm{E}-02 \mathrm{mSv}$.

- General precaution shall be exercised. Such as :

- Ensuring that all radiation protection features are properly functional and the required warning signs are posted

- The study shall be conducted in shielded area

The operator shall have protective leaded apparel in sufficient numbers to provide adequate protection for the patient and himself/herself.

Based on the data provided in the protocol, I find the study to be within acceptable limits established for research exposure to humans. If you have any questions or concerns regarding the protocol, please feel free to contact me

CC: Jennifer Hamilton, DDS

Human Use of Radiation and Radionuclide Committee

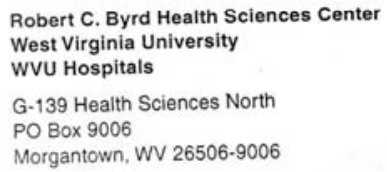




\section{Continuing Protocol Review West Virginia University Institutional Review Board PO Box 6845}

I To: Hamilton, Jennifer Amy

1st Reminder 07/05/06

2nd Reminder 08/02/06

3rd Reminder 09/05/06

Co-Investigators: Bagby, Michael D; Martin, Chris A; Ngan, Peter W

From: Lilo Ast,

Senior Program Coordinator for Research Compliance

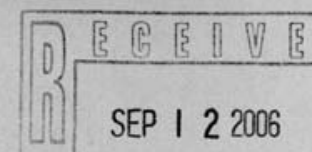

Project Title: 16710 - Attractiveness of Repose and Lateral Smiling Profiles using the Arnett and Andrews' Soft Tissue Diagnostic Standards

Last Annual Review Date: 10/12/2005

Review Category: Full Board

Date Last Consent Approved:

The Institutional Review Board (IRB) grants one-year approvals for the use of human subjects. The anniversary date on this project is approaching.

If checking A, B, or C below, attach a Progress Report (see page 2) and required additional pages. The IRB will notify you of the results of its review. The clean copy of the consent form, assent form, advertisement, and/or cover letter submitted with this review form, will be reviewed and, when approved, stamped and returned for use with future subjects. Attach a copy of all new information, letters, or text of verbal updates that have been approved by the IRB. Additional updates not previously
approved should also be included at this time.

If checking A, B, C, or D below, ensure that all key project personnel have received Human Participant Protections Training (and HIPAA Training, when applicable) prior to the renewal/approval date. For Training Requirements see

http://www.wvu.edu/ rc/irb/index.htm. Also see http://www.wvu.edw/ osp/coi_drpl.htm for Adhoc Reporting of Conflict of Interest in Research.

Check all that apply:

A. Enrollment of subjects began on (date) and will continue beyond the anniversary date. (Submit a clean, unstamped copy—on letterhead—of current Consent form / Assent form / Ad / Cover letter with the latest submission date printed in the bottom left hand corner of each page.)

B. Project is closed to enrollment and one of the following applies:

Xesearch is active only for data analysis

Subjects have completed all research-related interventions and will undergo long-term follow-up only.

Subjects are still undergoing research-related treatment.

C. Research began on

(date). Contact with human subjects will not continue beyond the anniversary date. Please close this file. For drug/device studies, attach a copy of the investigator's final report to the sponsor.

D. Funding or start of research is pending. Please keep this file active. (Submit a clean, unstamped copy - on letterhead - of current Consent form / Assent form / Ad / Cover letter with the latest submission date printed in the bottom left hand corner of each page.)

E. Project was never begun. Please close this file.

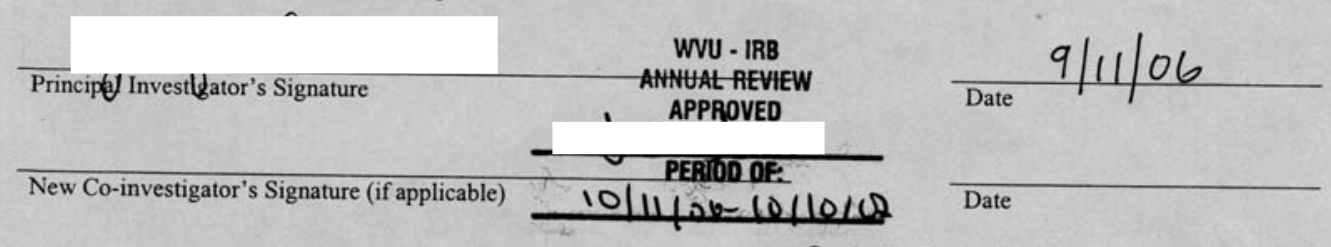




\section{Institutional Review Board Progress Report \\ HS \# 16710}

Instructions: Use a separate sheet if needed for any item. If any question is not applicable, put N/A next to the number for that question.

If the protocol receives expedited review, please indicate the Category of Expedited Review (1-7):

1 For each category below, indicate the number of subjects enrolled into the study last year at this institution.

Male Female Pregnant Children Male Female Pregnant Children

Women (under

Women (under 18)

Caucasian

African-American

Hispanic-American

\begin{tabular}{|c|c|c|c|c|}
\hline 6 & 15 & 0 & 15 & Native-American \\
\hline & 3 & 0 & 3 & Asian-American \\
\hline & & 8 & & Other \\
\hline
\end{tabular}

Total number of subjects enrolled since this project began:

Total number of records reviewed

24

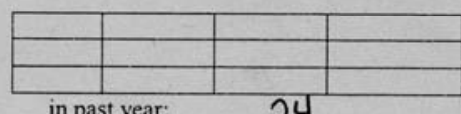

in past year:

24

2 Total number of subjects withdrawn since this project began: $\quad 0 \quad$ in past year: (Include the reason(s) for withdrawal)

3 a. Have all subjects signed a consent or assent form? If no, were consent or assent waived for this project?

b. Have there been any problems obtaining informed consent or assent? Explain.

c. Are all signed forms on file and available for review?

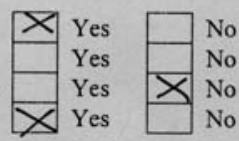

4 Have activities involving human subjects during the past year followed procedures as described in the approved protocol? $X$ Yes $\square$ No If not, describe any modifications.

5 Adverse Events NA

Use the table Adverse Events in Study Subjects on page 3 to list all adverse events at WVU and other sites in the last year. Provide a description and explanation of these events.

Note: An adverse event is one reportable to the sponsor or any event that occurs more frequently than anticipated.

a. For clinical, drug or device studies:

- If using an experimental drug or device for this protocol, what is its FDA status?

b. For nonclinical studies.

- Describe any expected or unexpected reactions resulting from participation in this project.

6 Were any grievances or complaints received about this study? $\square$ Yes $\square$ No If yes, please explain:

7 Were any eligibility or protocol deviations report to the Research Compliance office? $\square$ Yes $\square \square$ No If yes summarize here:

8 Attach a summary of the DSMB (Data Safety Monitoring Board) or DMC (Data Monitoring Committee) meetings (if applicable) - or - findings based on information collected by the data and safety monitoring plan submitted in the initial proposal. NA 9 Summarize the preliminary results of this research. Data analysis not complete. No preliminany
results as of yet.

10 List and explain any projected changes (for example, co-investigators, procedures, site of subject contact, or size, sex or age of population). Any new co-investigator(s) must sign the protocol review page (page one) and provide their qualifications (do not submit complete vitas). NA

11 Attach a summary of recent literature that suggests anything new or important for continuing the project (e.g., new reactions, new treatments, changes in riskbenefit ratios, etc.).

Form Revised Dec 2004

Continuing Protocol Review

Page 2 of 3 
Continuing Protocol Review (Continued)

12 Do the investigators plan to enroll more subjects? $\square$ Yes 13 a. If continuing to enroll subjects, attach a clean, unstamped copy - on letterhead-of all consent and assent forms,
cover letters and ads along with the last approved, stamped copy of each of these documents. b. If planning to modify the consent or assent form, cover letter or ad, use the Amendment Form and provide the
following:

1) photocopy of current stamped forms, letters and ads

2) modified forms, letters, or ads with changes indicated by hand drawn brackets

3) clean copy of the modified forms, letters or ads (without brackets required in $\# 2$ above)

\section{Adverse Events in Study Subjects}

\begin{tabular}{|l|l|l|l|l|}
\hline \multicolumn{1}{|l|}{ Type of Event } & Study Related & Not Study Related & $\begin{array}{l}\text { Possibly Study } \\
\text { Related }\end{array}$ & Date Reported \\
\hline $\begin{array}{l}\text { e.g., (death, thrombocytopenia, } \\
\text { anaphylaxis, etc.) }\end{array}$ & \multicolumn{1}{|c|}{ Check One } & & \\
\hline & & & & \\
\hline & & & & \\
\hline & & & & \\
\hline & & & & \\
\hline & & & \\
\hline
\end{tabular}

\begin{tabular}{|l|l|l|}
\hline \multicolumn{2}{|l|}{ Total Number of Each Type of Event in the Last Year (since Last Review) } & Tontal Number \\
\hline Type of Event & & \\
\hline & & \\
\hline & & \\
\hline & & \\
\hline & & \\
\hline & & \\
\hline & Continuing Protocol Review & Page 3 of 3 \\
\hline Form Revised Dec 2004 & & \\
\hline
\end{tabular}




\section{APPENDIX B CONSENT FORMS \& PHI}




\title{
ADULT CONSENT AND INFORMATION FORM
}

\author{
Attractiveness of Repose and Lateral Smiling \\ Profiles using the Arnett and Andrews' \\ Soft Tissue Diagnostic Standards.
}

NOV 182005

\section{Introduction}

You,

have been asked to participate in this research study,

which has been explained to you by Jennifer Hamilton, DDS. This study is being conducted by Jennifer Hamilton, DDS in the Department of Orthodontics at West Virginia University with funding provided by the University Health Associates.

This research is being conducted to fulfill the requirements for a Masters thesis in Orthodontics in the Department of Orthodontics at West Virginia University, under the supervision of Dr. Peter Ngan DDS, DMD.

\section{Purposes of the Study}

The purpose of this study is to learn more about society's views of facial attractiveness and the basis for such views. WVU expects to enroll approximately 30 subjects for participation in this study at the Orthodontic clinic.

\section{Description of Procedures}

This study involves analyzing patient records including photos and $\mathrm{x}$-rays included in the normal orthodontic records. You will be required to have one additional skull film with you smiling for diagnostic purposes. Your participation will take approximately one hour and will be completed in one to two appointments with evaluation by one to three orthodontists. The first appointment will consist of a short exam, photos, and two x-rays taken by the principal investigator, Jennifer Hamilton DDS. A brief exam lasting less than five minutes by at least one other orthodontist will also be done at this time. The rest of the records visit including models, exam, and additional x-rays, will be done by the resident with whom you were previously scheduled. The second appointment will only be needed if exam information needs verified and can be done at the next scheduled appointment. Photographs will be digitally altered and reviewed by a group of trained orthodontists and a class of students at WVU.

Submission date $10 / 24 / 05 \quad$ Page 1 of 4

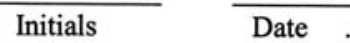


Attractiveness of Repose and Lateral Smiling

Profiles using the Arnett and Andrews'

Soft Tissue Diagnostic Standards.

Risks and Discomforts

There are no expected or known risks from participating in this study, except that

expected from the normal orthodontic records visit which includes exposure to $\mathrm{x}$-rays.

Alternatives

You do not have to participate in this study. Alternatives include the normal orthodontic records visit consisting of 2-4 $\mathrm{x}$-rays instead of 3-5 $\mathrm{x}$-rays being taken.

\section{Benefits}

You may not receive any direct benefit from this study. The knowledge gained from this study may eventually benefit others by aiding orthodontists to plan treatment with facial attractiveness as a consideration.

\section{Financial Considerations}

No payments will be made for participating in the study. You will have to pay for the normal orthodontic records visit. You will not be charged for the additional x-ray needed for participation in this study.

\section{Confidentiality}

Any information about you that is obtained as a result of your participation in this research will be kept as confidential as legally possible. Your research records and test results, just like hospital records, may be subpoenaed by court order or may be inspected by federal regulatory authorities without your additional consent.

In addition, there are certain instances where the researcher is legally required to give information to the appropriate authorities. These would include mandatory reporting of infectious diseases, mandatory reporting of information about behavior that is imminently dangerous to you or to others, such as suicide, child abuse, etc.

Photos and $\mathrm{x}$-rays will be kept locked up during the study and will be included in your orthodontic chart following completion of research.

In any publications that result from this research, neither your name nor any information from which you might be identified will be published without your consent. 


\section{Attractiveness of Repose and Lateral Smiling \\ Profiles using the Arnett and Andrews' \\ Soft Tissue Diagnostic Standards.}

\section{Voluntary Participation}

Participation in this study is voluntary. You are free to withdraw your consent to participate in this study at any time.

Refusal to participate or withdrawal will not affect your future care and will involve no penalty to you.

In the event new information becomes available that may affect your willingness to participate in this study, this information will be given to you so that you can make an informed decision about whether or not to continue your participation.

You have been given the opportunity to ask questions about the research, and you have received answers concerning areas you did not understand.

Upon signing this form, you will receive a copy.

I willingly consent to participate in this research.

Signature of Subject

Printed Name

Date Time

The participant has had the opportunity to have questions addressed. The participant willingly agrees to be in the study.

Signature of Investigator

Printed Name

Date Time 
Attractiveness of Repose and Lateral Smiling

Profiles using the Arnett and Andrews'

Soft Tissue Diagnostic Standards.

\section{Contact Persons}

In the event you experience any side effects or injury related to this research, you should contact Dr. Hamilton at (304) 293-5217. For more information about this research and about research-related risks or injury, you can contact Dr. Peter Ngan at (304) 293-3223. For information regarding your rights as a research subject, you may contact the Office of Research Compliance at (304) 293-7073. 


\title{
ASSENT FORM
}

Attractiveness of Repose and Lateral Smiling

Profiles using the Arnett and Andrews'

Soft Tissue Diagnostic Standards.

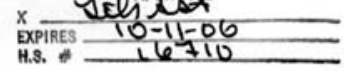

Introduction

You, have been asked to be in this research study, which has

been explained to you by Dr. Jennifer Hamilton.

\section{Purposes of the Study}

You have been told that the purpose of this study is to learn more about how orthodontic treatment and braces can affect facial beauty.

\section{Description of Procedures}

The study will be done at WVU School of Dentistry, Department of Orthodontics. You will continue with the normal records appointment and Dr. Hamilton will take some photos and one additional $x$-ray. The entire visit should take between one to two hours and will end your involvement in the study.

\section{Risks and Discomforts}

There should be no additional risks or discomforts other than those experienced with a normal orthodontics records visit.

\section{Benefits}

This study may not help you, but what we learn from the study may help other people in the future.

\section{Confidentiality}

We promise that anything we learn about you in this study will be kept as secret as possible.

\section{Voluntary Participation}

You do not have to do this. No one will be mad at you if you refuse to do this or if you decide to quit.

\author{
Submission date $\quad 10 / 24 / 05 \quad$ Page 1 of 2 \\ Initials $\quad$ Date


Attractiveness of Repose and Lateral Smiling

Profiles using the Arnett and Andrews'

Soft Tissue Diagnostic Standards.

You have been allowed to ask questions about the research, and all of your questions were answered.

I willingly agree to be in this research.

Signature of Subject

Printed Name

Date

Time

The child has had the opportunity to have questions addressed. The child willingly agrees to be in the study.

Signature of Investigator

Printed Name

Date Time

Submission date $\quad 10 / 24 / 05$

Page 2 of 2

Initials

Date 


\title{
PARENTAL OR GUARDIAN CONSENT AND INFORMATION 1 a vaponved
}

PARENTAL OR GUARDIAN CONSENT AND INFORMATION FORARPRES $\frac{10-11-06}{167.76}$

\author{
Attractiveness of Repose and Lateral Smiling \\ Profiles using the Arnett and Andrews' \\ Soft Tissue Diagnostic Standards.
}

Introduction

You,

have been asked to allow your child

to participate in this research study, which has been

explained to you and your child by Jennifer Hamilton, DDS. This study is being conducted by Jennifer Hamilton, DDS in the Department of Orthodontics at West Virginia University with funding provided by University Health Associates.

This research is being conducted to fulfill the requirements for a Masters thesis in Orthodontics in the Department of Orthodontics at West Virginia University, under the supervision of Dr. Peter Ngan DMD, MS.

\section{Purposes of the Study}

The purpose of this study is to learn more about society's views of facial attractiveness and the basis for such views. WVU expects to enroll approximately 30 subjects for participation in this study at the Orthodontic clinic.

\section{Description of Procedures}

This study involves analyzing patient records including photos and $\mathrm{x}$-rays included in the normal orthodontic records. Your child will be required to have one additional skull film taken while smiling for diagnostic purposes. Your child's participation will take approximately one hour and will be completed in one to two appointments with evaluation by one to three orthodontists. The first appointment will consist of a short exam, photos, and two x-rays taken by the principal investigator, Jennifer Hamilton DDS. A brief exam lasting less than five minutes by at least one other orthodontist will also be done at this time. The rest of the records visit including models, exam, and additional $\mathrm{x}-$ rays, will be done by the resident with whom your child was previously scheduled. The second appointment will only be needed if exam information needs verified and can be done at the next scheduled appointment. Photographs will be digitally altered and reviewed by a group of trained orthodontists and a class of students at WVU.

Submission date $\quad 10 / 24 / 05 \quad$ Page 1 of 4

$\overline{\text { Initials }} \overline{\text { date }}$ 


\section{Attractiveness of Repose and Lateral Smiling Profiles using the Arnett and Andrews' Soft Tissue Diagnostic Standards.}

Risks and Discomforts

There are no expected or known risks to your child from participating in this study, except that expected from the normal orthodontic records visit which includes exposure to $\mathrm{x}$-rays.

\section{Alternatives}

Your child does not have to participate in this study. Alternatives include the normal orthodontic records visit consisting of 2-4 $\mathrm{x}$-rays instead of 3-5 $\mathrm{x}$-rays being taken.

\section{Benefits}

Your child may not receive any direct benefit from this study. The knowledge gained from this study may eventually benefit others by aiding orthodontists to plan treatment with facial attractiveness as a consideration.

\section{Financial Considerations}

No payments will be made for your child's participation in the study. You will have to pay for the normal orthodontic records visit. You will not be charged for the additional $\mathrm{x}$-ray needed for participation in this study.

\section{Confidentiality}

Any information about your child that is obtained as a result of participation in this research will be kept as confidential as legally possible. Your child's research records and test results, just like hospital records, may be subpoenaed by court order or may be inspected by federal regulatory authorities without your additional consent.

In addition, there are certain instances where the researcher is legally required to give information to the appropriate authorities. These would include mandatory reporting of infectious diseases, mandatory reporting of information about behavior that is imminently dangerous to you or to others, such as suicide, child abuse, etc.

Photos and $\mathrm{x}$-rays will be kept locked up during the study and will be included in your child's orthodontic chart following completion of research.

In any publications that result from this research, neither your child's name nor any information from which your child might be identified will be published without your consent.

Submission date

$10 / 24 / 05$

Page 2 of 4

Initials

date 


\section{Attractiveness of Repose and Lateral Smiling Profiles using the Arnett and Andrews' Soft Tissue Diagnostic Standards.}

\section{Voluntary Participation}

Participation in this study is voluntary. You or your child may refuse to participate in this study. You or your child are free to withdraw your consent to participate in this study at any time.

Refusal to participate or withdrawal will not affect your child's future care and will involve no penalty to you or your child.

In the event new information becomes available that may affect your willingness to allow your child to participate in this study, this information will be given to you so that you can make an informed decision about whether or not to continue your child's participation.

You have been given the opportunity to ask questions about the research, and you have received answers concerning areas you did not understand.

Upon signing this form, you will receive a copy.

I willingly consent to allow my child to participate in this research.

Signature of Parent or Guardian

\section{Printed Name}

Date Time

The parent/guardian has had the opportunity to have questions addressed. The parent/guardian willingly agrees to allow his/her child to be in the study.

Signature of Investigator

\section{Printed Name}

Date Time

Submission date $10 / 24 / 05$

Page 3 of 4

$$
\text { Initials }
$$


Attractiveness of Repose and Lateral Smiling

Profiles using the Arnett and Andrews'

Soft Tissue Diagnostic Standards.

\section{Contact Persons}

In the event you experience any side effects or injury related to this research, you should contact Dr. Hamilton at (304) 293-5217. For more information about this research and about research-related risks or injury, you can contact Dr. Peter Ngan at (304) 293-3223.

For information regarding your rights as a research subject, you may contact the Office of Research Compliance at (304) 293-7073.

Submission date

$\overline{\text { Initials }}$ date 


\section{Authorization to Use or Disclose Protected Health Information (PHI)}

\section{West Virginia University}

I hereby voluntarily authorize the use or disclosure of my individually identifiable health information as described below.

Patient Name:

Date of Birth:
ID Number:

IRB Protocol \#:

Persons/organizations providing the protected health information (e.g. hospitals):

Patients from the WVU School of Dentistry, Department of Orthodontics

Persons/organizations receiving the information (e.g. investigators, clinical coordinators, sponsor, FDA):

Jennifer Hamilton DDS, Peter Ngan DMD, Chris Martin DDS, Michael Bagby DMD

The following information will be used:

Lateral profile repose and smiling photos and lateral ceph films in repose and smiling will be evaluated and computer enhanced. All PHI will be coded and kept in a locked desk to protect the privacy of participating patients.

The information is being disclosed for the following purposes (Start with the Title of the study and include additional information e.g. screening and recruiting subjects; analyzing research data, or other specified purposes):

For the Master's thesis project titled "Attractiveness of Repose and Lateral Smiling Profiles using the Arnett and Andrews' Soft Tissue Diagnostic Standards."

I may revoke this authorization at any time by notifying the Principal Investigator in writing at: Jennifer Hamilton DDS, 1076 Health Sciences North, PO Box 9480 Morgantown, WV 26506

If I do revoke my authorization, any information previously disclosed cannot be withdrawn. Once information about me is disclosed in accordance with this authorization, the recipient may redisclose it and the information may no longer be protected by federal privacy regulations.

Page 1 of 2 


\section{Authorization to Use or Disclose Protected Health Information (Contd.)}

I may refuse to sign this authorization form. My clinical treatment may not be affected by whether or not I sign this form. I may not be allowed to participate in the research if I do not sign the form.

This authorization will expire on the date that the research study ends. (Other options for expiration include an actual date of expiration, occurrence of a particular event, or "none" if the authorization will have no expiration date.)

Expiration date: None

I will be given a copy of this authorization form.

Signature of subject or subject's legal representative

(Form MUST be completed before signing)

Printed name of subject's legal representative
Relationship to the subject
\begin{tabular}{|l}
\hline Parent \\
Medical power of attorney/representative \\
Legal guardian \\
Health care surrogate
\end{tabular}

Date

WEST VIRGINIA UNIVERSITY Institution Review Board for the Protection of Human Research Subjects Initials

Initials

$\overline{ }$

$$
\text { NOV } 182005
$$

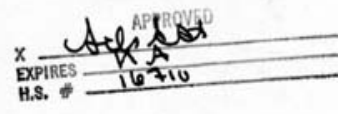

Page 2 of 2 


\section{APPENDIX C SUBJECT PHOTO COMPOSITES}


SUBJECT 1

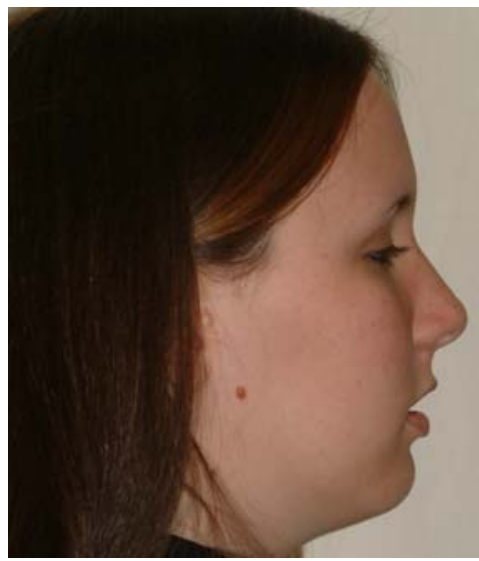

ORIGINAL

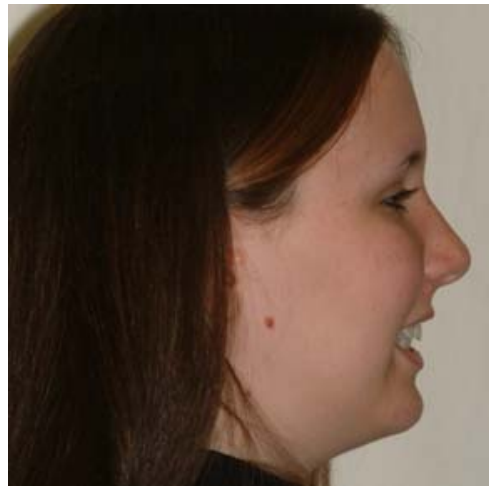

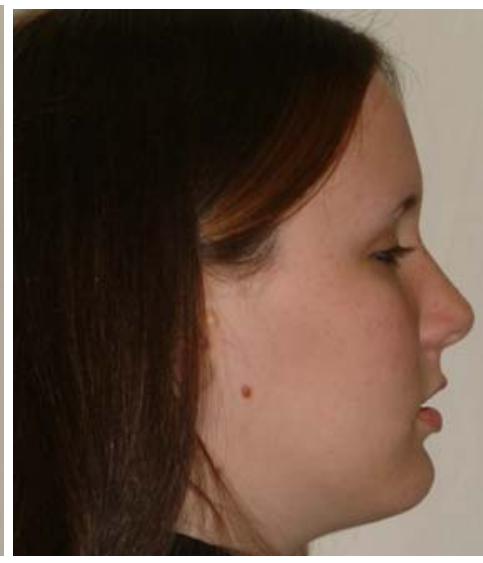

ARNETT

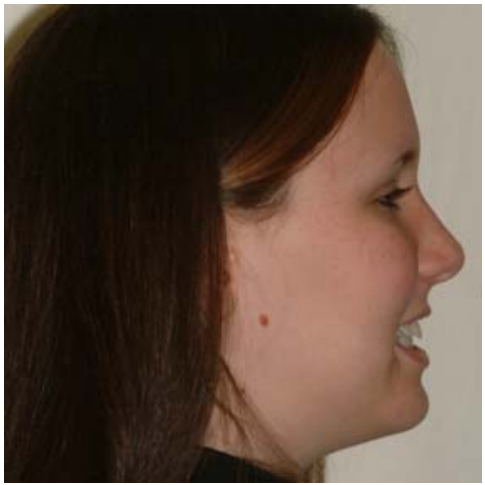

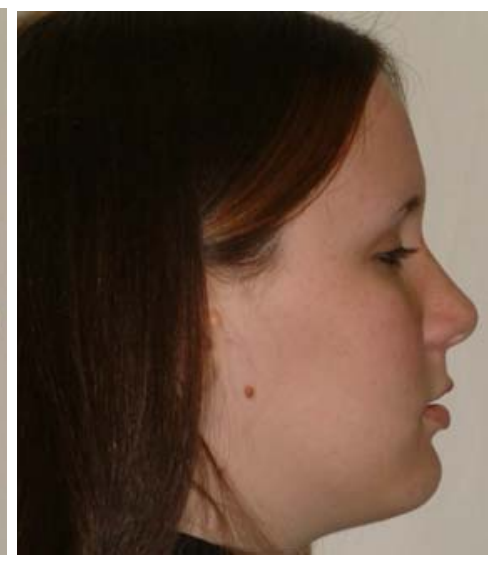

SIX ELEMENTS

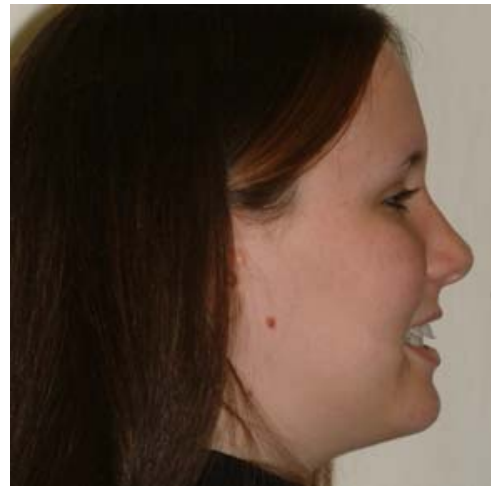


SUBJECT 2

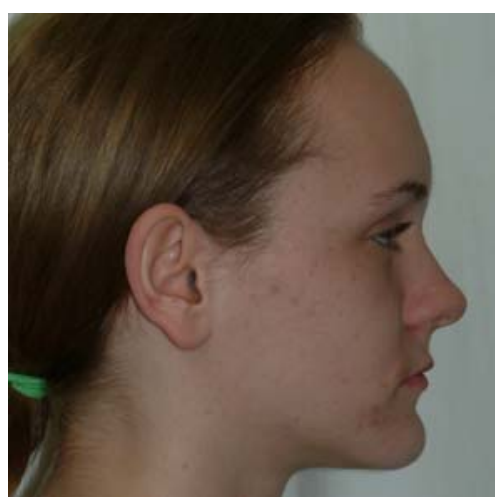

ORIGINAL

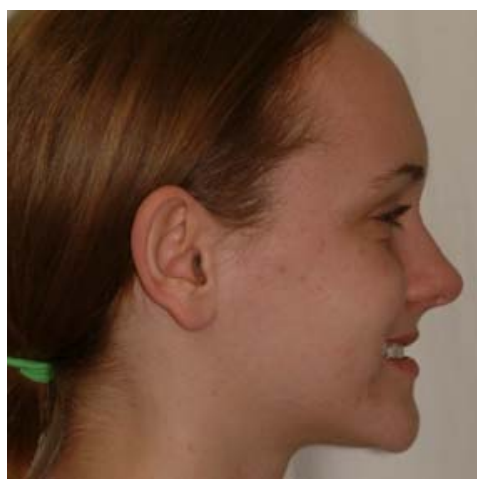

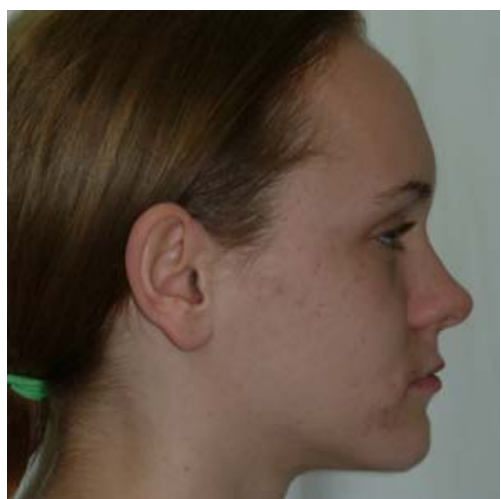

ARNETT

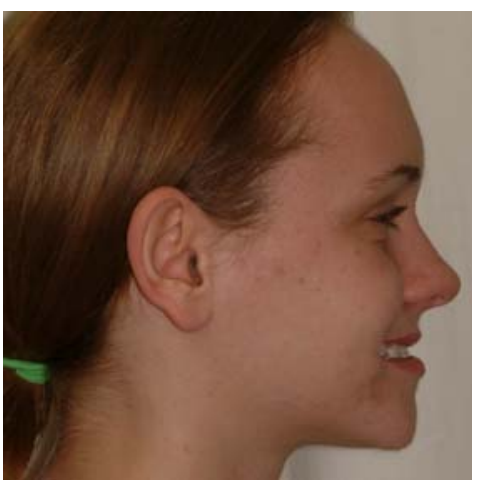

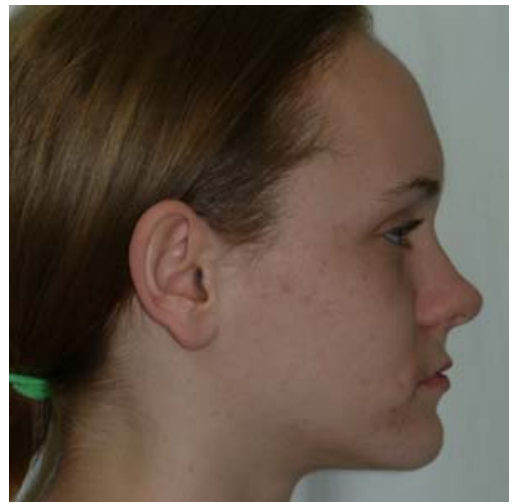

SIX ELEMENTS

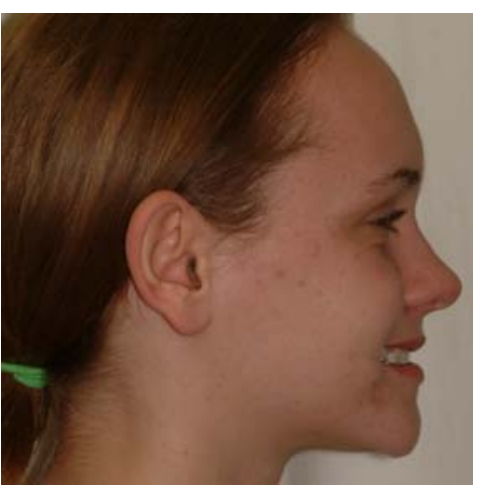


SUBJECT 3

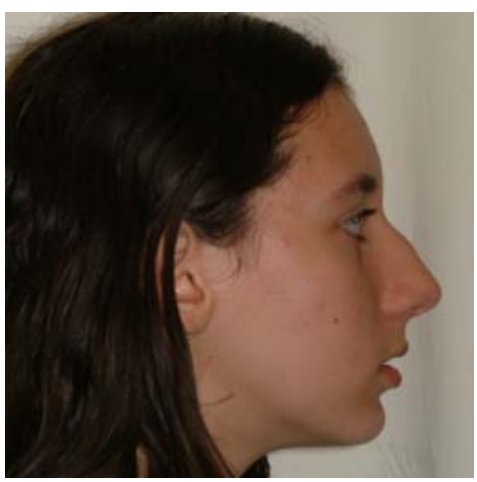

ORIGINAL

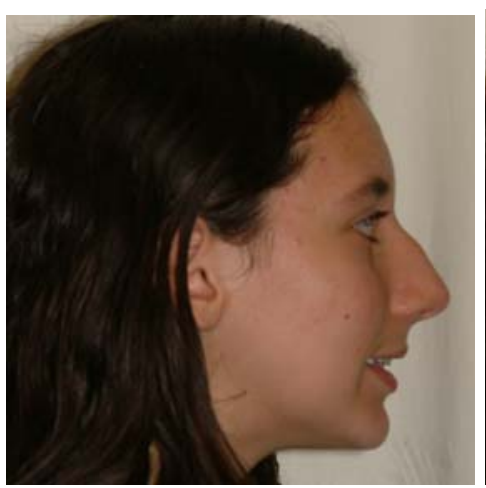

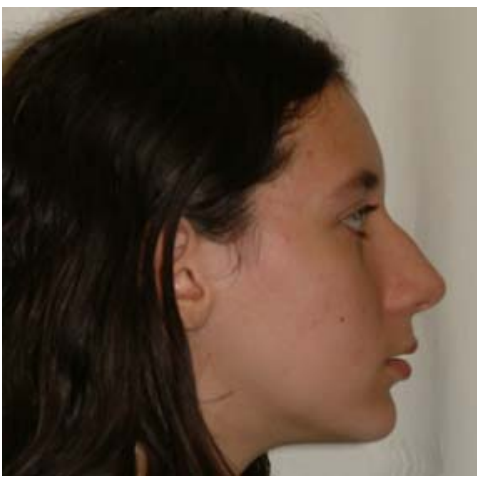

ARNETT

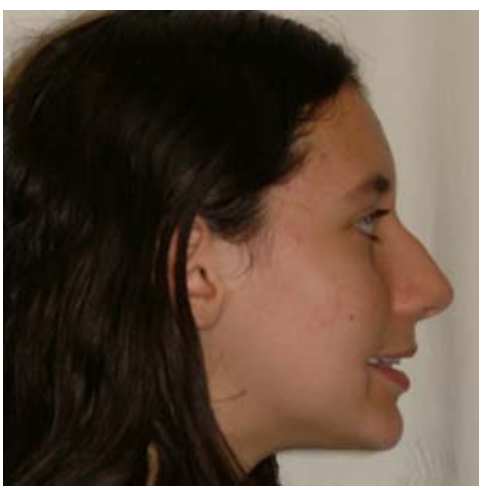

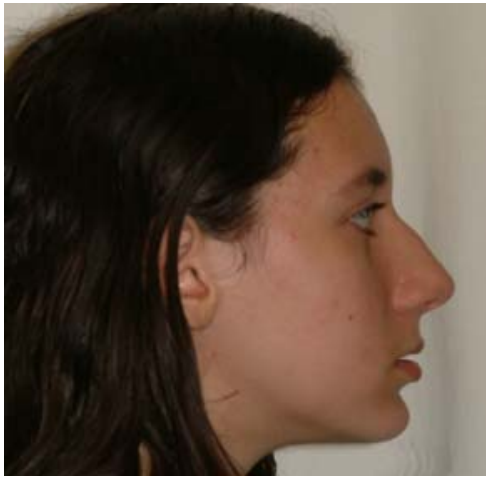

SIX ELEMENTS

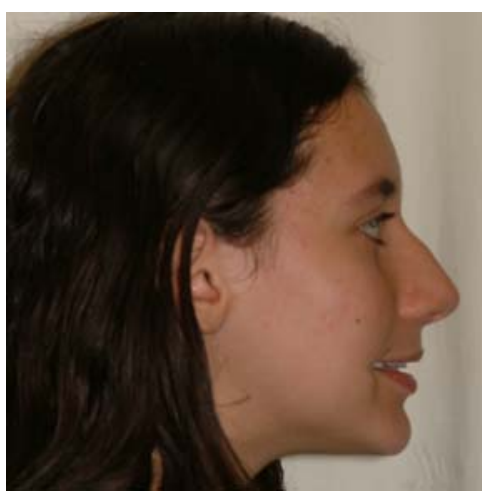


SUBJECT 4

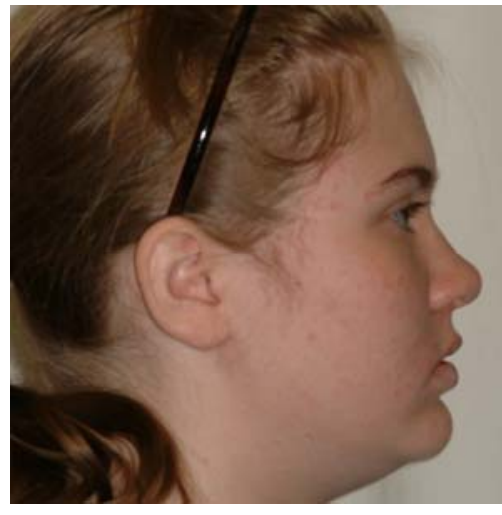

ORIGINAL

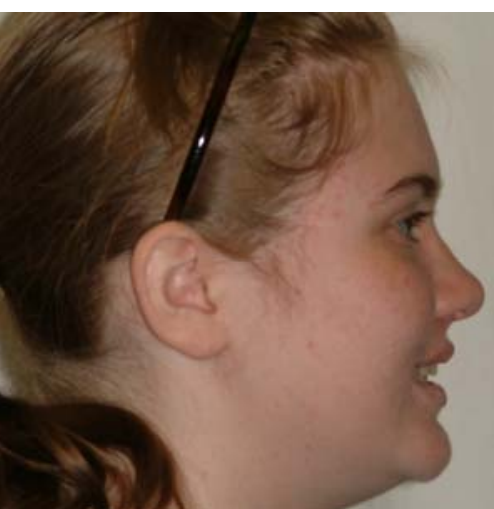

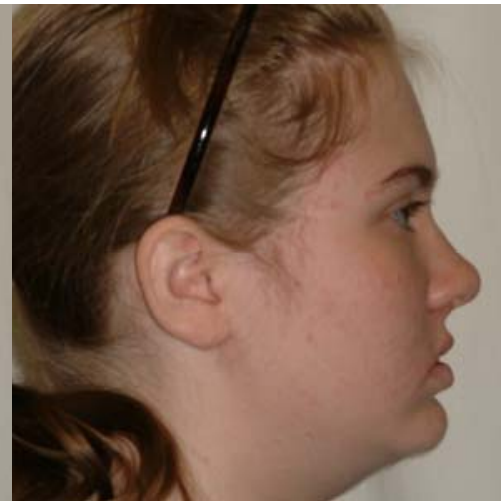

ARNETT

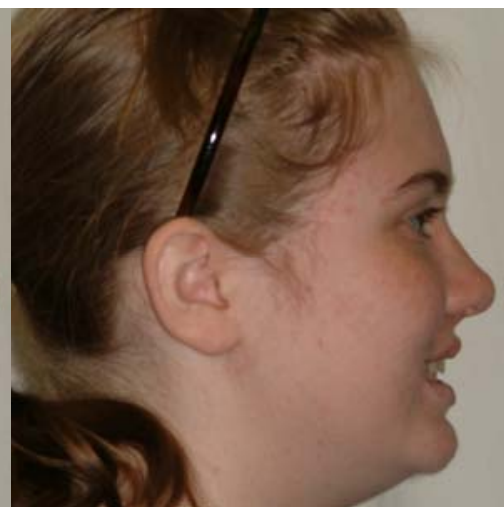

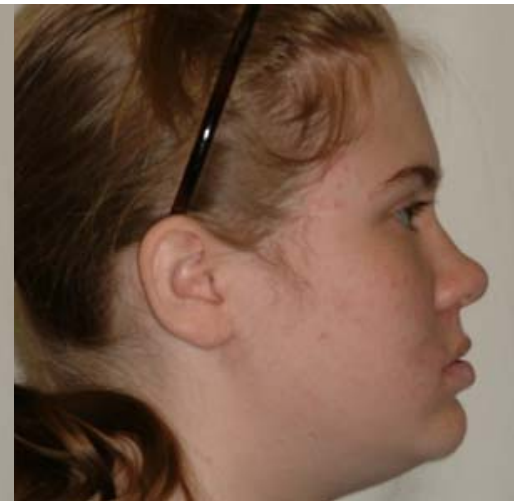

SIX ELEMENTS

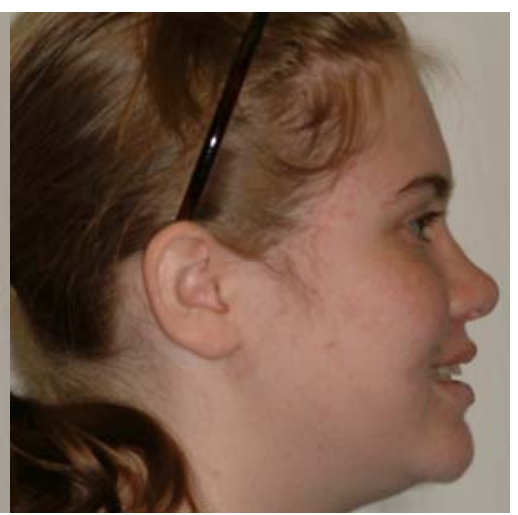


SUBJECT 5

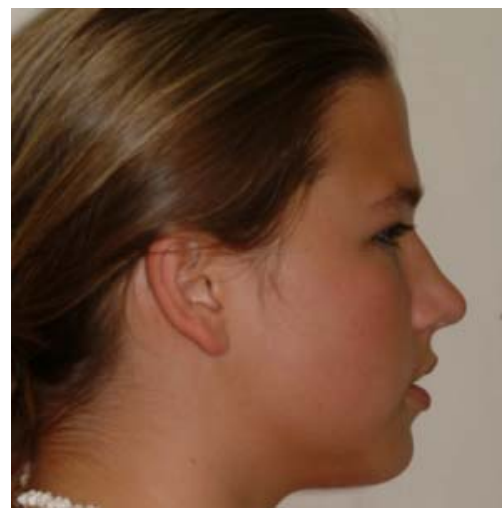

ORIGINAL

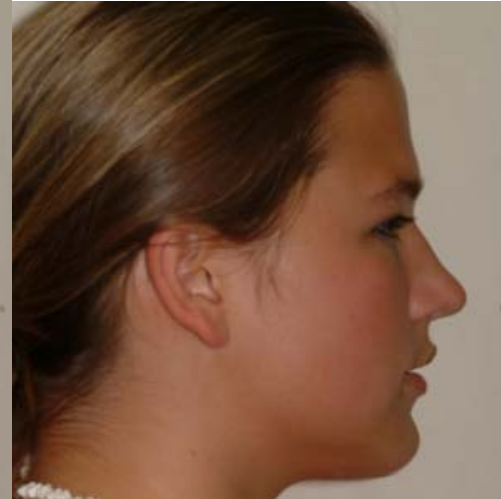

ARNETT

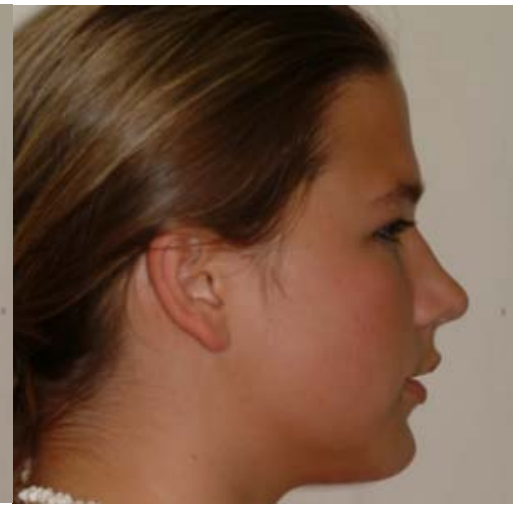

SIX ELEMENTS

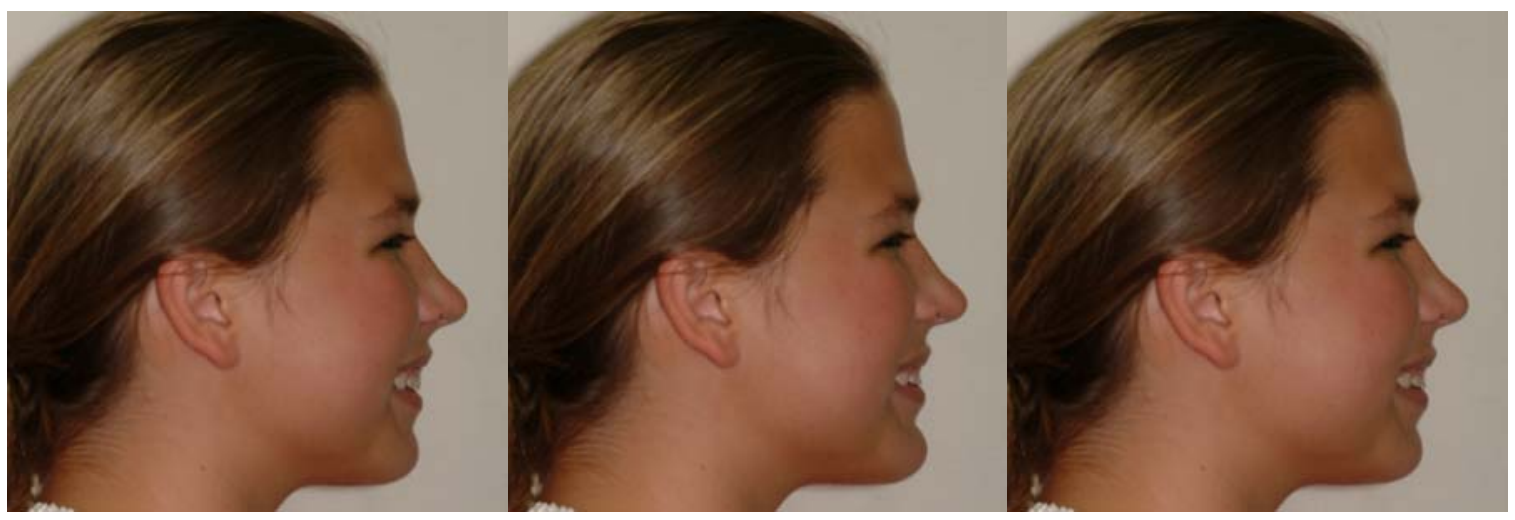


SUBJECT 6

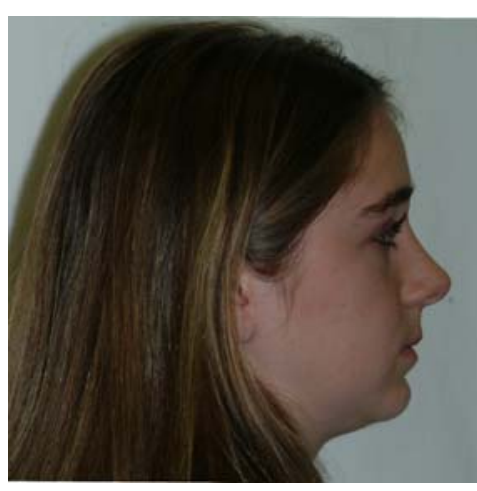

ORIGINAL

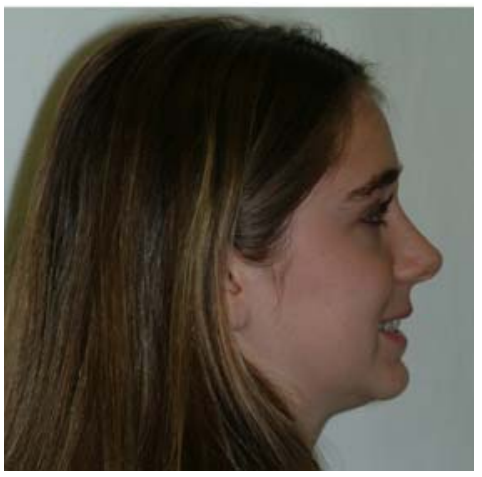

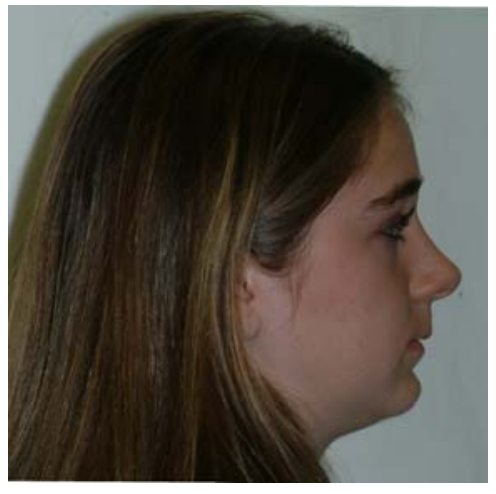

ARNETT

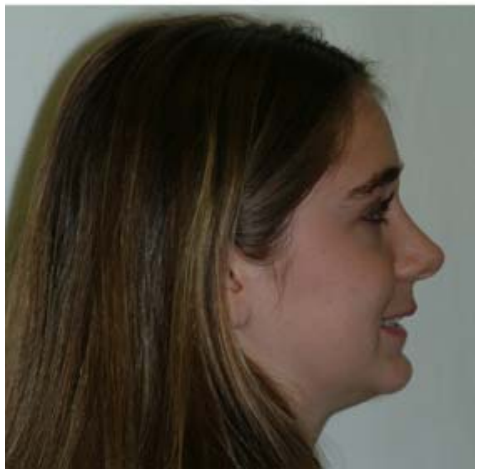

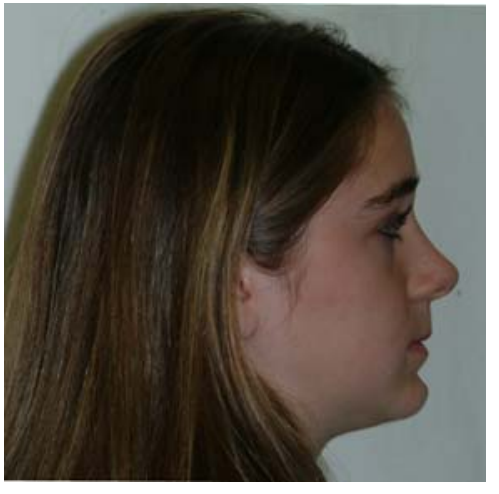

SIX ELEMENTS

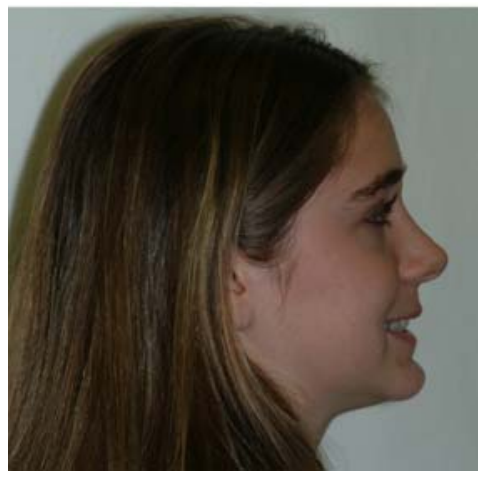


SUBJECT 7
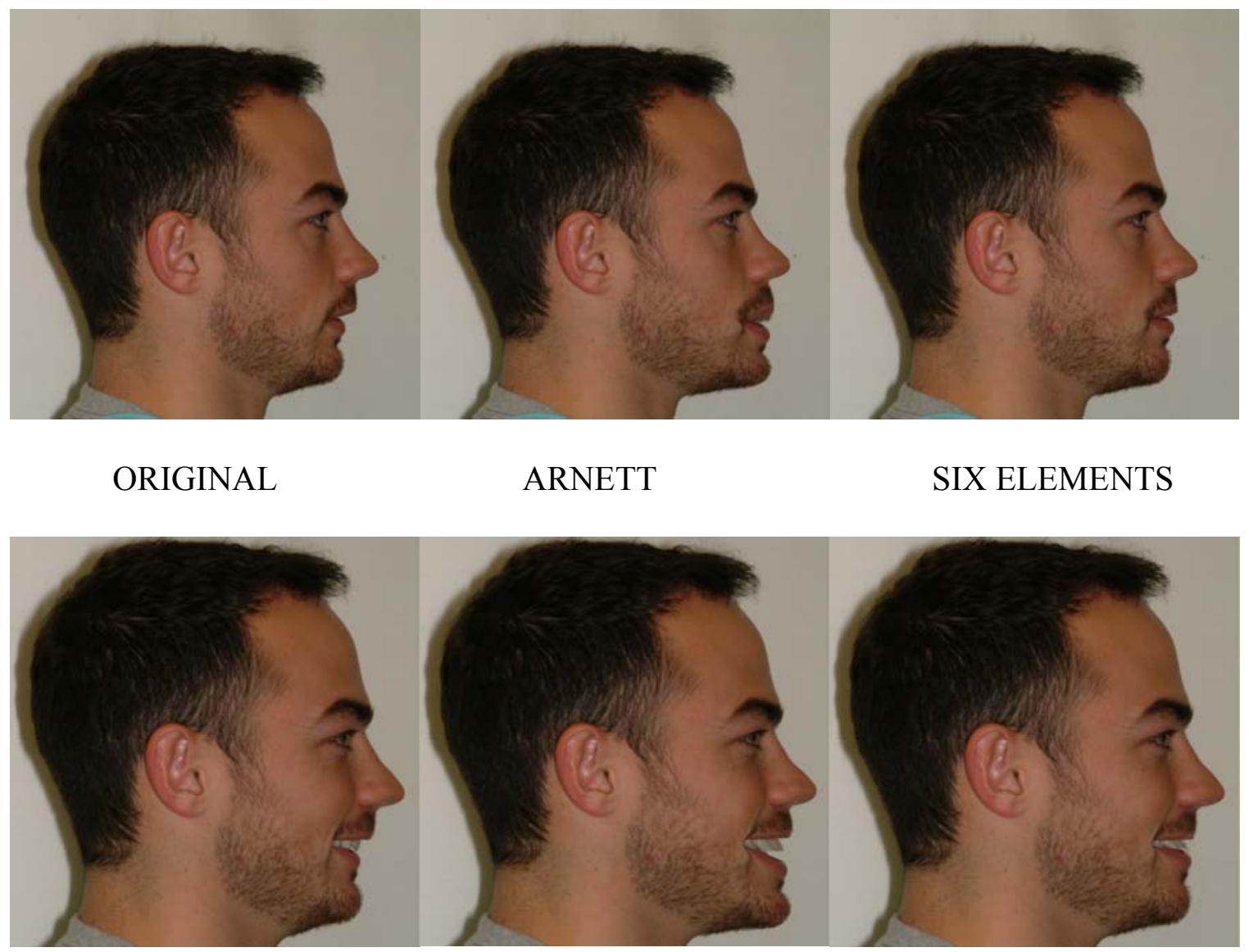
SUBJECT 8

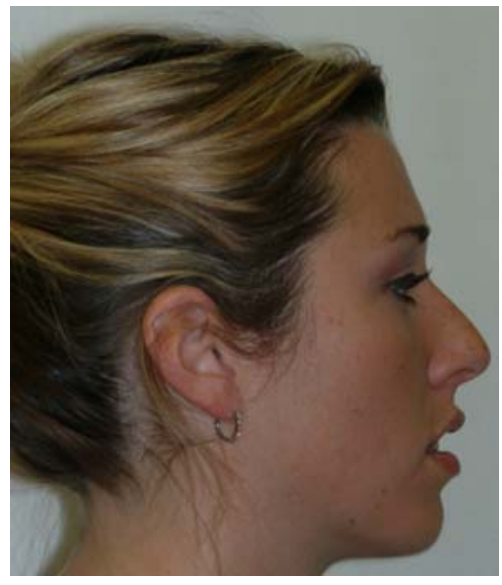

ORIGINAL

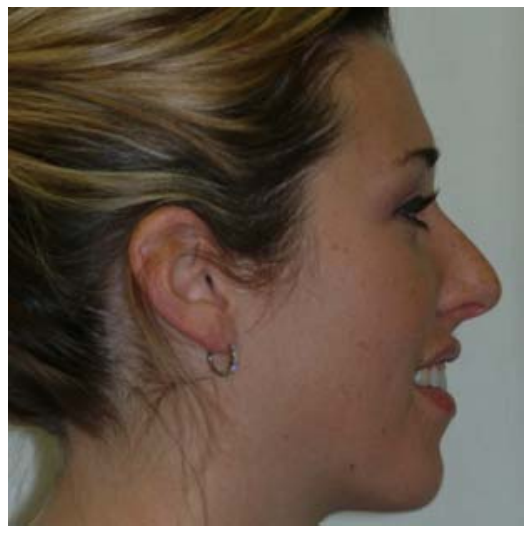

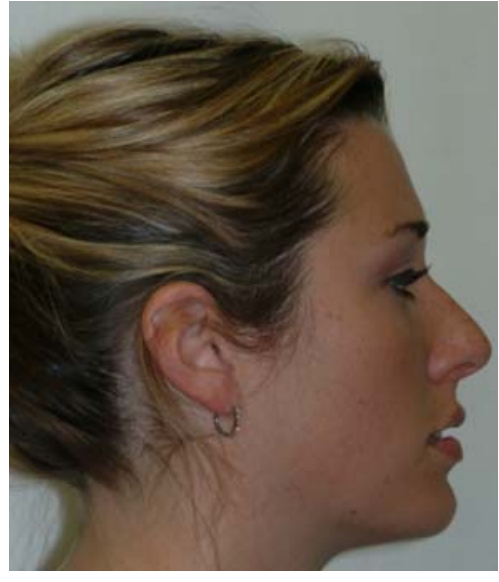

ARNETT

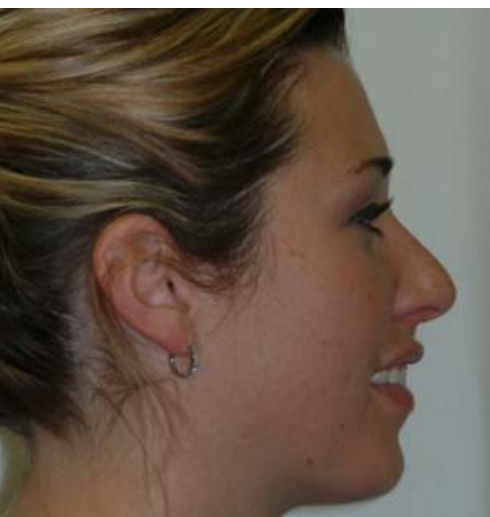

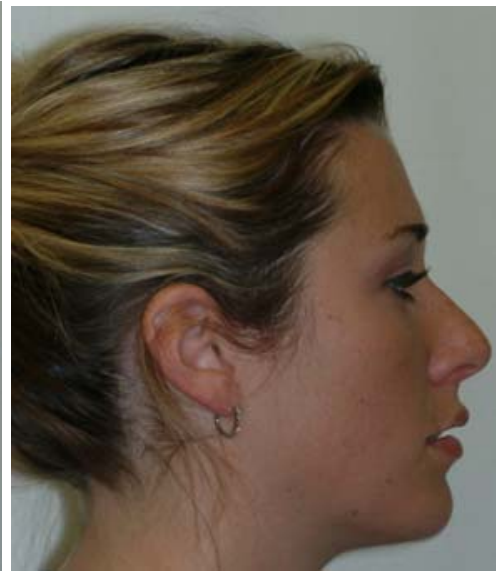

SIX ELEMENTS

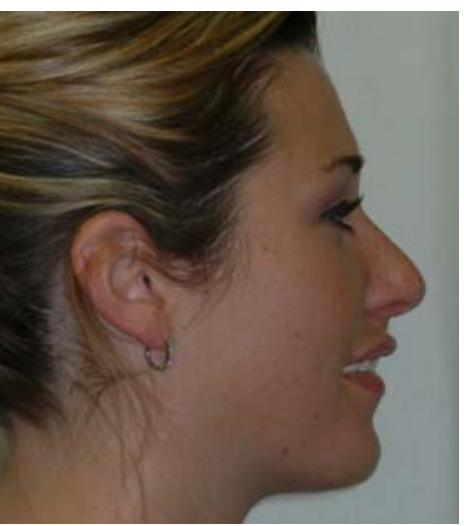


SUBJECT 9

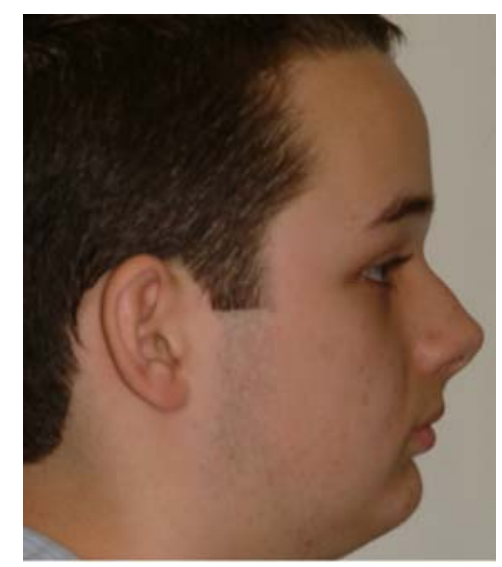

ORIGINAL

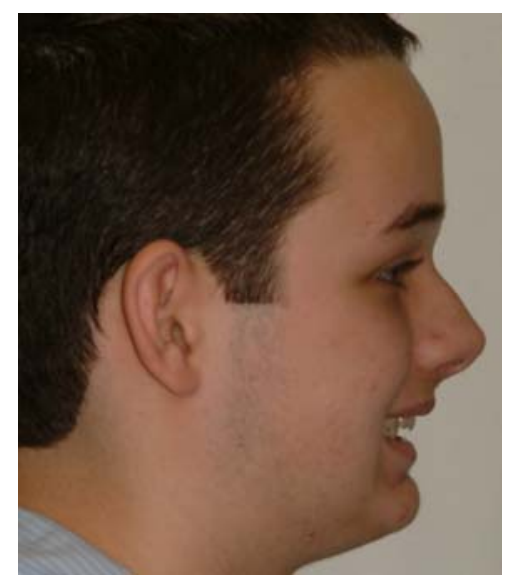

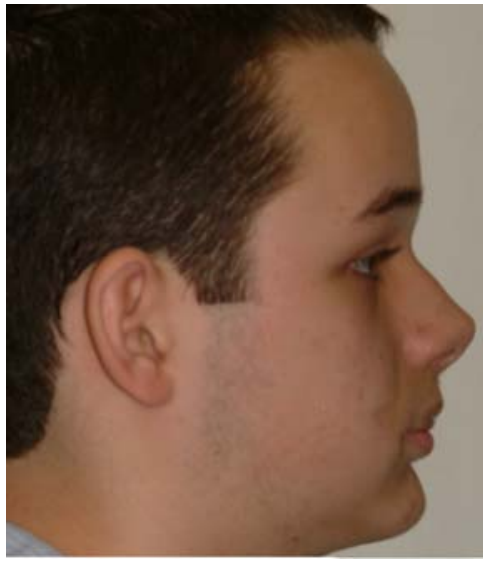

ARNETT

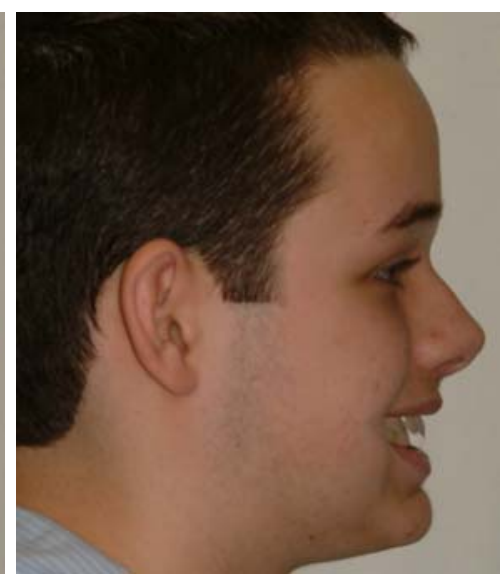

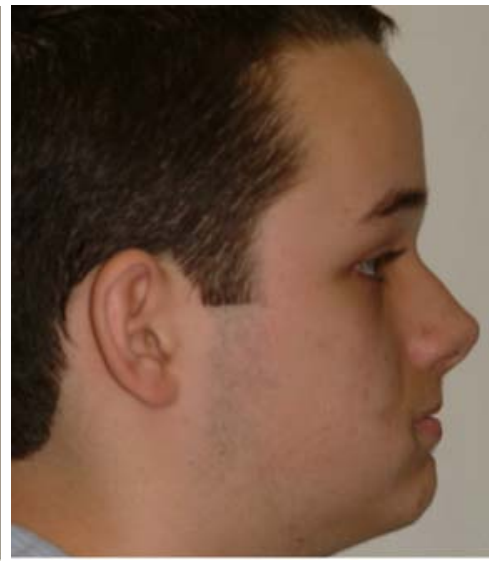

SIX ELEMENTS

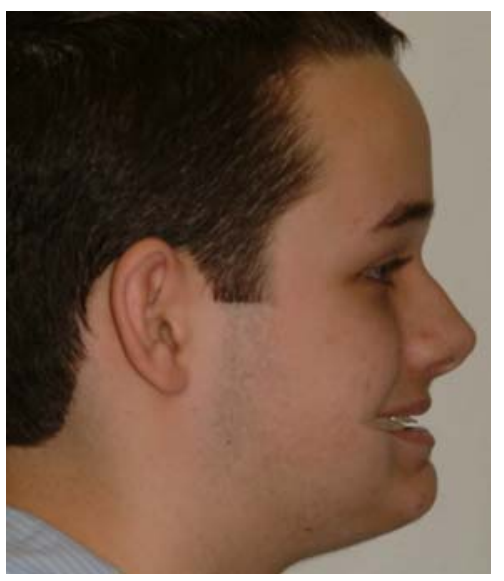


SUBJECT 10

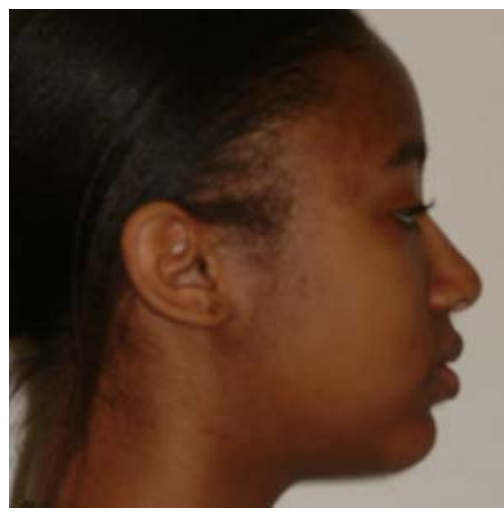

ORIGINAL

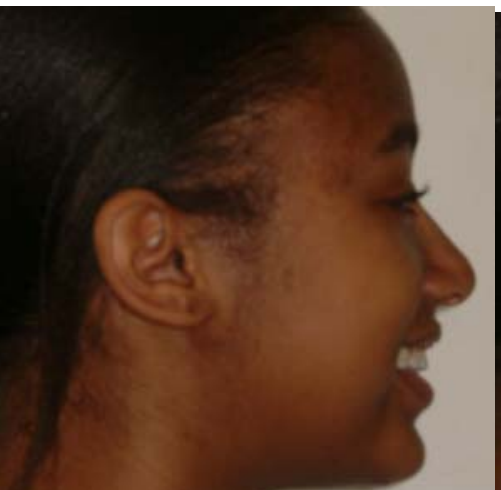

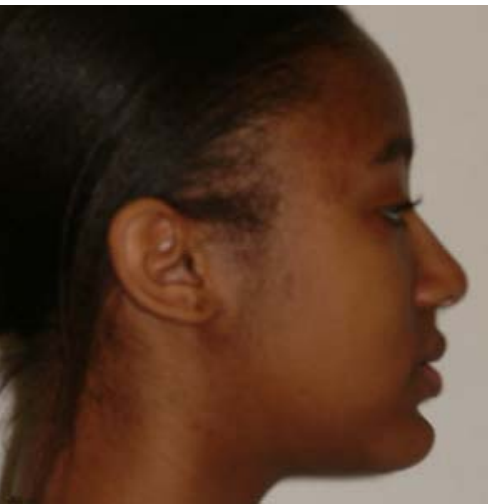

ARNETT

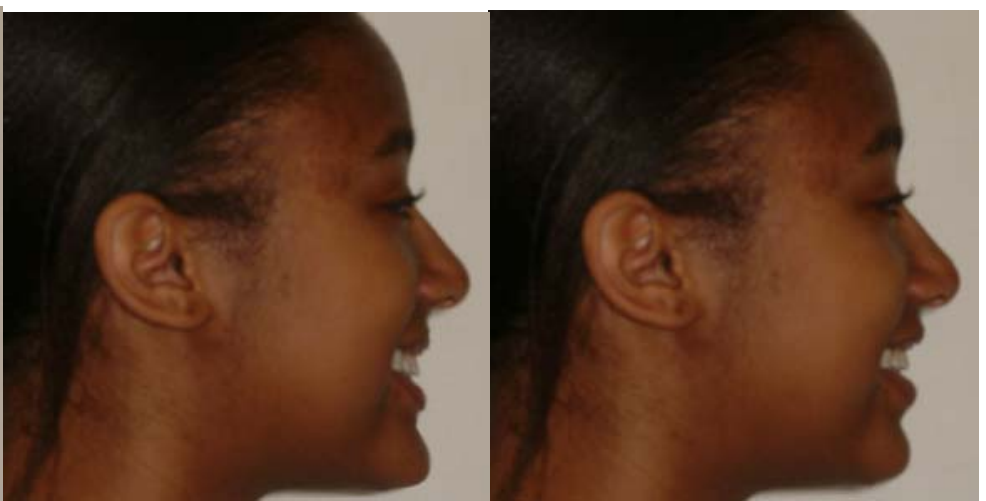


SUBJECT 11
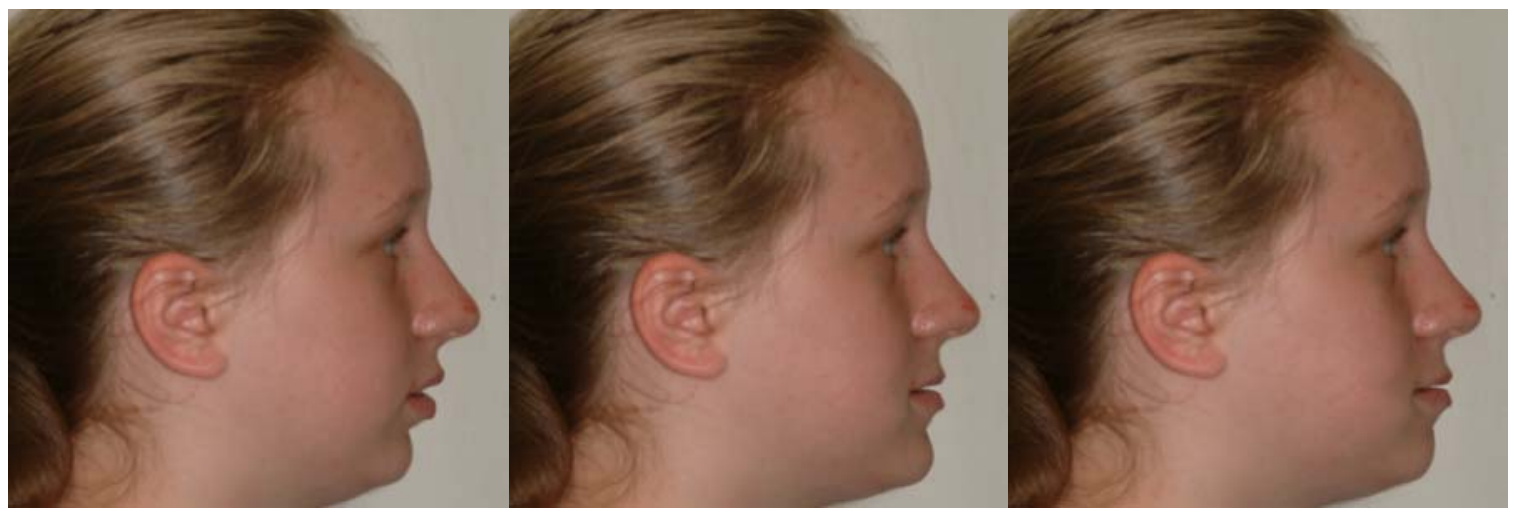

ORIGINAL

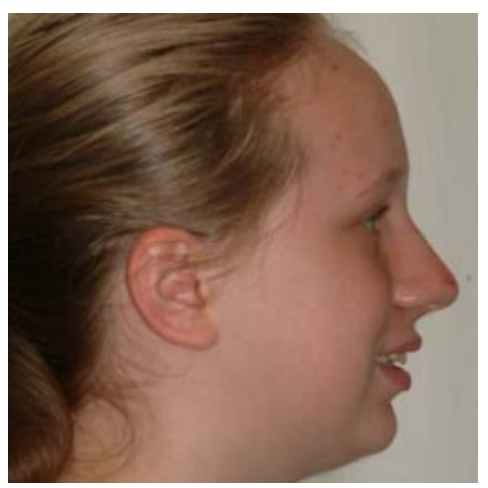

ARNETT

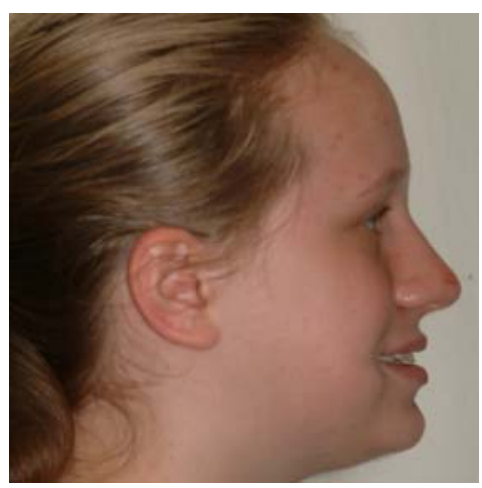

SIX ELEMENTS

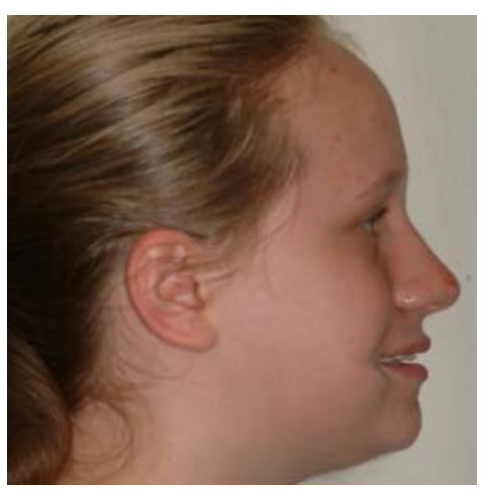


SUBJECT 12

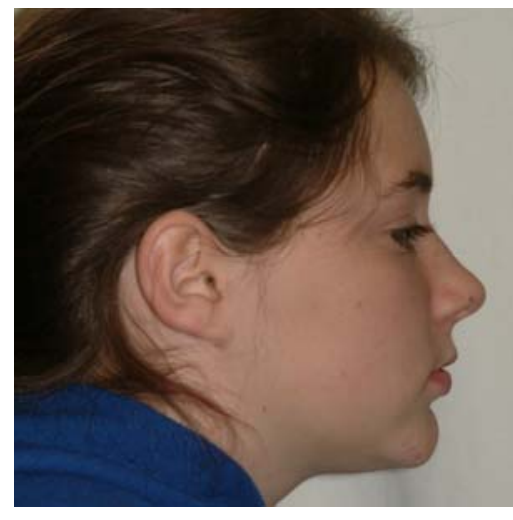

ORIGINAL

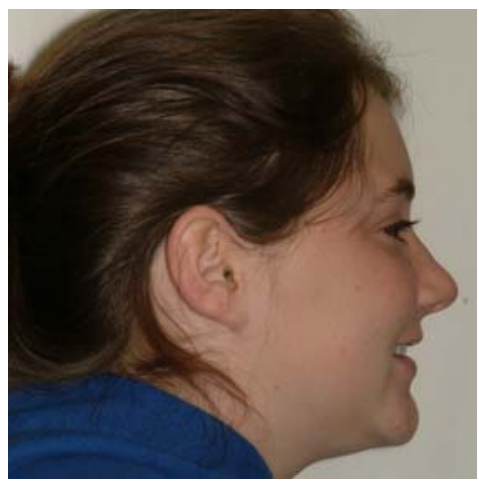

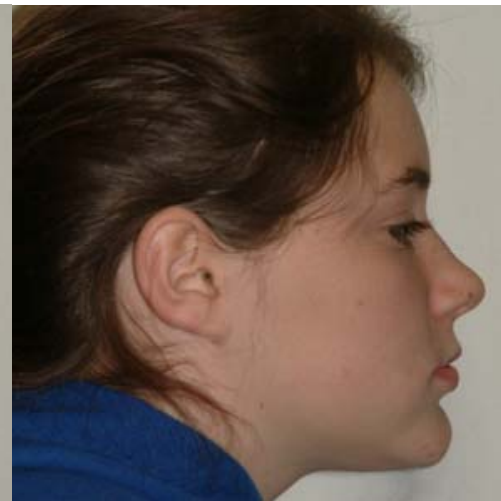

ARNETT

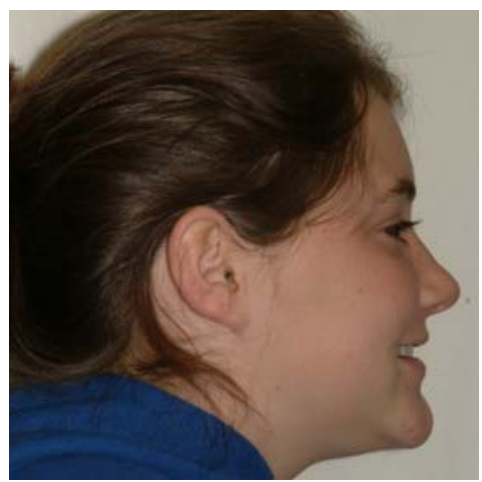

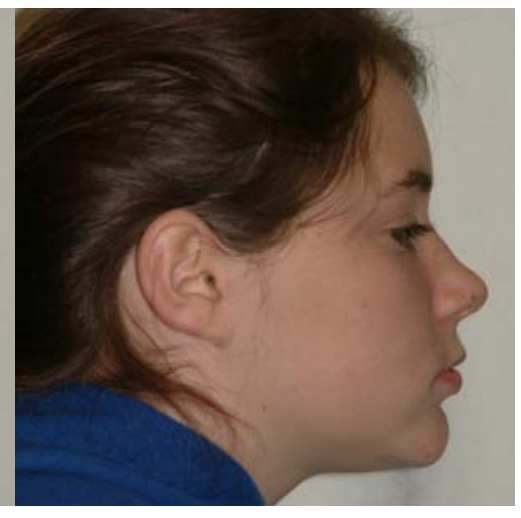

SIX ELEMENTS

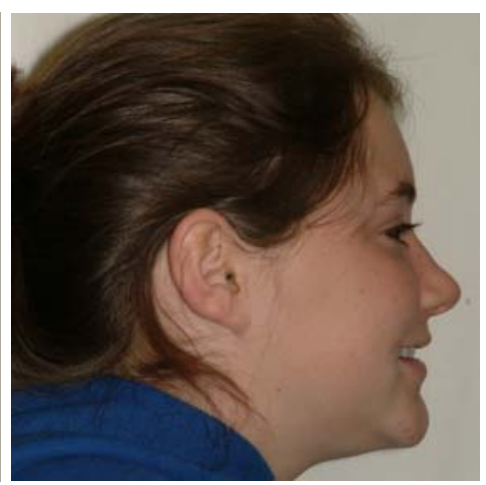


SUBJECT 13
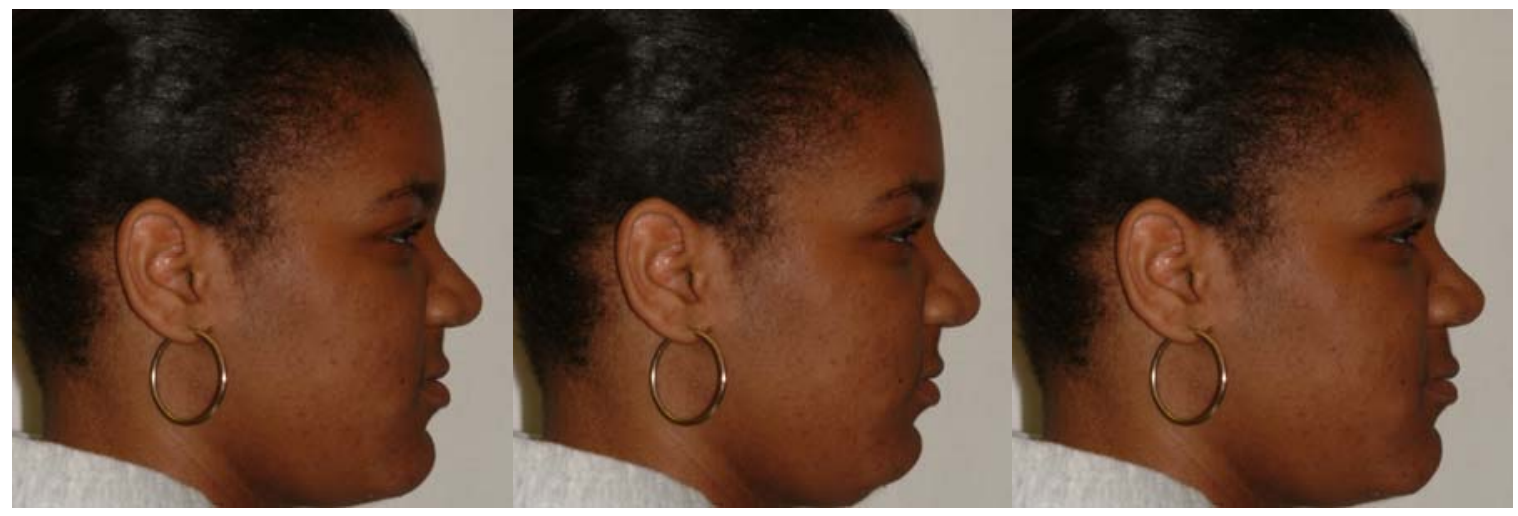

ORIGINAL

ARNETT

SIX ELEMENTS

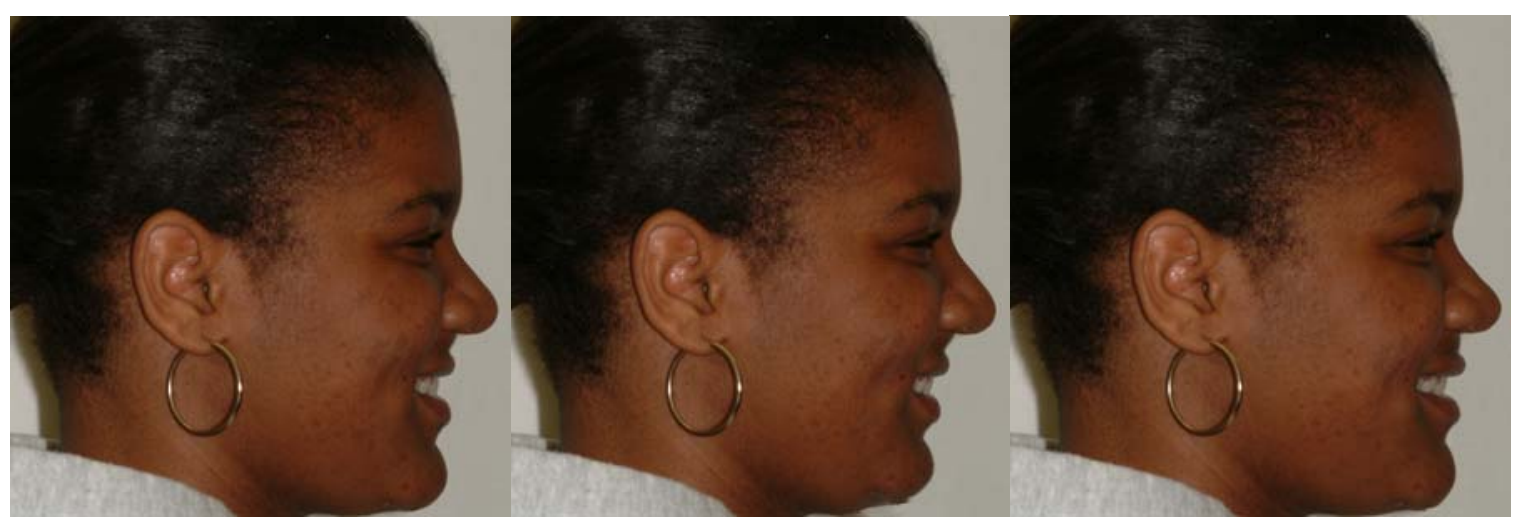


SUBJECT 14

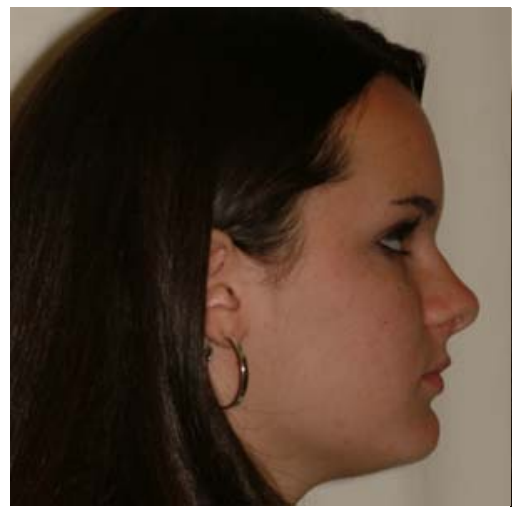

ORIGINAL

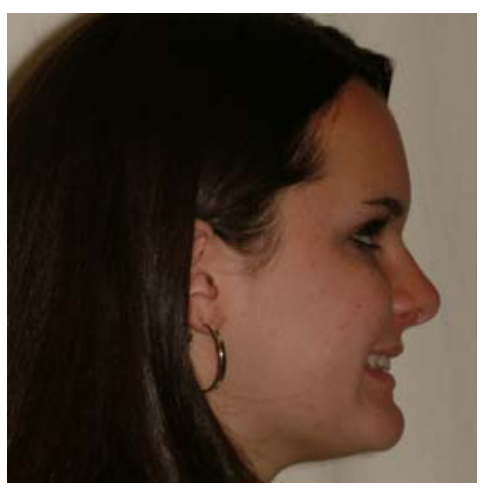

ARNETT

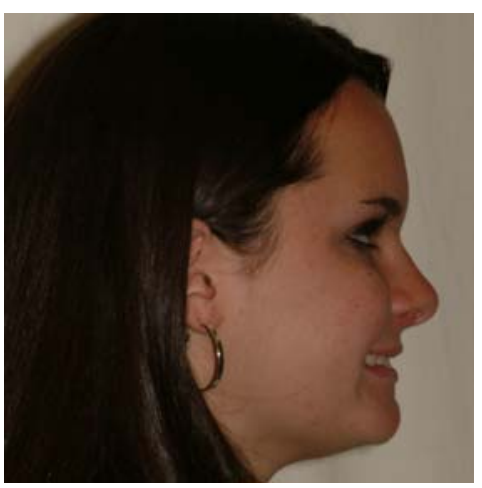

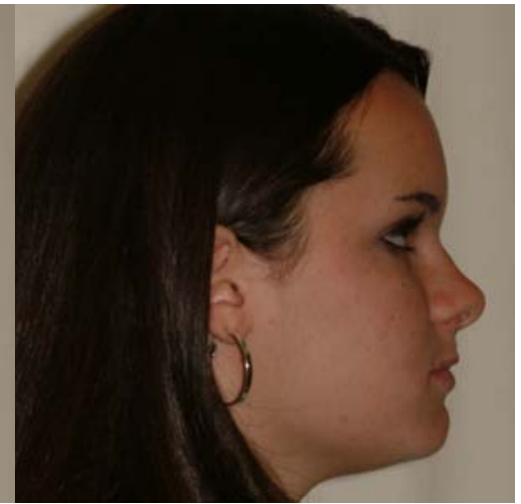

SIX ELEMENTS

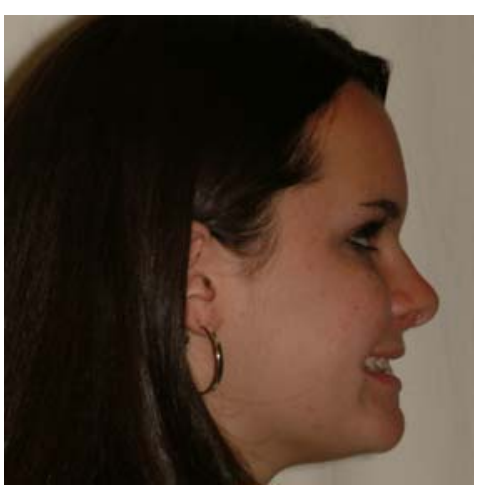


SUBJECT 15

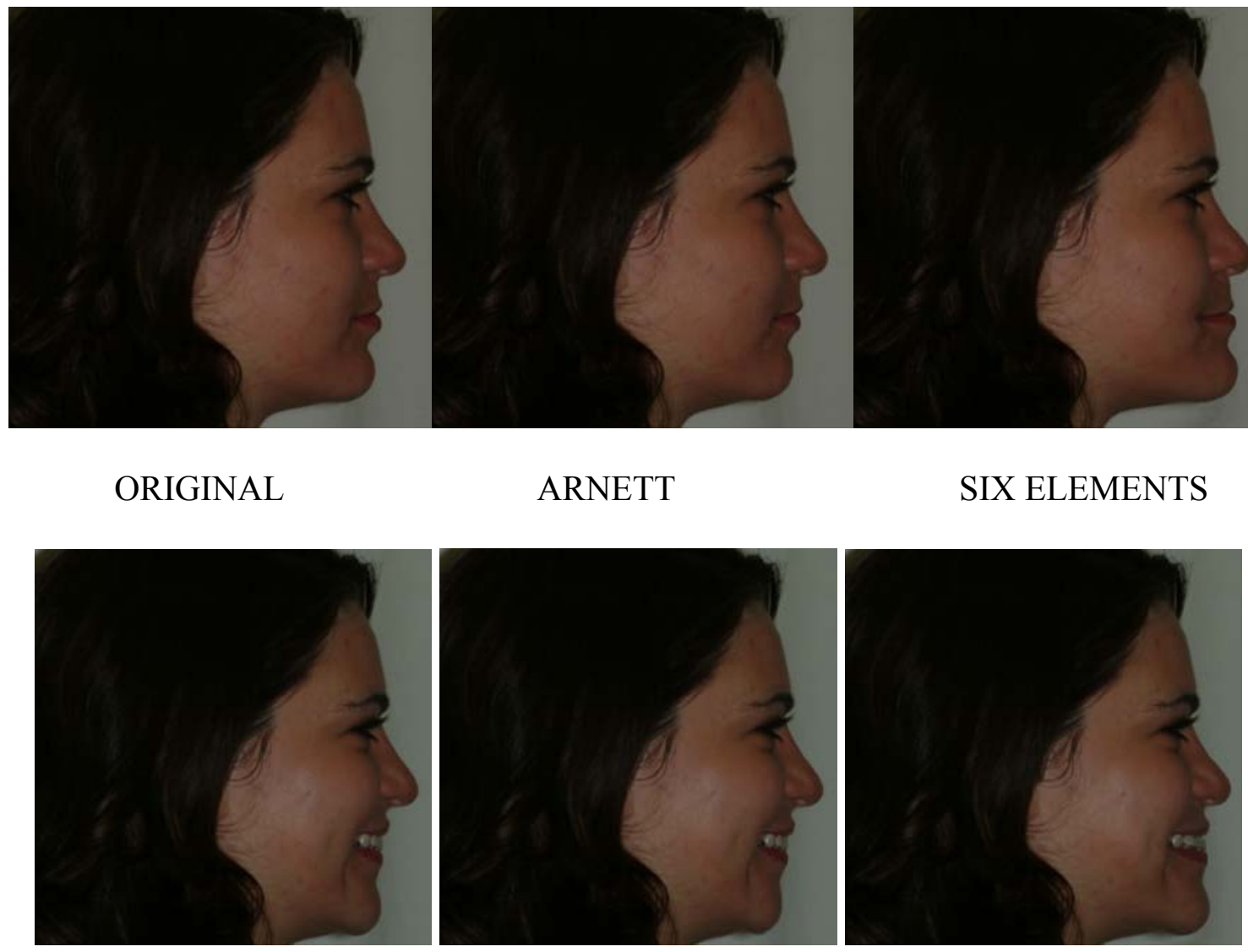


SUBJECT 16
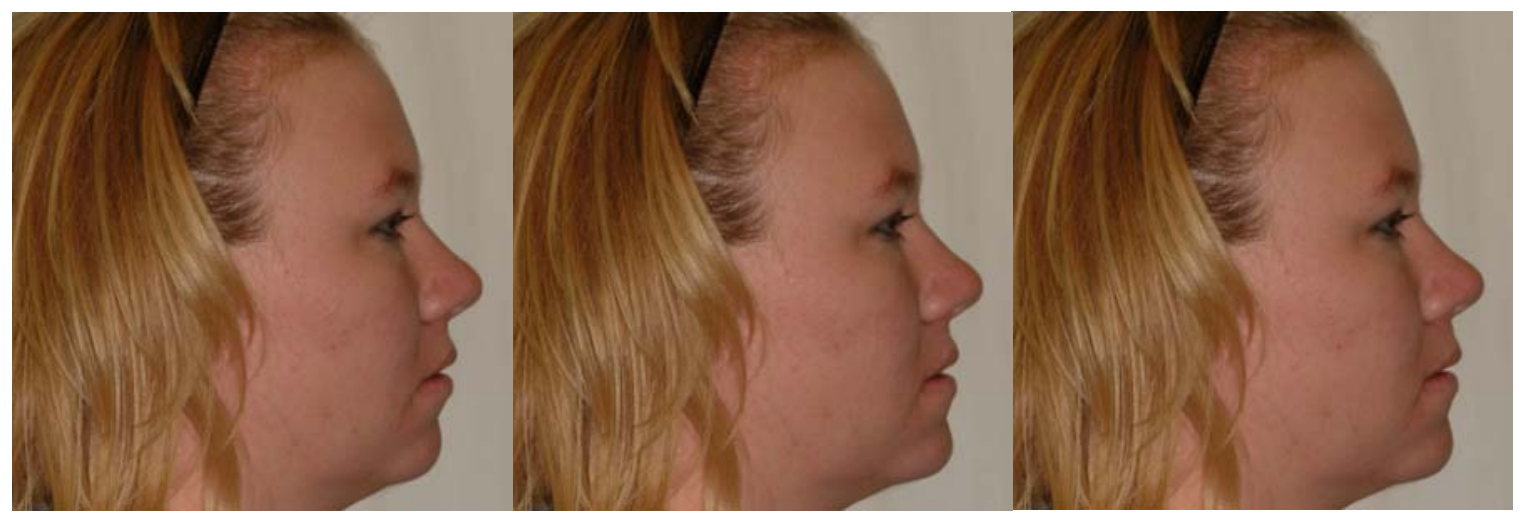

ORIGINAL

ARNETT

SIX ELEMENTS
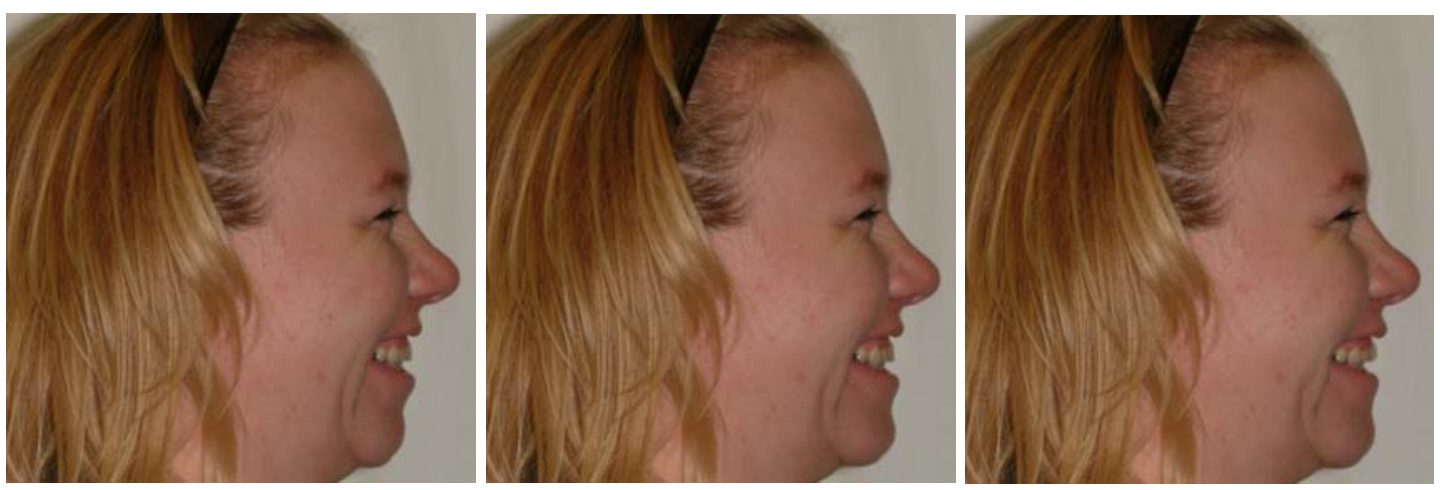
SUBJECT 17

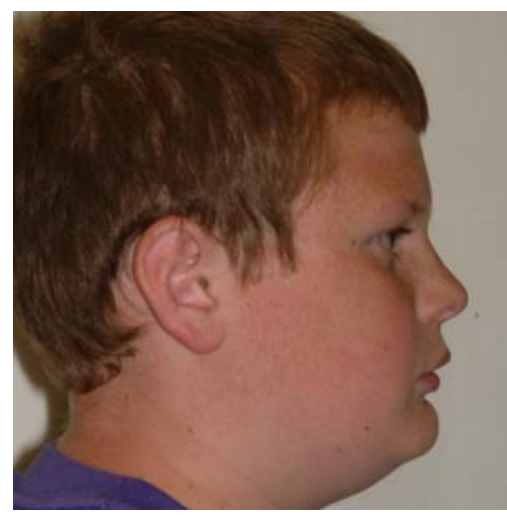

ORIGINAL

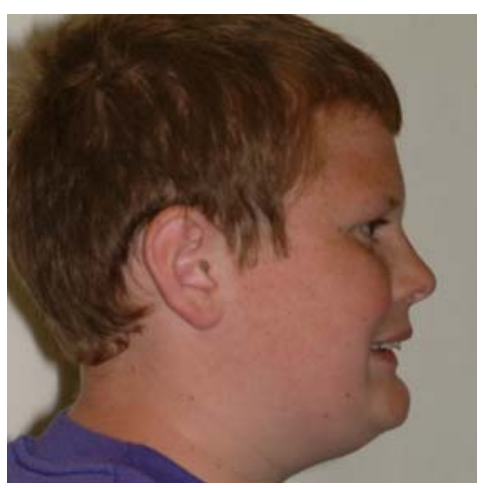

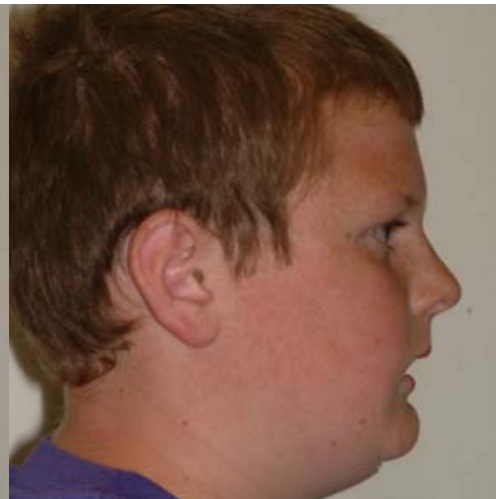

ARNETT

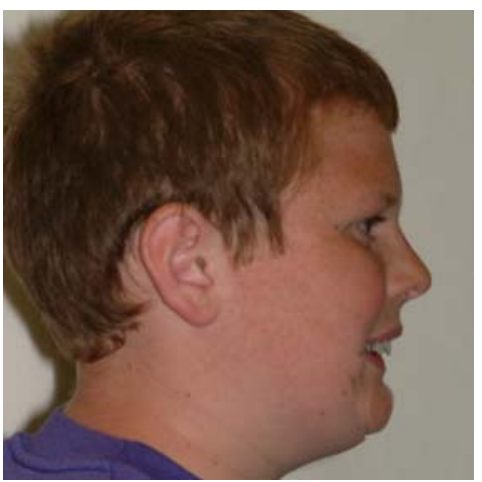

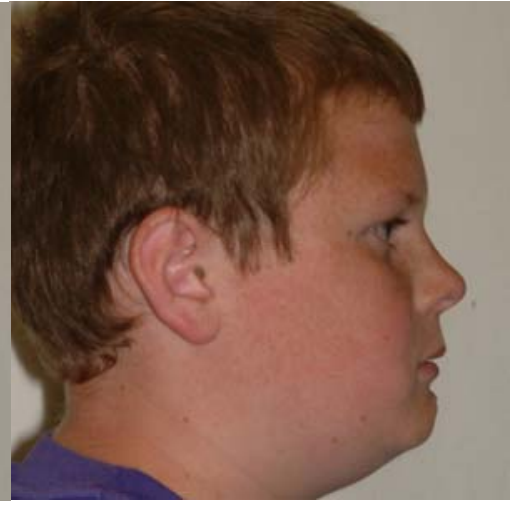

SIX ELEMENTS

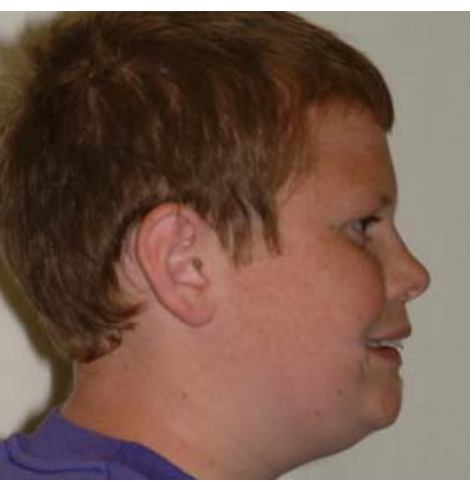


SUBJECT 18

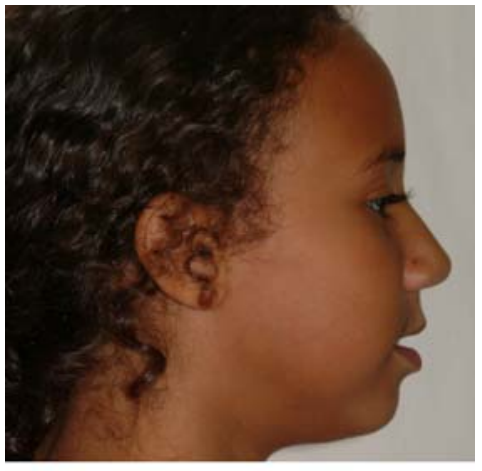

ORIGINAL

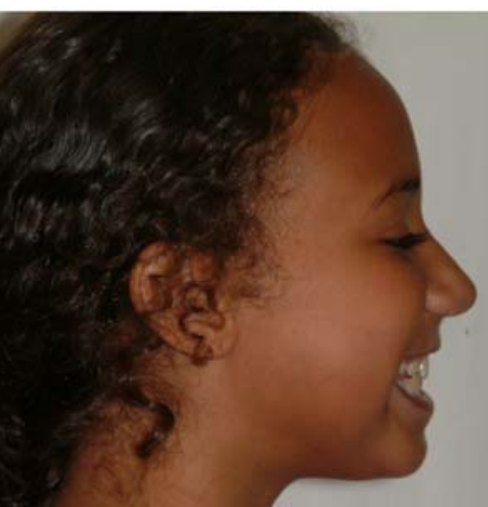

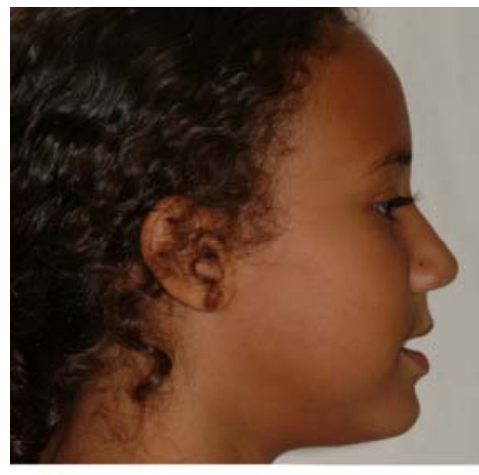

ARNETT

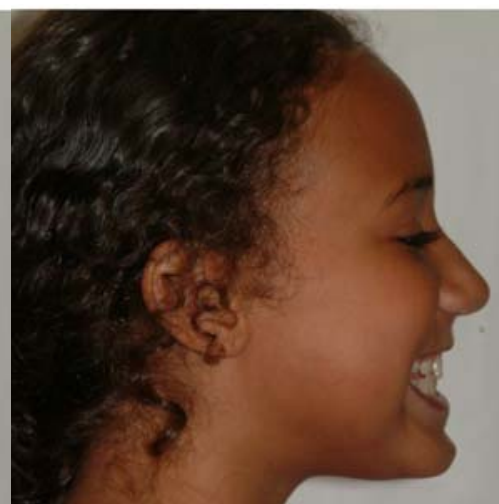

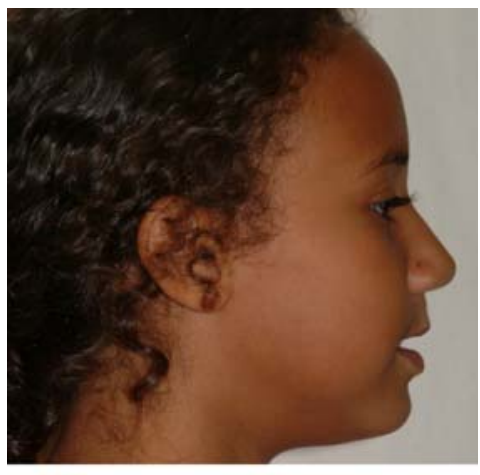

SIX ELEMENTS

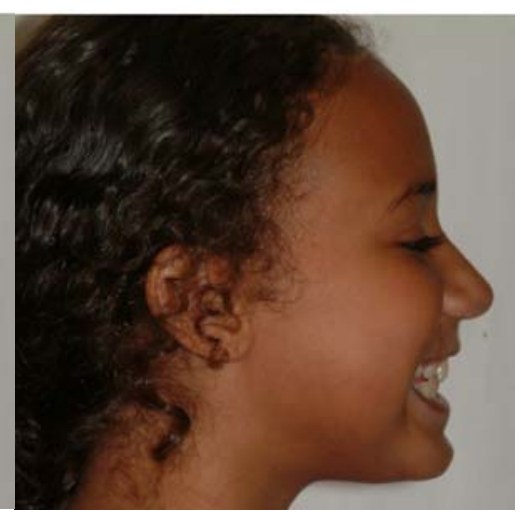


SUBJECT 19

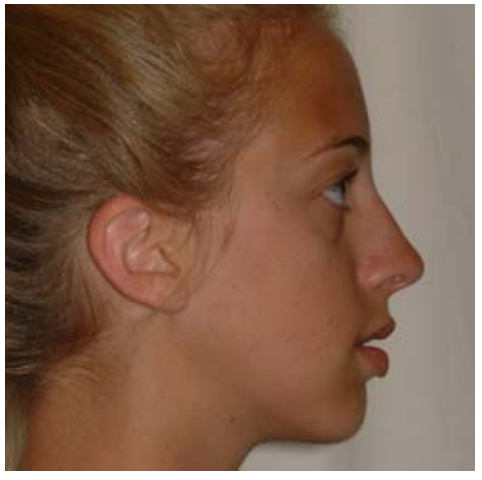

ORIGINAL

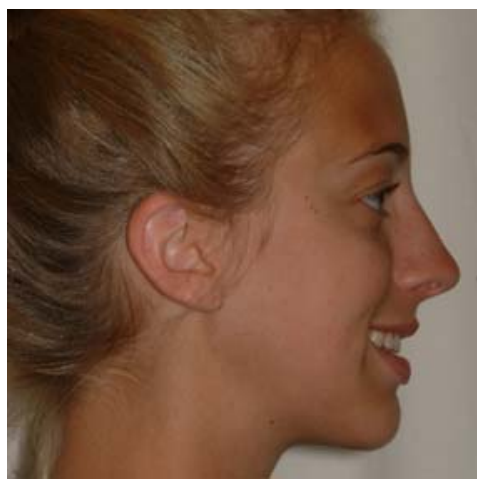

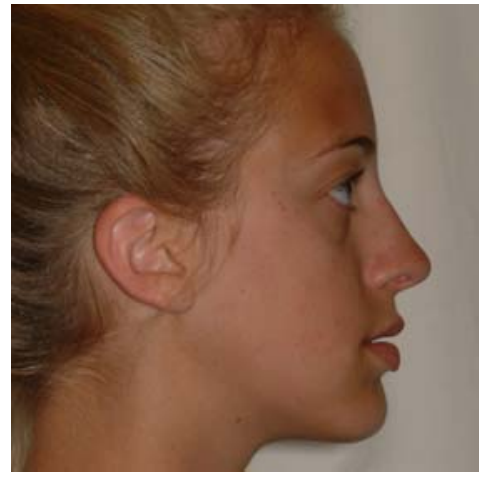

ARNETT

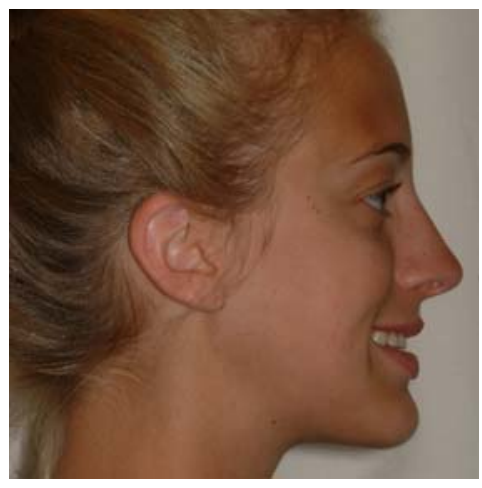

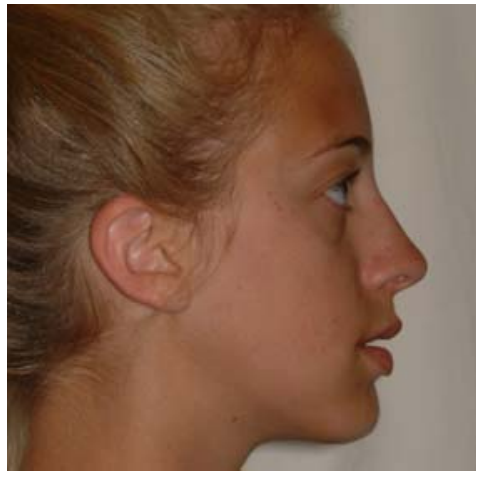

SIX ELEMENTS

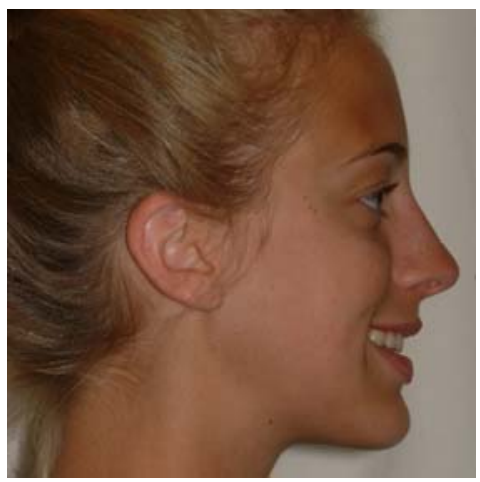


SUBJECT 20

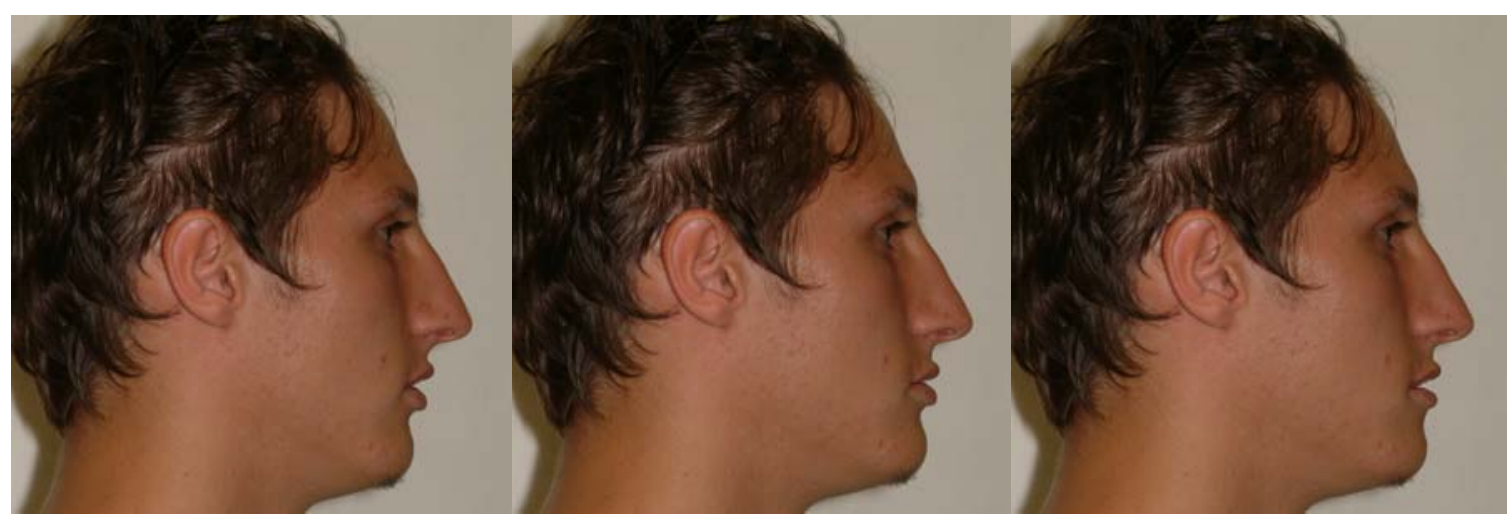

ORIGINAL

ARNETT

SIX ELEMENTS

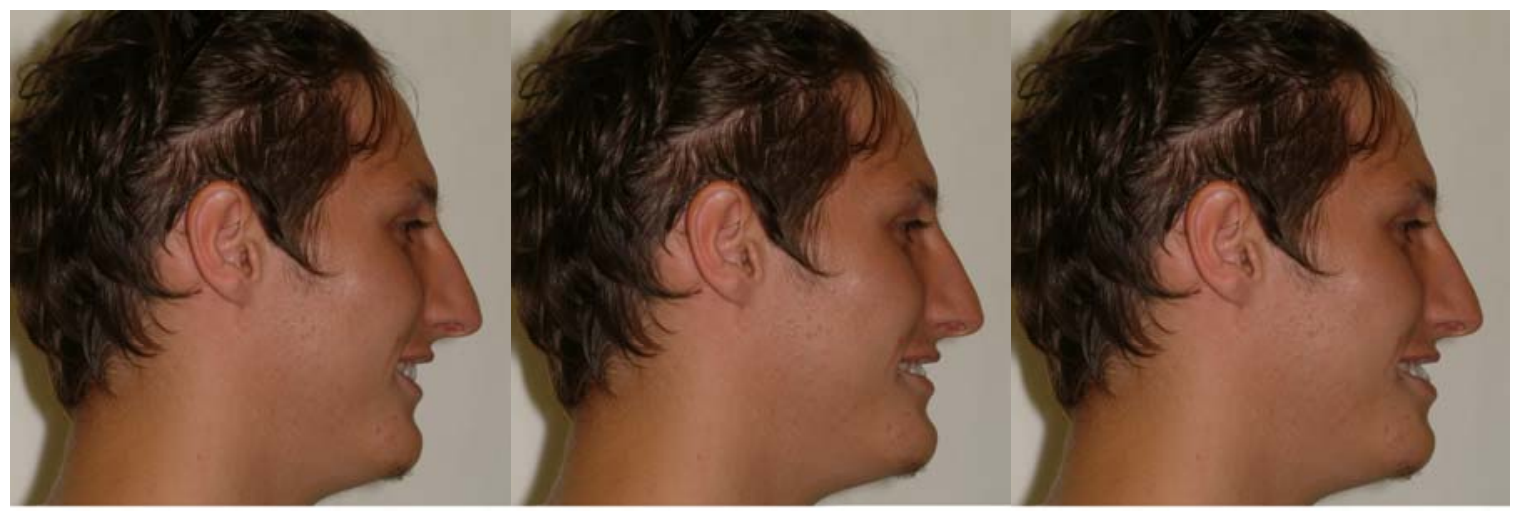


SUBJECT 21

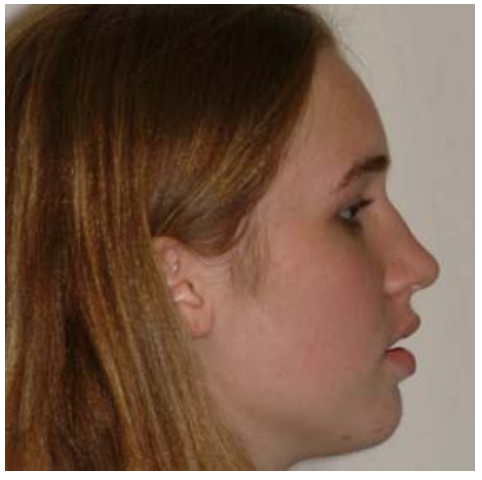

ORIGINAL

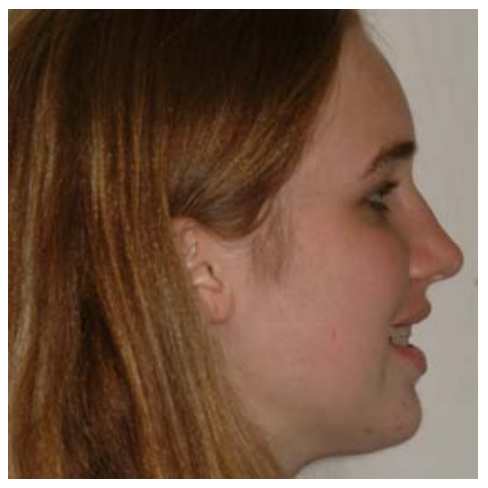

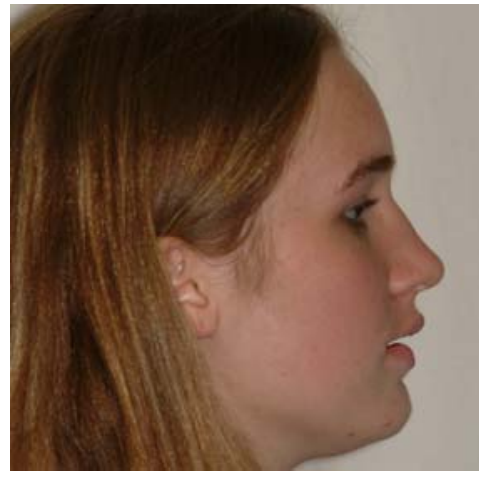

ARNETT

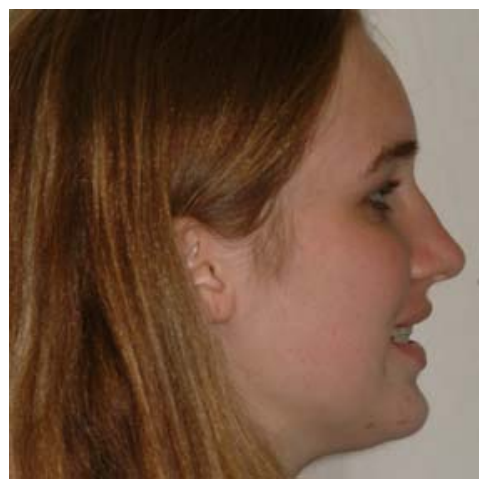

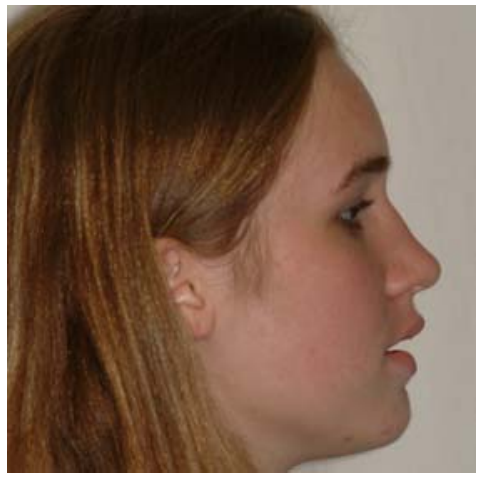

SIX ELEMENTS

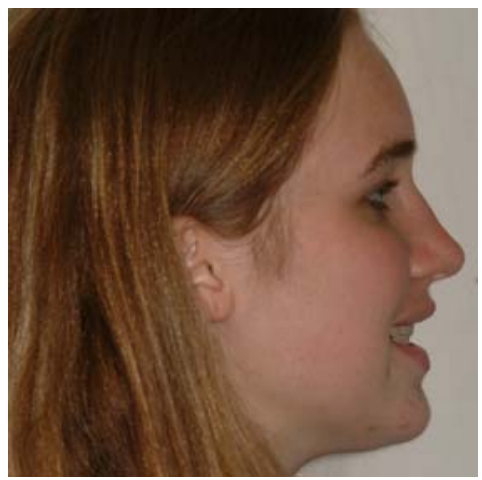


SUBJECT 22

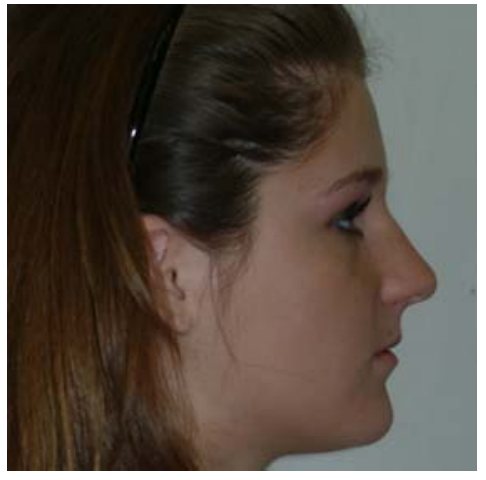

ORIGINAL

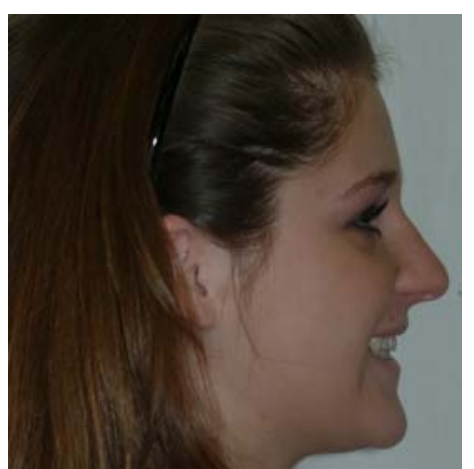

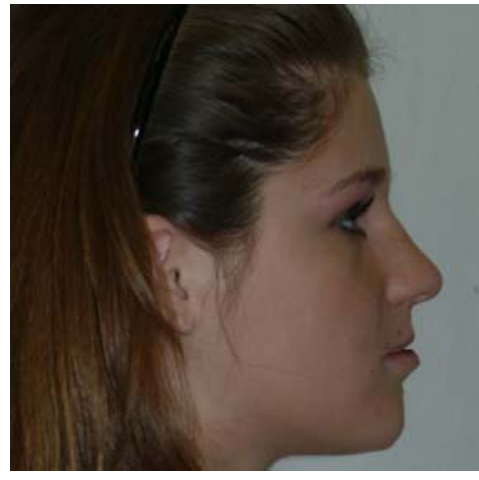

ARNETT

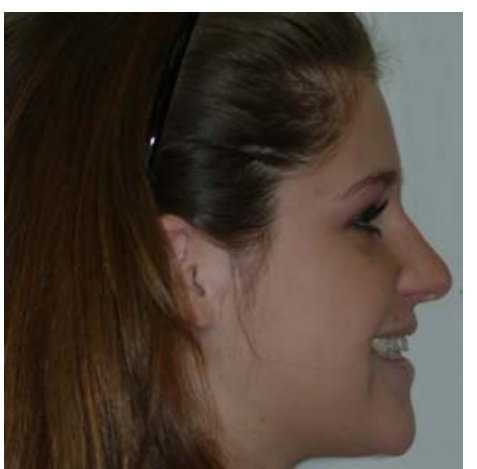

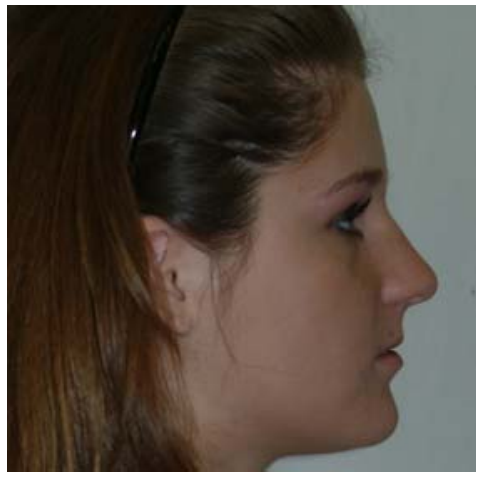

SIX ELEMENTS

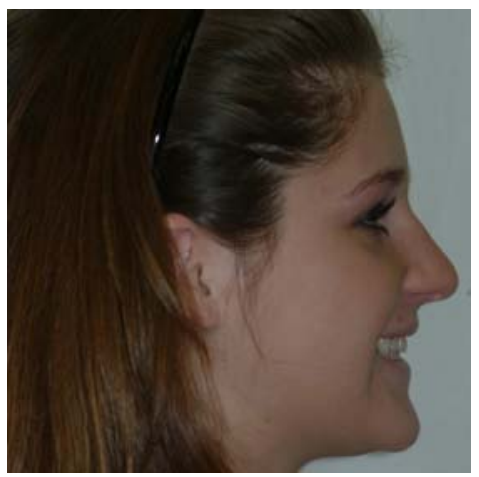


SUBJECT 23

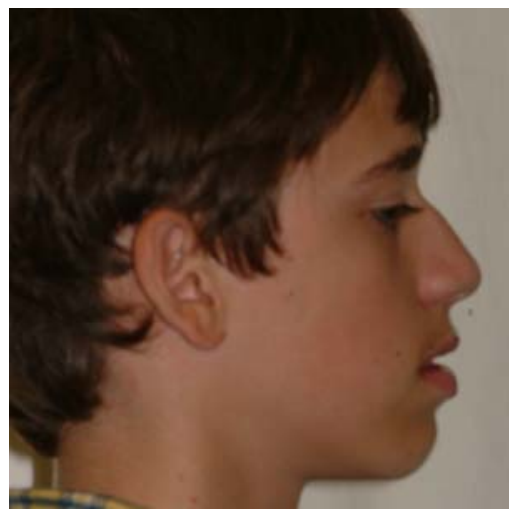

ORIGINAL

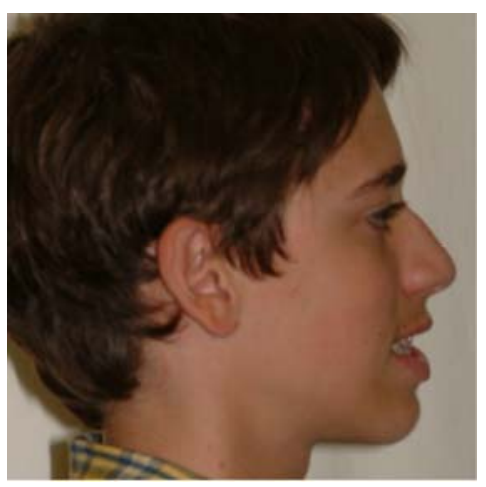

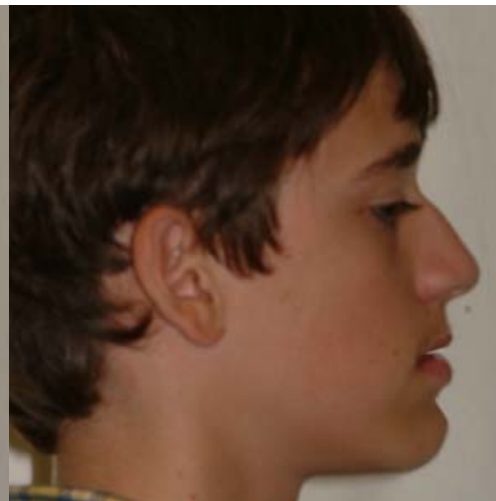

ARNETT

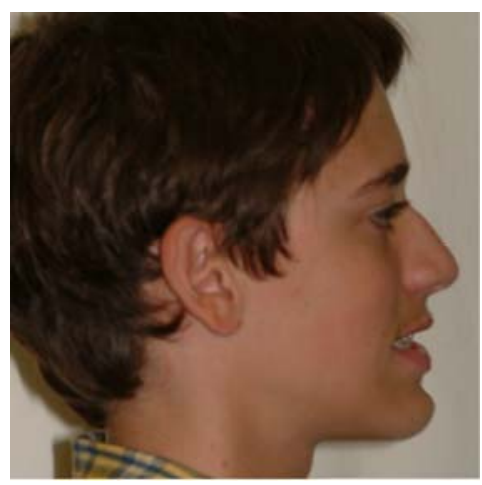

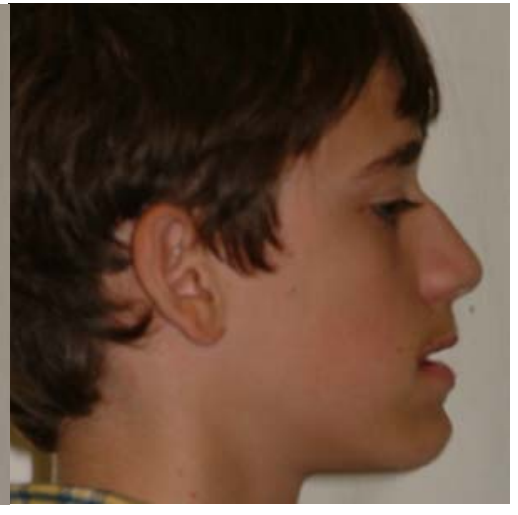

SIX ELEMENTS

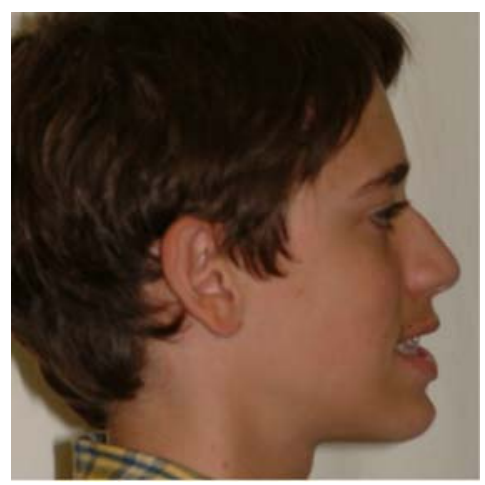




\section{APPENDIX D STATISTICS}


1. For Repose cases, procedure 6e is preferred over the Arn procedure. $\mathrm{P}<0.0001$.

2. For Repose cases, Non-pro raters prefer procedure 6e over the Arn procedure. $\mathrm{P}<0.0001$

3. For Repose cases, Pro raters prefer procedure 6e over the Arn procedure. $\mathrm{P}<0.0001$

4. For Smiling cases, procedure 6e is preferred over the Arn procedure. $\mathrm{P}<0.0001$.

5. For smiling cases, Non-pro raters prefer procedure 6e over the Arnett procedure. $\mathrm{P}<0.0001$

6. For smiling cases, Pro raters prefer procedure 6 e over the Arnett procedure. $\mathrm{P}=0.003$

7. The mean of 6e-NPI is significantly greater than the mean of Arnett-NPI. Overall, procedure 6e has greater mean Net Profile Index (NPI) than the procedure Arnett. That is procedure $6 \mathrm{e}$ is preferred over the Arnett procedure. $\mathrm{P}<0.0001$.

8. Non-Pro raters prefer procedure 6 e over the Arnett procedure. $\mathrm{P}<0.0001$

9. Pro raters prefer procedure $6 \mathrm{e}$ over the Arnett procedure. $\mathrm{P}<0.0001$

10. For Repose cases, procedure 6e is preferred over the Original. $\mathrm{P}<0.0001$.

11. For Repose cases, Non-Pro raters prefer procedure $6 \mathrm{e}$ is over the Original. $\mathrm{P}=0.0003$.

12. For Repose cases, Pro raters prefer procedure $6 \mathrm{e}$ is over the Original. $\mathrm{P}<0.0003$

13. For Smiling cases, there is no significant difference between procedure 6e and the Original. $\mathrm{P}=0.35$.

14. In Smiling cases, for Non-Pro raters there is no significant difference between procedure $6 \mathrm{e}$ and the Original. $\mathrm{P}=0.92$.

15. In Smiling cases, Pro raters prefer procedure 6e over the Original. $\mathrm{P}=0.01$.

16. For Repose cases, there is no significant difference between procedure Arnett and the Original. $\mathrm{P}=0.66$.

17. In Repose cases, for Non-Pro raters there is no significant difference between procedure Arnett and the Original. $\mathrm{P}=0.29$.

18. In Repose cases, for Pro raters prefer procedure Arnett over the Original. $\mathrm{P}=0.002$.

19. For Smiling cases, procedure Original is preferred over the Arnett. $\mathrm{P}<0.0001$.

20. For Smiling cases, Non-Pro raters prefer Original over the Arnett. $\mathrm{P}<0.0001$.

21.For Smiling cases, for Pro raters there is no significant difference between Original and the Arnett. $\mathrm{P}=0.63$. 
The findings above are summarized in Tables 1,2 3 .

Table 1. 6e vs Arnett

\begin{tabular}{|l|l|l|l|}
\hline Preference & Pro Raters & Non-Pro Raters & Pro\&Non-Pro Raters \\
\hline Repose & $6 \mathrm{e}$ & $6 \mathrm{e}$ & $6 \mathrm{e}$ \\
\hline Smiling & $6 \mathrm{e}$ & $6 \mathrm{e}$ & $6 \mathrm{e}$ \\
\hline NPI & $6 \mathrm{e}$ & $6 \mathrm{e}$ & $6 \mathrm{e}$ \\
\hline
\end{tabular}

Table 2. 6e vs Original

\begin{tabular}{|l|l|l|l|}
\hline Preference & Pro Raters & Non-Pro Raters & Pro\&Non-Pro Raters \\
\hline Repose & 6e & $6 \mathrm{e}$ & $6 \mathrm{e}$ \\
\hline Smiling & 6e & No preference & No preference \\
\hline
\end{tabular}

Table 3. Arnett vs Original

\begin{tabular}{|l|l|l|l|}
\hline Preference & Pro Raters & Non-Pro Raters & Pro\&Non-Pro Raters \\
\hline Repose & Arnett & No preference & No preference \\
\hline Smiling & No preference & Original & Original \\
\hline
\end{tabular}

22. For Repose cases, there is no evidence of rater status differences. $\mathrm{P}=0.12$

For Repose cases, there is no significant evidence that Pro raters prefer 6e over Arnett, more than Non-Pro raters.

23. For Repose cases, there is no significant evidence of rater gender differences in preference of $6 \mathrm{e}$ over Arnett. $\mathrm{P}=0.75$. That is, for Repose cases, there is no significant evidence that Male raters prefer 6e over Arnett more than the Female raters.

24. For Repose cases, there is no evidence of subject gender differences in preference of 6e over Arnett. $\mathrm{P}=0.23$.

25. For Smiling cases, there is no evidence of rater status differences. $\mathrm{P}=0.44$.

For Smiling cases, there is no significant evidence that Pro raters prefer 6e over Arnett, more than Non-Pro raters.

26. For Smiling cases, there is no significant evidence of rater gender differences in preference of 6e over Arnett. $\mathrm{P}=0.74$. That is, for Smiling cases, there is no significant evidence that Male raters prefer 6e over Arnett more than the Female raters.

27. For Smiling cases, there is no evidence of subject gender differences in preference of 6e over Arnett. $\mathrm{P}=0.84$.

28. With respect to NPI, there is no evidence of rater status differences. $\mathrm{P}=0.09$.

With respect to NPI, there is no significant evidence that Pro raters prefer 6e over Arnett, more than Non-Pro raters. 
29. With respect to NPI, there is no evidence of rater gender differences. $\mathrm{P}=0.68$.

With respect to NPI, there is no significant evidence that Male raters prefer 6e over Arnett, more than Female raters.

30. With respect to NPI, there is no evidence of subject gender differences in preference of $6 \mathrm{e}$ over Arnett. $\mathrm{P}=0.37$.

31. Cronbach's Alpha indicates that the measurements are most reliable for Subject 20, followed by Subject 11 and Subject 1. Overall reliability is satisfactory. 


\section{Matched Pairs}

\section{Difference: 6E REP-ARN REP}

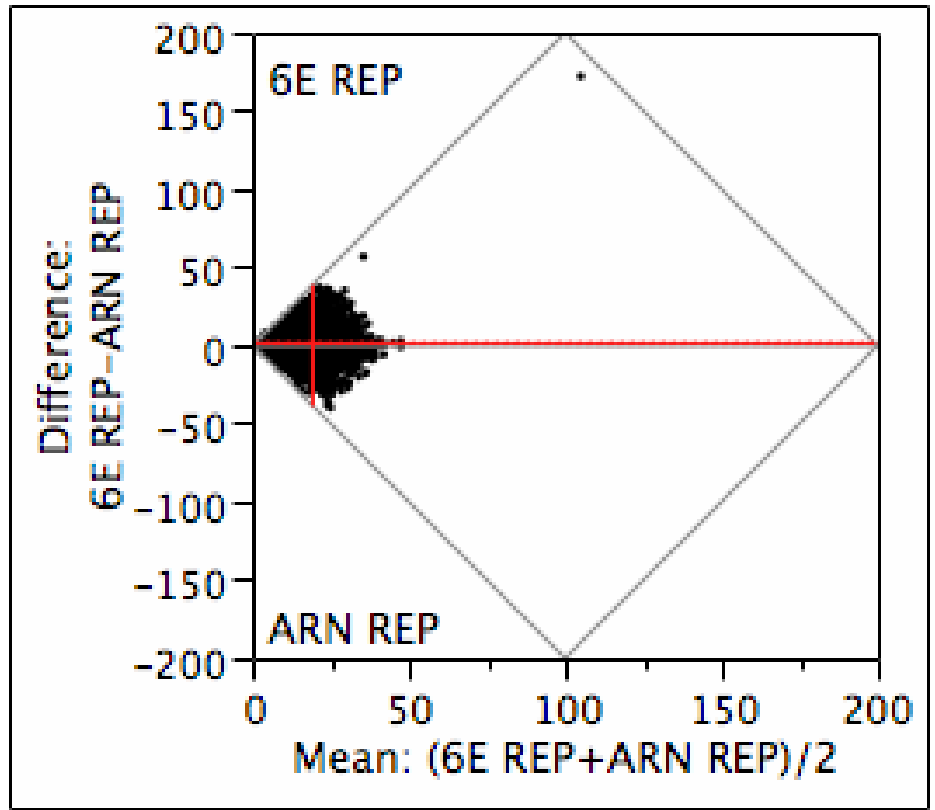

$\begin{array}{lrlr}\text { 6E REP } & 20.0599 & \text { t-Ratio } & 5.347736 \\ \text { ARN REP } & 18.7161 & \text { DF } & 2271 \\ \text { Mean } & 1.34375 & \text { Prob }> & <.0001 \\ \text { Difference } & & |\mathrm{t}| & \\ \text { Std Error } & 0.25127 & \text { Prob }>\mathrm{t} & <.0001 \\ \text { Upper95\% } & 1.8365 & \text { Prob }<\mathrm{t} & 1.0000 \\ \text { Lower95\% } & 0.851 & & \\ \mathrm{~N} & 2272 & & \\ \text { Correlation } & 0.29592 & & \end{array}$

For Repose cases, procedure 6e is preferred over the Arn procedure. $\mathrm{P}<0.0001$. 


\section{Matched Pairs Rstatus=NONPRO}

\section{Difference: 6E REP-ARN REP}

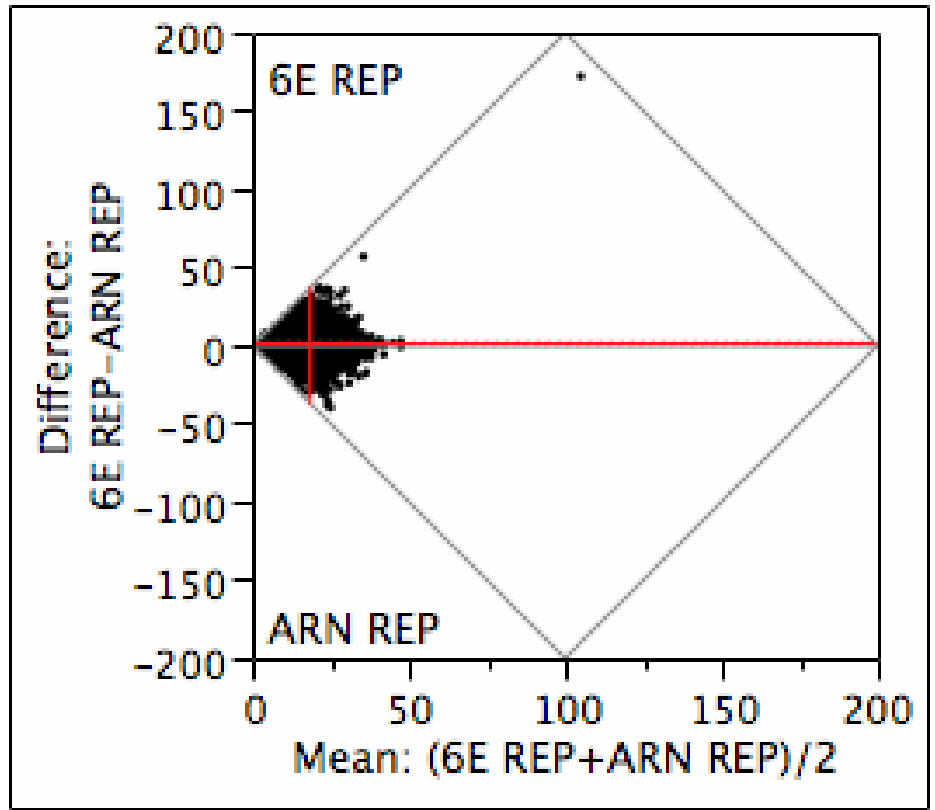

$\begin{array}{lrlr}\text { 6E REP } & 19.1733 & \text { t-Ratio } & 4.472571 \\ \text { ARN REP } & 17.9894 & \text { DF } & 1880 \\ \text { Mean } & 1.18394 & \text { Prob }> & <.0001 \\ \text { Difference } & & |\mathrm{t}| & \\ \text { Std Error } & 0.26471 & \text { Prob }>\mathrm{t} & <.0001 \\ \text { Upper95\% } & 1.70311 & \text { Prob < t } & 1.0000 \\ \text { Lower95\% } & 0.66478 & & \\ \text { N } & 1881 & & \\ \text { Correlation } & 0.33204 & & \end{array}$

For Repose cases, Non-pro raters prefer procedure 6e over the Arn procedure. $\mathrm{P}<0.0001$ 


\section{Matched Pairs Rstatus=PRO \\ Difference: 6E REP-ARN REP}

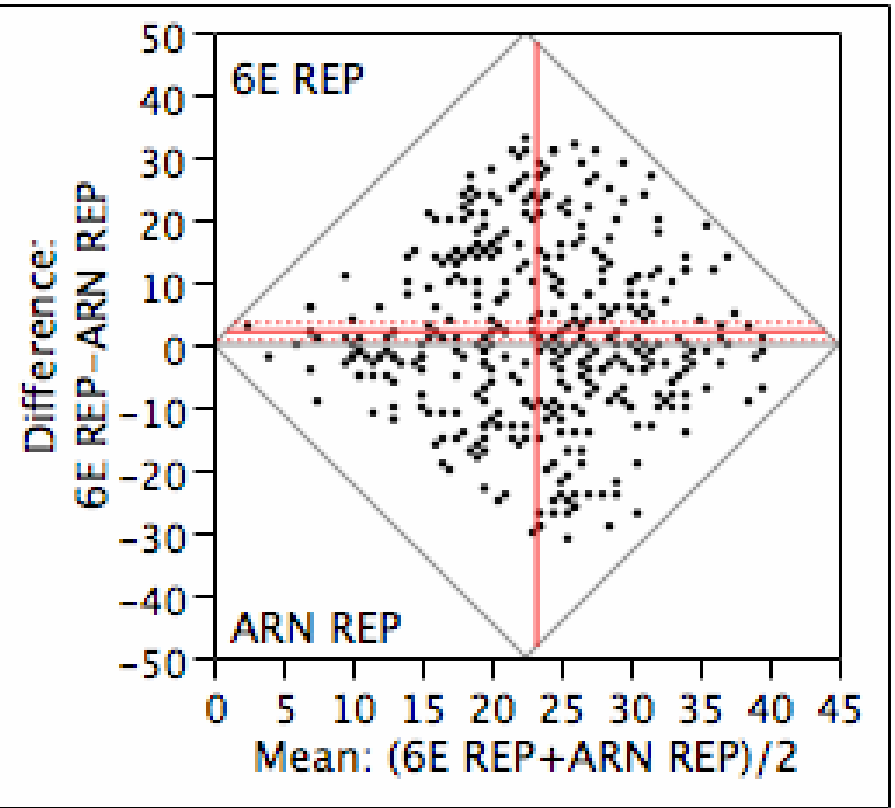

$\begin{array}{lrlr}\text { 6E REP } & 24.3248 & \text { t-Ratio } & 2.959409 \\ \text { ARN REP } & 22.2123 & \text { DF } & 390 \\ \text { Mean } & 2.11253 & \text { Prob }> & 0.0033 \\ \text { Difference } & & |\mathrm{t}| & \\ \text { Std Error } & 0.71384 & \text { Prob }>\mathrm{t} & 0.0016 \\ \text { Upper95\% } & 3.51598 & \text { Prob }<\mathrm{t} & 0.9984 \\ \text { Lower95\% } & 0.70908 & & \\ \text { N } & 391 & & \\ \text { Correlation } & -0.0031 & & \end{array}$

For Repose cases, Pro raters prefer procedure 6e over the Arn procedure. $\mathrm{P}<0.0001$ 


\section{Matched Pairs}

\section{Difference: 6E SM-ARN SM}

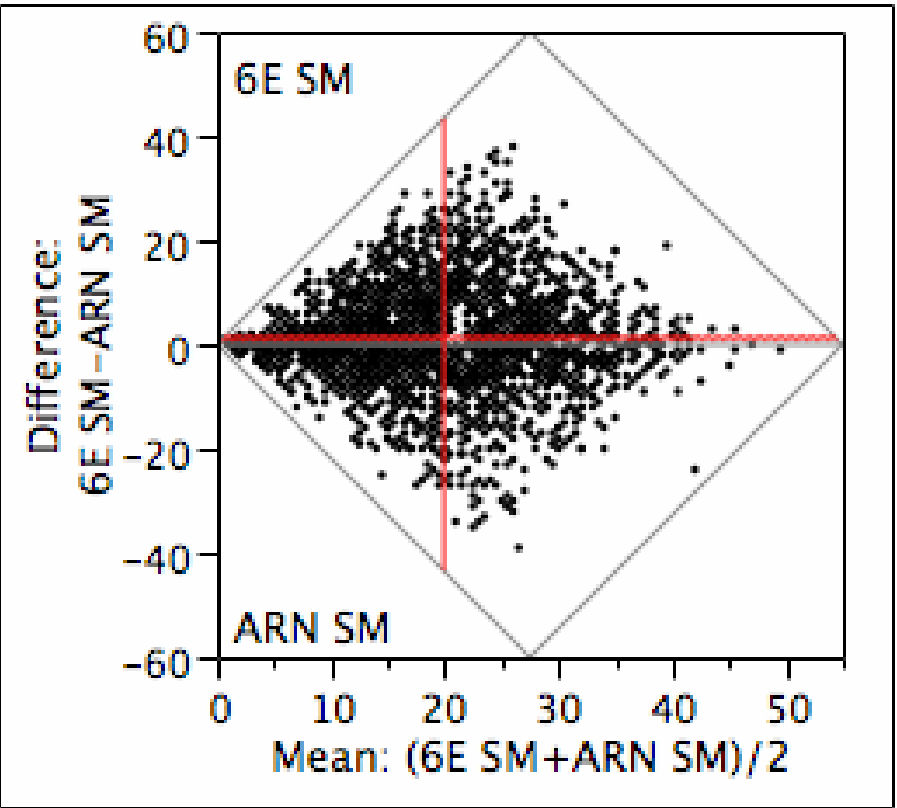

$\begin{array}{lrlr}\text { 6E SM } & 20.5455 & \text { t-Ratio } & 5.892857 \\ \text { ARN SM } & 19.2545 & \text { DF } & 2274 \\ \text { Mean } & 1.29099 & \text { Prob }> & <.0001 \\ \text { Difference } & & |\mathrm{t}| & \\ \text { Std Error } & 0.21908 & \text { Prob }>\mathrm{t} & <.0001 \\ \text { Upper95\% } & 1.7206 & \text { Prob < t } & 1.0000 \\ \text { Lower95\% } & 0.86138 & & \\ \text { N } & 2275 & & \\ \text { Correlation } & 0.46074 & & \end{array}$

For Smiling cases, procedure 6e is preferred over the Arn procedure. $\mathrm{P}<0.0001$. 


\section{Matched Pairs Rstatus=NONPRO}

\section{Difference: 6E SM-ARN SM}

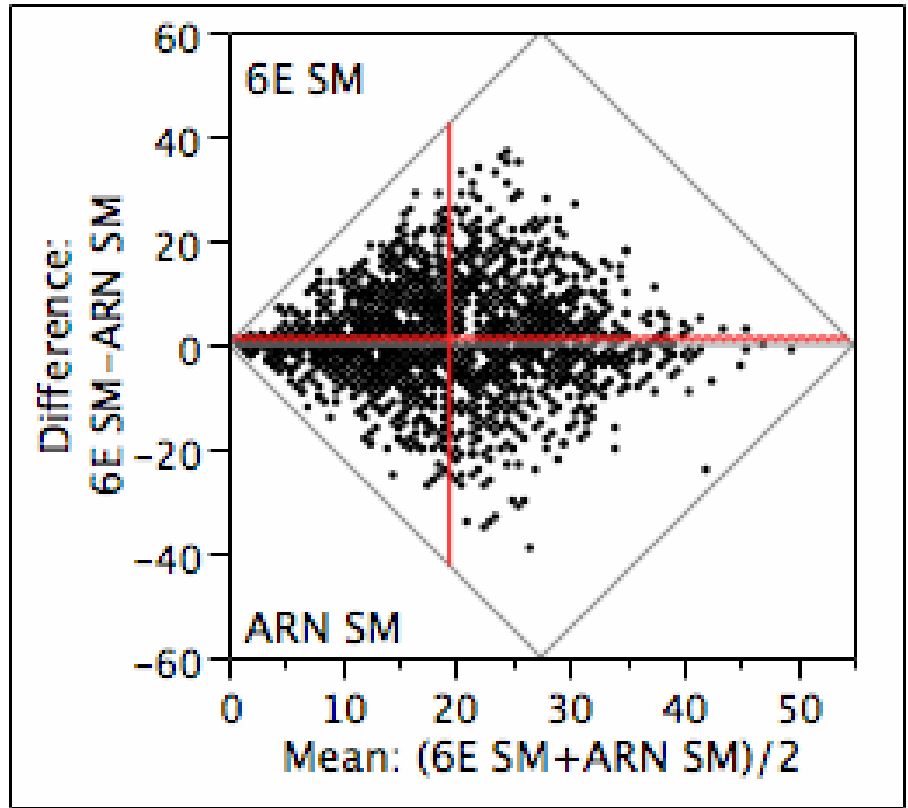

$\begin{array}{lrlr}\text { 6E SM } & 20.0579 & \text { t-Ratio } & 5.213379 \\ \text { ARN SM } & 18.8392 & \text { DF } & 1883 \\ \text { Mean } & 1.21868 & \text { Prob }> & <.0001 \\ \text { Difference } & & |\mathrm{t}| & \\ \text { Std Error } & 0.23376 & \text { Prob }>\mathrm{t} & <.0001 \\ \text { Upper95\% } & 1.67714 & \text { Prob < t } & 1.0000 \\ \text { Lower95\% } & 0.76023 & & \\ \mathrm{~N} & 1884 & & \\ \text { Correlation } & 0.47971 & & \end{array}$

For smiling cases, Non-pro raters prefer procedure 6e over the Arnett procedure.

$\mathrm{P}<0.0001$ 


\section{Matched Pairs Rstatus=PRO}

\section{Difference: 6E SM-ARN SM}

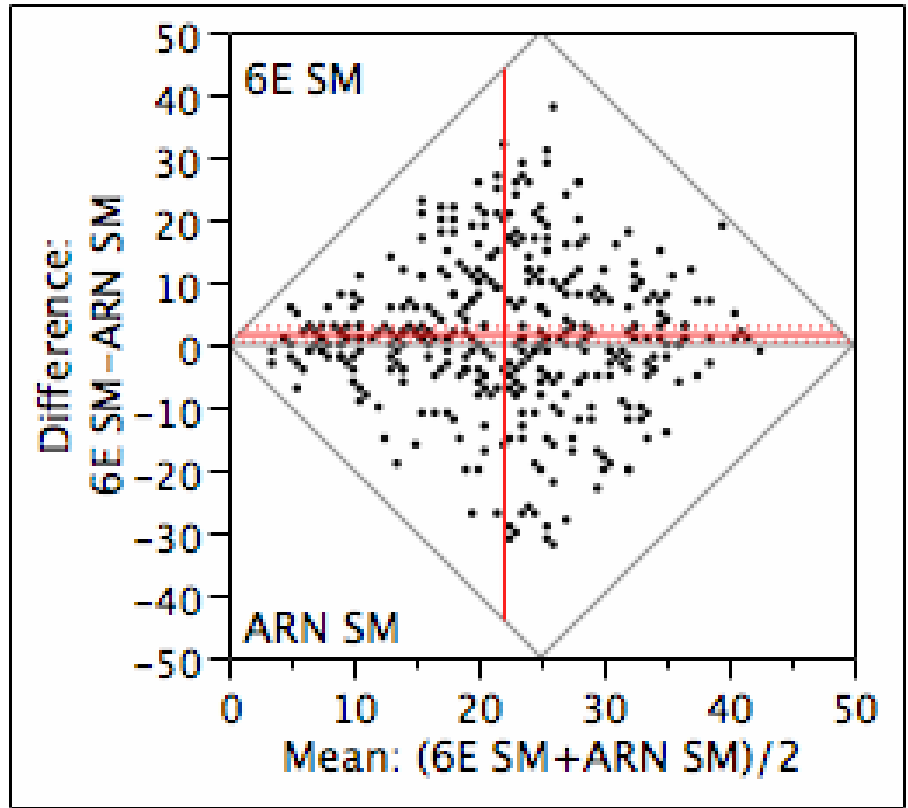

$\begin{array}{lrlr}\text { 6E SM } & 22.8951 & \text { t-Ratio } & 2.745199 \\ \text { ARN SM } & 21.2558 & \text { DF } & 390 \\ \text { Mean } & 1.63939 & \text { Prob }> & 0.0063 \\ \text { Difference } & & |\mathrm{t}| & \\ \text { Std Error } & 0.59718 & \text { Prob }>\mathrm{t} & 0.0032 \\ \text { Upper95\% } & 2.81349 & \text { Prob }<\mathrm{t} & 0.9968 \\ \text { Lower95\% } & 0.46529 & & \\ \text { N } & 391 & & \\ \text { Correlation } & 0.34762 & & \end{array}$

For smiling cases, Pro raters prefer procedure 6e over the Arnett procedure. $\mathrm{P}=0.003$ 


\section{Matched Pairs}

\section{Difference: 6E NPI-Arnett NPI}

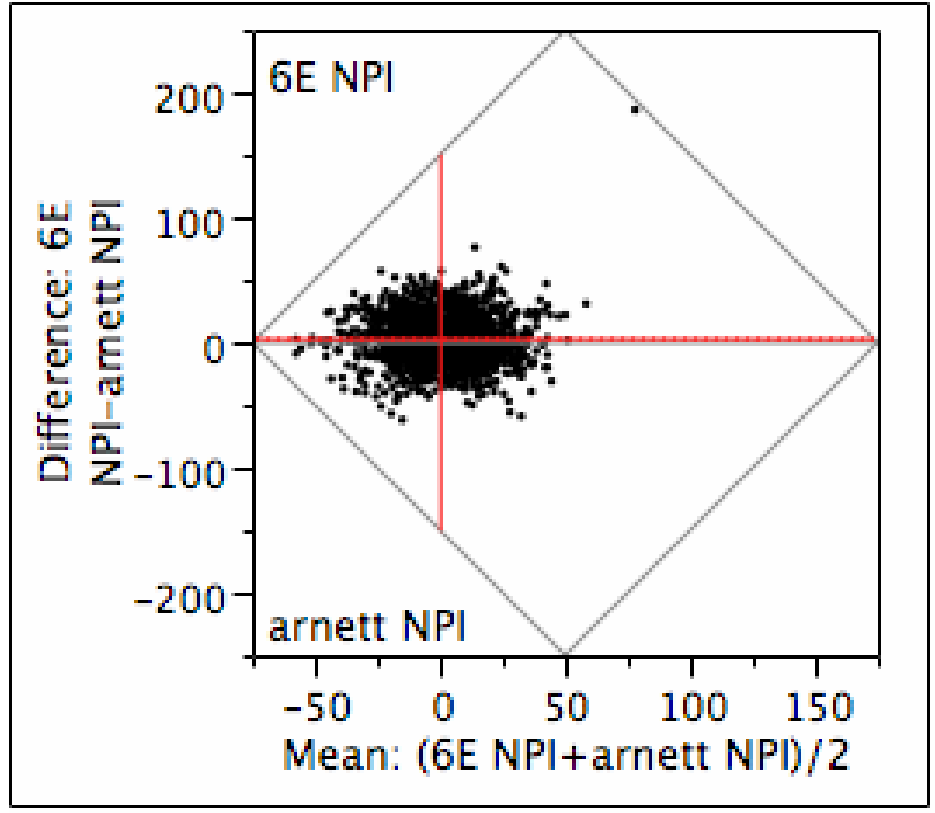

$\begin{array}{lrlr}\text { 6E NPI } & 1.60079 & \text { t-Ratio } & 7.27651 \\ \text { Arnett NPI } & -0.975 & \text { DF } & 2276 \\ \text { Mean } & 2.57576 & \text { Prob }> & <.0001 \\ \text { Difference } & & |\mathrm{t}| & \\ \text { Std Error } & 0.35398 & \text { Prob }>\mathrm{t} & <.0001 \\ \text { Upper95\% } & 3.26992 & \text { Prob < t } & 1.0000 \\ \text { Lower95\% } & 1.8816 & & \\ \text { N } & 2277 & & \\ \text { Correlation } & 0.48306 & & \end{array}$

The mean of 6e-NPI is significantly greater than the mean of Arnett-NPI. Overall, procedure 6e has greater mean Net Profile Index (NPI) than the procedure Arnett. That is procedure $6 \mathrm{e}$ is preferred over the Arnett procedure. $\mathrm{P}<0.0001$. 


\section{Matched Pairs Rstatus=NONPRO}

\section{Difference: 6E NPI-Arnett NPI}

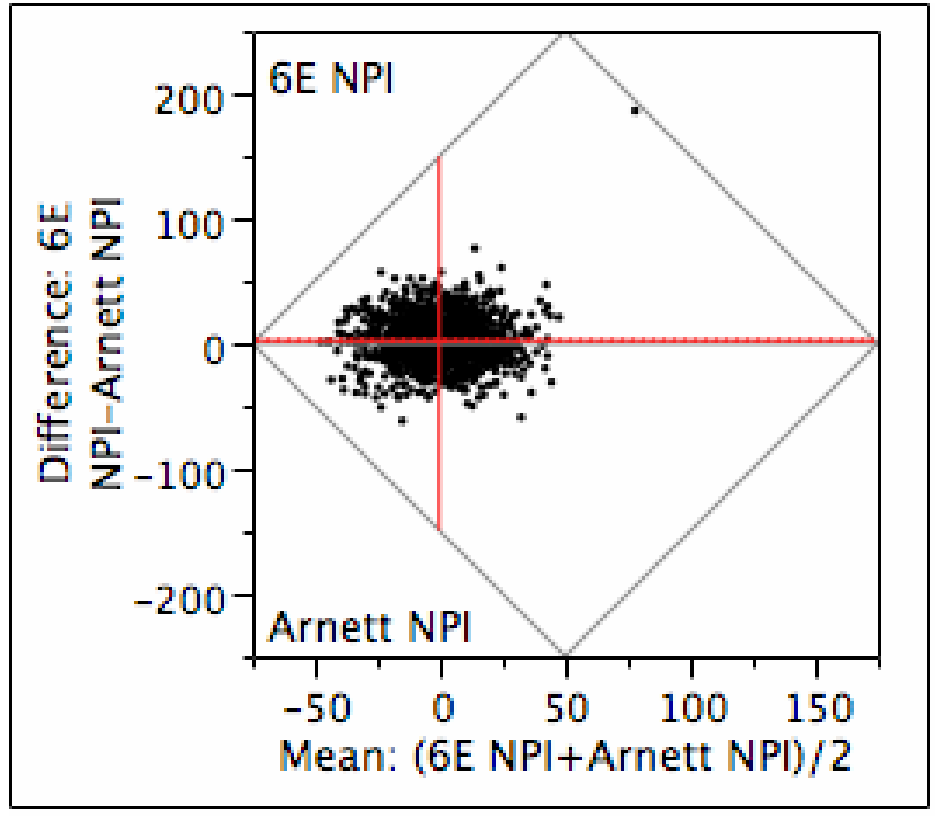

$\begin{array}{lrlr}\text { 6E NPI } & 0.82503 & \text { t-Ratio } & 6.176655 \\ \text { Arnett NPI } & -1.5069 & \text { DF } & 1885 \\ \text { Mean } & 2.33192 & \text { Prob }> & <.0001 \\ \text { Difference } & & |\mathrm{t}| & \\ \text { Std Error } & 0.37754 & \text { Prob }>\mathrm{t} & <.0001 \\ \text { Upper95\% } & 3.07235 & \text { Prob }<\mathrm{t} & 1.0000 \\ \text { Lower95\% } & 1.59148 & & \\ \text { N } & 1886 & & \\ \text { Correlation } & 0.45654 & & \end{array}$

Non-Pro raters prefer procedure $6 \mathrm{e}$ over the Arnett procedure. $\mathrm{P}<0.0001$ 
Matched Pairs Rstatus=PRO

Difference: 6E NPI-Arnett NPI

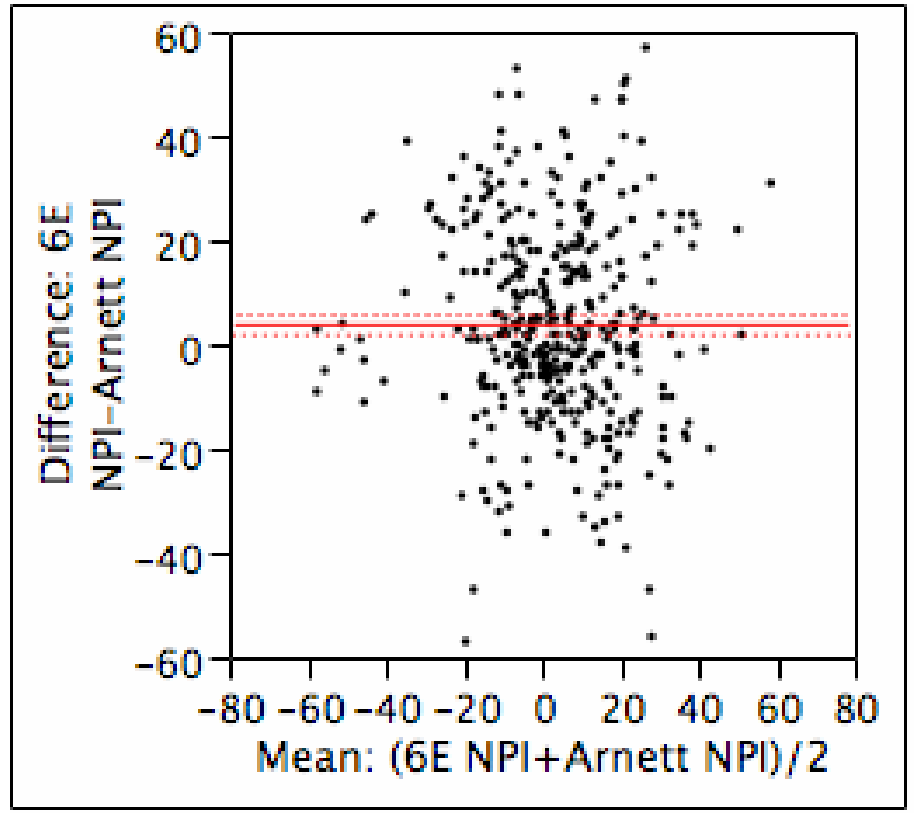

\begin{tabular}{|c|c|c|c|}
\hline $6 \mathrm{E} \quad \mathrm{NPI}$ & 5.34271 & t-Ratio & 3.88802 \\
\hline Arnett NPI & 1.59079 & DF & 390 \\
\hline Mean & 3.75192 & Prob > & ๑. . 0001 \\
\hline Difference & & $|t|$ & \\
\hline Std Error & 0.96499 & Prob $>t$ & $<.0001$ \\
\hline Upper95\% & 5.64916 & Prob $<t$ & 0.9999 \\
\hline Lower 95\% & 1.85468 & & \\
\hline $\mathrm{N}$ & 391 & & \\
\hline Correlation & 0.54932 & & \\
\hline
\end{tabular}

Pro raters prefer procedure $6 \mathrm{e}$ over the Arnett procedure. $\mathrm{P}<0.0001$ 


\section{Matched Pairs}

\section{Difference: 6E REP-ORIG REP}

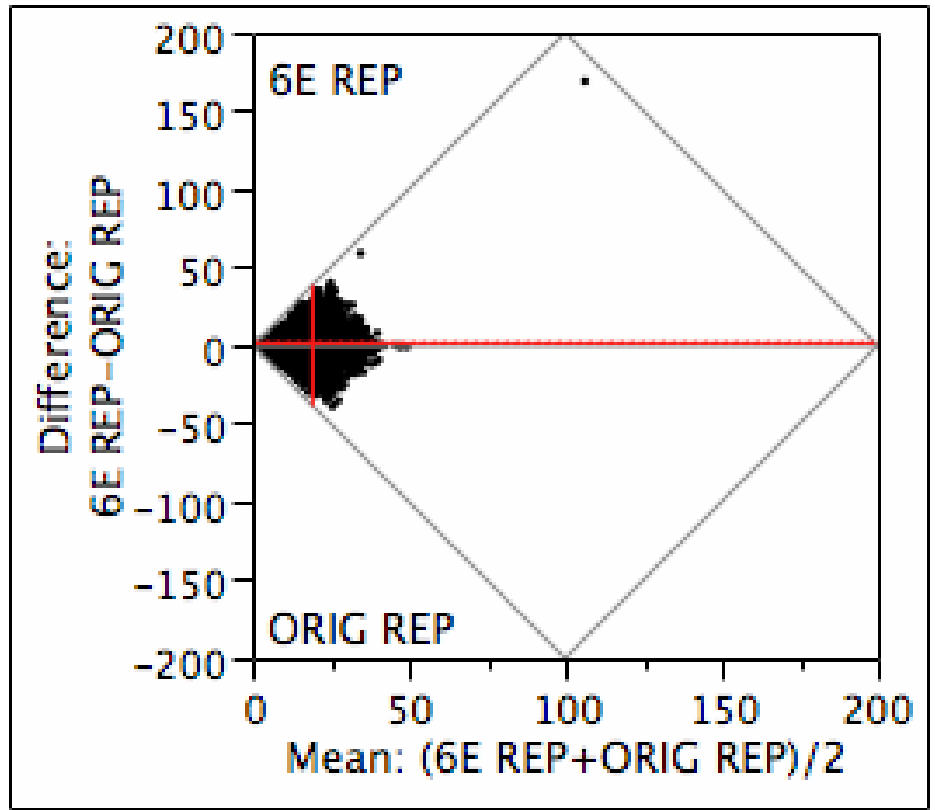

$\begin{array}{lrlr}\text { 6E REP } & 20.0599 & \text { t-Ratio } & 5.802898 \\ \text { ORIG REP } & 18.6197 & \text { DF } & 2271 \\ \text { Mean } & 1.44014 & \text { Prob }> & <.0001 \\ \text { Difference } & & |\mathrm{t}| & \\ \text { Std Error } & 0.24818 & \text { Prob }>\mathrm{t} & <.0001 \\ \text { Upper95\% } & 1.92682 & \text { Prob }<\mathrm{t} & 1.0000 \\ \text { Lower95\% } & 0.95347 & & \\ \text { N } & 2272 & & \\ \text { Correlation } & 0.28813 & & \end{array}$

For Repose cases, procedure 6e is preferred over the Original. $\mathrm{P}<0.0001$. 


\section{Matched Pairs Rstatus=NONPRO}

\section{Difference: 6E REP-ORIG REP}

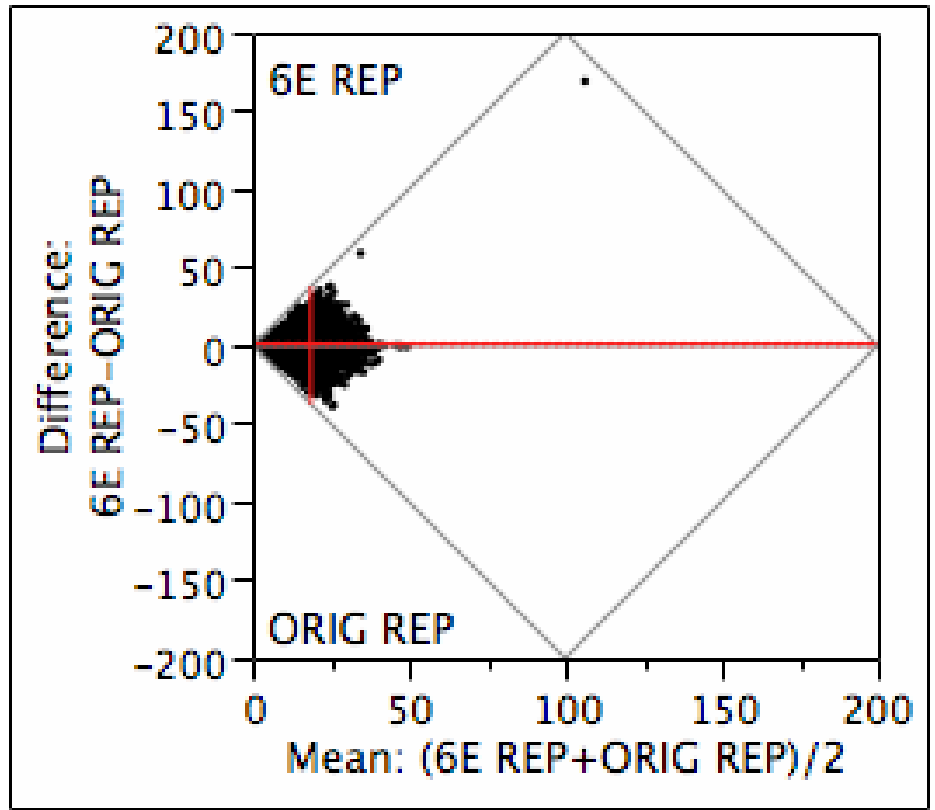

$\begin{array}{lrlr}\text { 6E REP } & 19.1733 & \text { t-Ratio } & 3.446958 \\ \text { ORIG REP } & 18.2695 & \text { DF } & 1880 \\ \text { Mean } & 0.90377 & \text { Prob }> & 0.0006 \\ \text { Difference } & & |\mathrm{t}| & \\ \text { Std Error } & 0.26219 & \text { Prob }>\mathrm{t} & 0.0003 \\ \text { Upper95\% } & 1.418 & \text { Prob }<\mathrm{t} & 0.9997 \\ \text { Lower95\% } & 0.38955 & & \\ \text { N } & 1881 & & \\ \text { Correlation } & 0.3241 & & \end{array}$

For Repose cases, Non-Pro raters prefer procedure 6e is over the Original. $\mathrm{P}=0.0003$. 
Matched Pairs Rstatus=PRO

Difference: 6E REP-ORIG REP

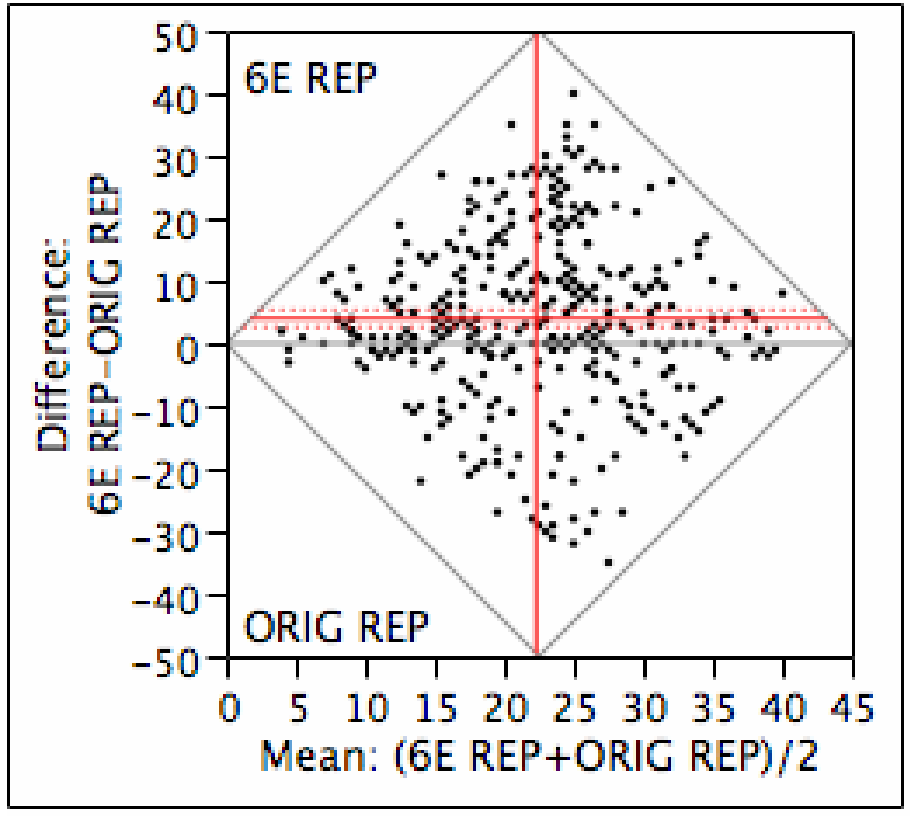

$\begin{array}{lrlr}\text { 6E REP } & 24.3248 & \text { t-Ratio } & 5.869625 \\ \text { ORIG REP } & 20.3043 & \text { DF } & 390 \\ \text { Mean } & 4.02046 & \text { Prob }> & <.0001 \\ \text { Difference } & & |\mathrm{t}| & \\ \text { Std Error } & 0.68496 & \text { Prob }>\mathrm{t} & <.0001 \\ \text { Upper95\% } & 5.36714 & \text { Prob }<\mathrm{t} & 1.0000 \\ \text { Lower95\% } & 2.67378 & & \\ \text { N } & 391 & & \\ \text { Correlation } & 0.06935 & & \end{array}$

For Repose cases, Pro raters prefer procedure 6e is over the Original. $\mathrm{P}<0.0003$. 


\section{Matched Pairs}

\section{Difference: 6E SM-ORIG SM}

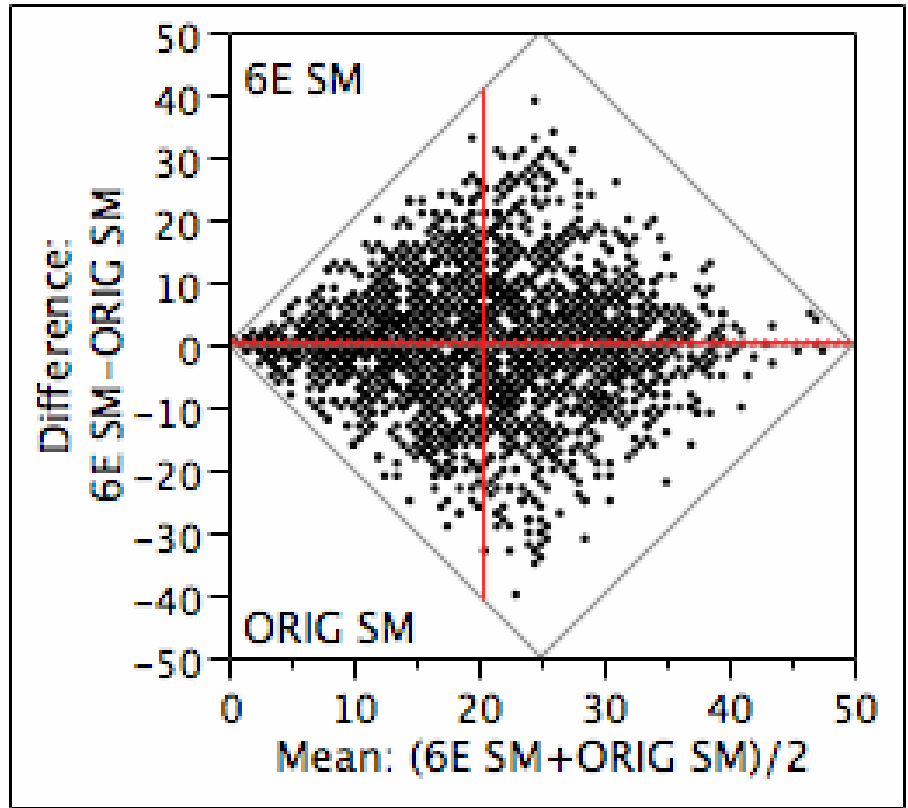

$\begin{array}{lrlr}\text { 6E SM } & 20.5455 & \text { t-Ratio } & 0.925879 \\ \text { ORIG SM } & 20.3371 & \text { DF } & 2274 \\ \text { Mean } & 0.20835 & \text { Prob }> & 0.3546 \\ \text { Difference } & & |\mathrm{t}| & \\ \text { Std Error } & 0.22503 & \text { Prob }>\mathrm{t} & 0.1773 \\ \text { Upper95\% } & 0.64964 & \text { Prob }<\mathrm{t} & 0.8227 \\ \text { Lower95\% } & -0.2329 & & \\ \text { N } & 2275 & & \\ \text { Correlation } & 0.43506 & & \end{array}$

For Smiling cases, there is no significant difference between procedure 6e and the Original. $\mathrm{P}=0.35$. 


\section{Matched Pairs Rstatus=NONPRO}

\section{Difference: 6E SM-ORIG SM}

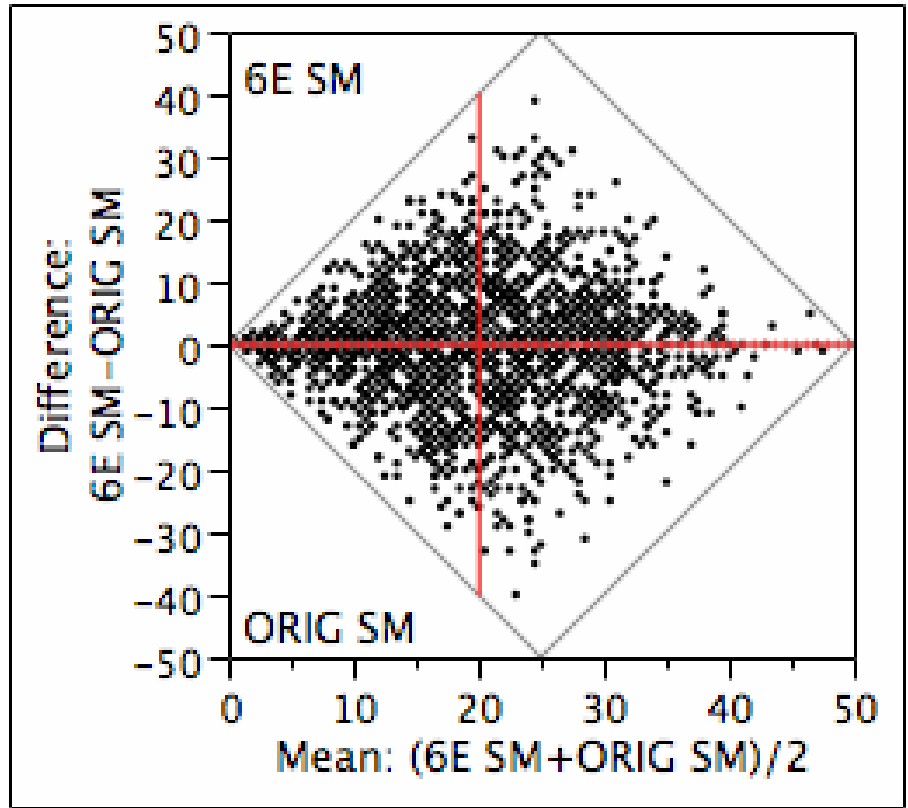

$\begin{array}{lrlr}\text { 6E SM } & 20.0579 & \text { t-Ratio } & -\odot .09471 \\ \text { ORIG SM } & 20.0807 & \text { DF } & 1883 \\ \text { Mean } & -0.0228 & \text { Prob }> & 0.9246 \\ \text { Difference } & & |\mathrm{t}| & \\ \text { Std Error } & 0.24098 & \text { Prob }>\mathrm{t} & 0.5377 \\ \text { Upper95\% } & 0.44979 & \text { Prob }<\mathrm{t} & 0.4623 \\ \text { Lower95\% } & -0.4954 & & \\ \text { N } & 1884 & & \\ \text { Correlation } & 0.45336 & & \end{array}$

In Smiling cases,for Non-Pro raters there is no significant difference between procedure $6 \mathrm{e}$ and the Original. $\mathrm{P}=0.92$. 


\section{Matched Pairs Rstatus=PRO}

\section{Difference: 6E SM-ORIG SM}

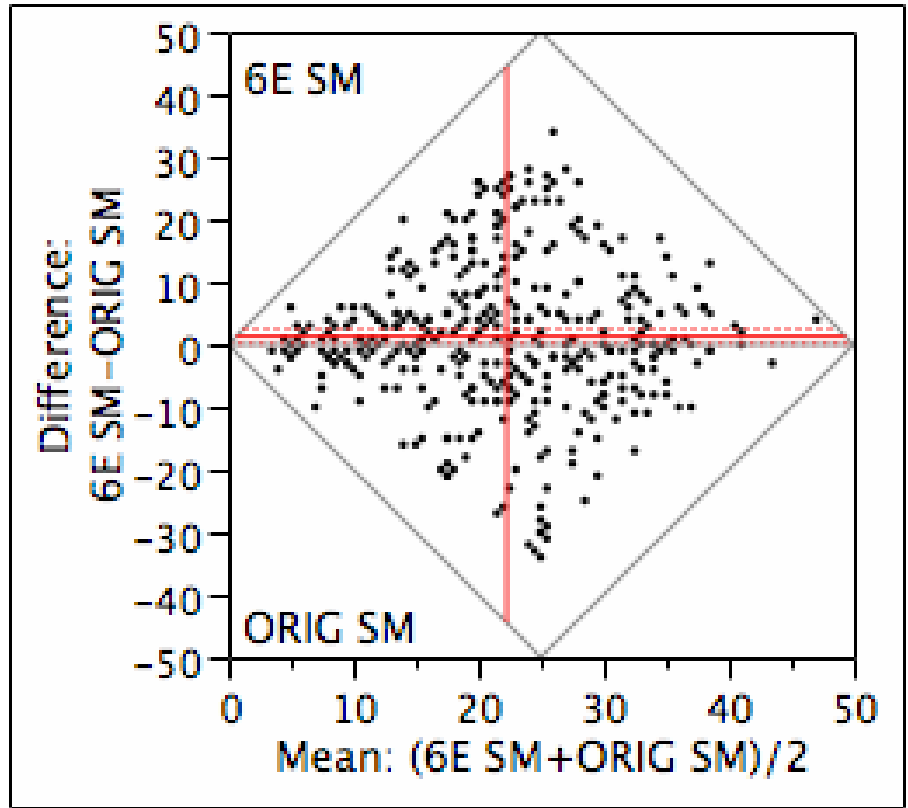

6E SM

ORIG SM

Mean

Difference

Std Error

Upper $95 \%$

Lower 95\%

$\mathrm{N}$

Correlation
22.8951

21.5729

1.32225

DF

Prob >

$|\mathrm{t}|$

0.60261 Prob $>\mathrm{t}$

2.50703 Prob $<\mathrm{t}$

0.13748

391

0.33704

In Smiling cases, Pro raters prefer procedure 6e over the Original. $\mathrm{P}=0.01$. 


\section{Matched Pairs}

\section{Difference: ARN REP-ORIG REP}

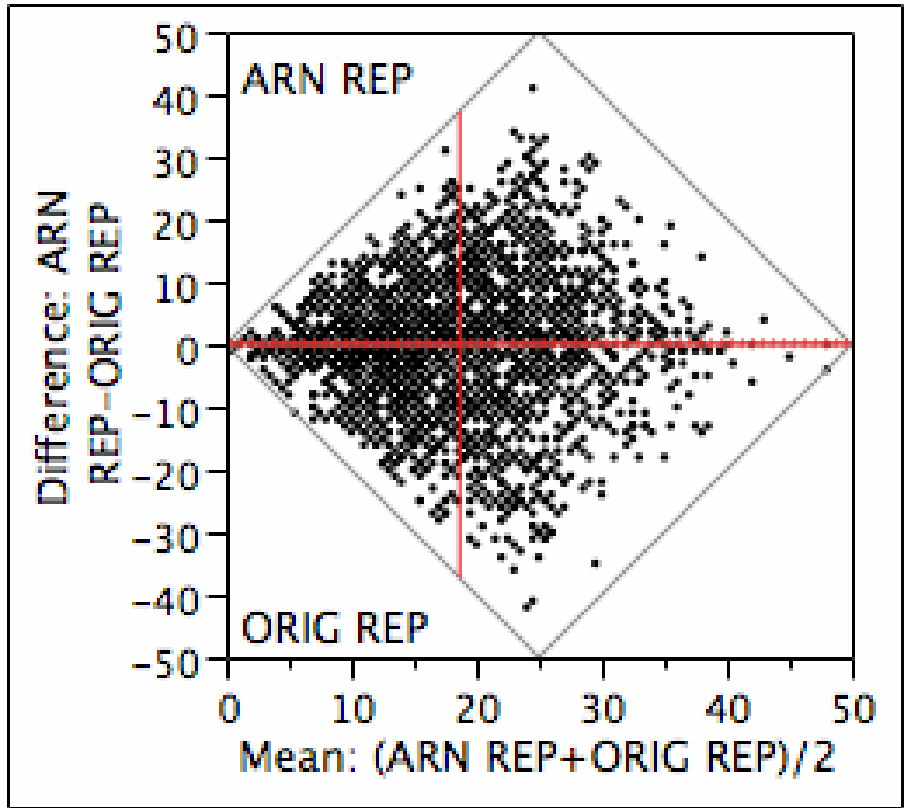

$\begin{array}{lrlr}\text { ARN REP } & 18.7267 & \text { t-Ratio } & 0.43888 \\ \text { ORIG REP } & 18.6208 & \text { DF } & 2275 \\ \text { Mean } & 0.10589 & \text { Prob }> & 0.6608 \\ \text { Difference } & & |\mathrm{t}| & \\ \text { Std Error } & 0.24127 & \text { Prob }>\mathrm{t} & 0.3304 \\ \text { Upper95\% } & 0.57901 & \text { Prob }<\mathrm{t} & 0.6696 \\ \text { Lower95\% } & -0.3672 & & \\ \text { N } & 2276 & & \\ \text { Correlation } & 0.28479 & & \end{array}$

For Repose cases, there is no significant difference between procedure Arnett and the Original. $\mathrm{P}=0.66$. 


\section{Matched Pairs Rstatus=NONPRO}

\section{Difference: ARN REP-ORIG REP}

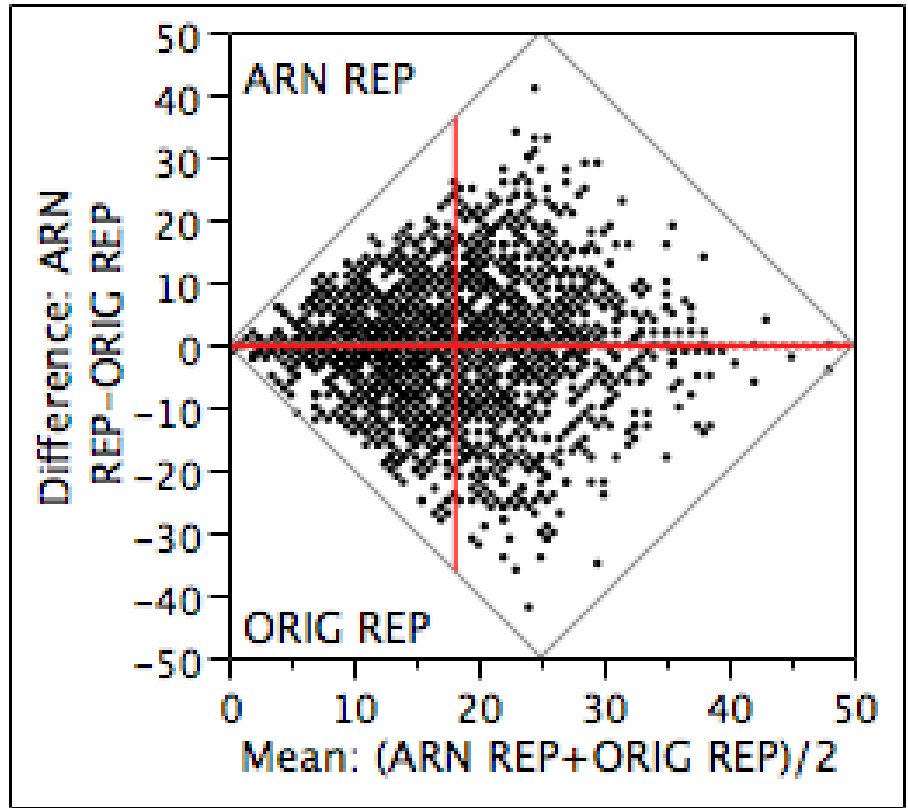

$\begin{array}{lrlr}\text { ARN REP } & 18.0037 & \text { t-Ratio } & -1.05547 \\ \text { ORIG REP } & 18.2716 & \text { DF } & 1884 \\ \text { Mean } & -0.2679 & \text { Prob }> & 0.2913 \\ \text { Difference } & & |\mathrm{t}| & \\ \text { Std Error } & 0.25382 & \text { Prob }>\mathrm{t} & 0.8543 \\ \text { Upper95\% } & 0.2299 & \text { Prob < t } & 0.1457 \\ \text { Lower95\% } & -0.7657 & & \\ \text { N } & 1885 & & \\ \text { Correlation } & 0.31819 & & \end{array}$

In Repose cases,for Non-Pro raters there is no significant difference between procedure Arnett and the Original. $\mathrm{P}=0.29$. 
Matched Pairs Rstatus=PRO

\section{Difference: ARN REP-ORIG REP}

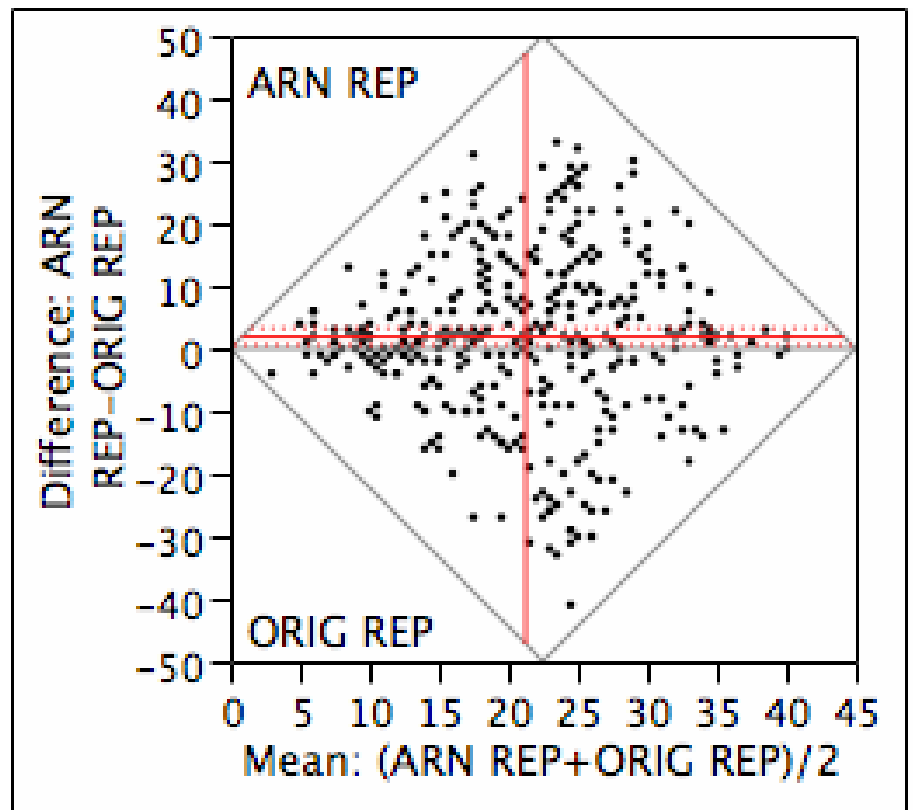

$\begin{array}{lrlr}\text { ARN REP } & 22.2123 & \text { t-Ratio } & 2.794715 \\ \text { ORIG REP } & 20.3043 & \text { DF } & 390 \\ \text { Mean } & 1.90793 & \text { Prob }> & 0.0055 \\ \text { Difference } & & |\mathrm{t}| & \\ \text { Std Error } & 0.68269 & \text { Prob }>\mathrm{t} & 0.0027 \\ \text { Upper95\% } & 3.25014 & \text { Prob }<\mathrm{t} & 0.9973 \\ \text { Lower95\% } & 0.56571 & & \\ \text { N } & 391 & & \\ \text { Correlation } & 0.09736 & & \end{array}$

In Repose cases,for Pro raters prefer procedure Arnett over the Original. $\mathrm{P}=0.002$. 


\section{Matched Pairs}

\section{Difference: ARN SM-ORIG SM}

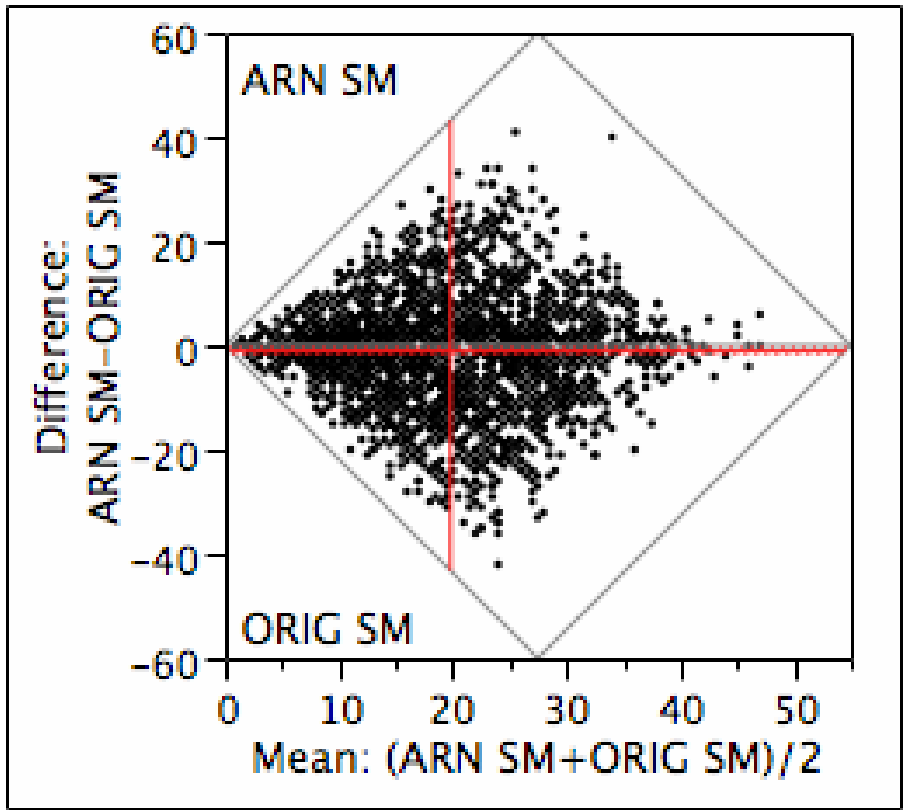

$\begin{array}{lrlr}\text { ARN SM } & 19.2575 & \text { t-Ratio } & -4.64927 \\ \text { ORIG SM } & 20.3388 & \text { DF } & 2275 \\ \text { Mean } & -1.0813 & \text { Prob }> & <.0001 \\ \text { Difference } & & |\mathrm{t}| & \\ \text { Std Error } & 0.23257 & \text { Prob }>\mathrm{t} & 1.0000 \\ \text { Upper95\% } & -0.6252 & \text { Prob }<\mathrm{t} & <.0001 \\ \text { Lower95\% } & -1.5374 & & \\ \text { N } & 2276 & & \\ \text { Correlation } & 0.39139 & & \end{array}$

For Smiling cases, procedure Original is preferred over the Arnett. $\mathrm{P}<0.0001$. 


\section{Matched Pairs Rstatus=NONPRO}

\section{Difference: ARN SM-ORIG SM}

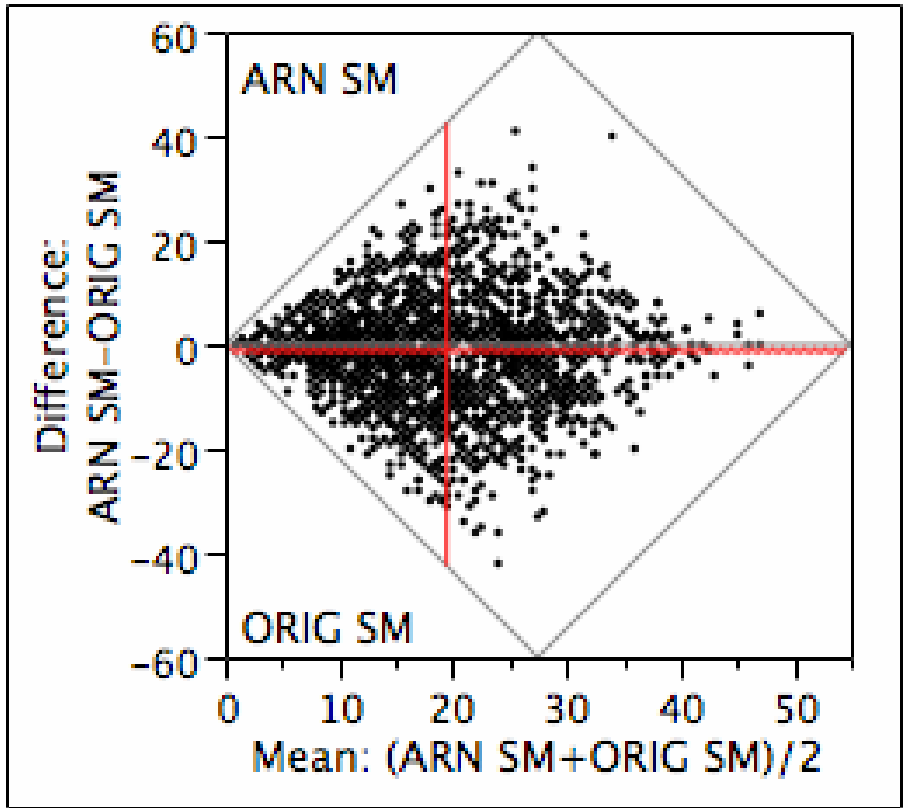

$\begin{array}{lrlr}\text { ARN SM } & 18.843 & \text { t-Ratio } & -5.05772 \\ \text { ORIG SM } & 20.0828 & \text { DF } & 1884 \\ \text { Mean } & -1.2398 & \text { Prob }> & <.0001 \\ \text { Difference } & & |\mathrm{t}| & \\ \text { Std Error } & 0.24513 & \text { Prob }>\mathrm{t} & 1.0000 \\ \text { Upper95\% } & -0.759 & \text { Prob }<\mathrm{t} & <.0001 \\ \text { Lower95\% } & -1.7205 & & \\ \text { N } & 1885 & & \\ \text { Correlation } & 0.42821 & & \end{array}$

For Smiling cases, Non-Pro raters prefer Original over the Arnett. $\mathrm{P}<0.0001$. 


\section{Matched Pairs Rstatus=PRO}

\section{Difference: ARN SM-ORIG SM}

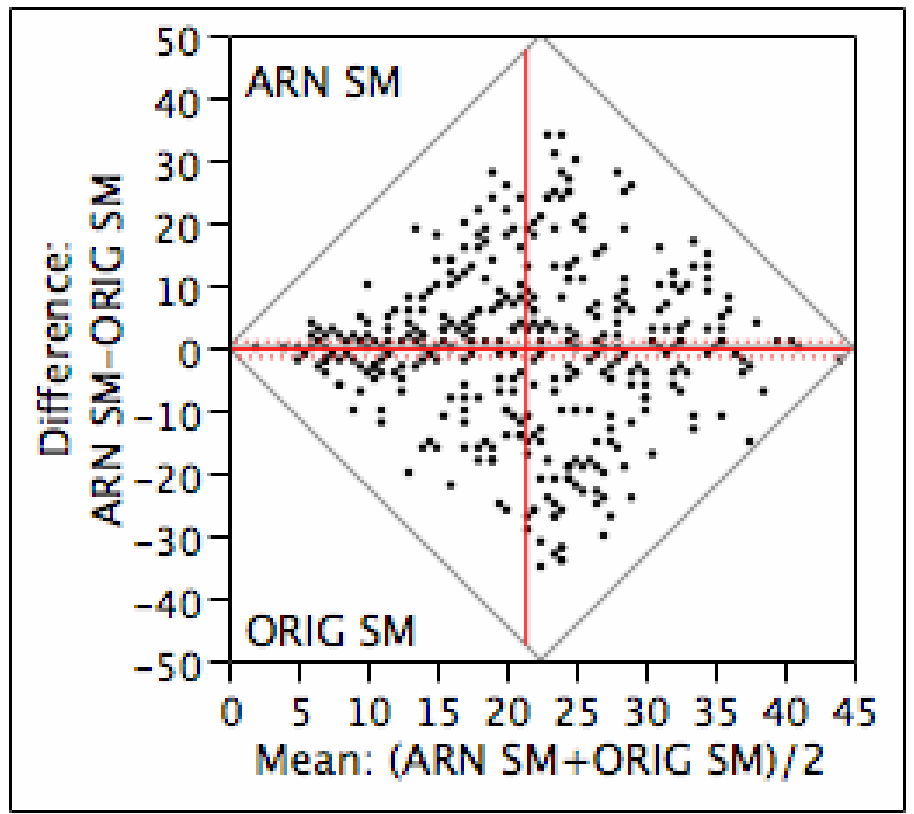

$\begin{array}{lrlr}\text { ARN SM } & 21.2558 & \text { t-Ratio } & -0.4806 \\ \text { ORIG SM } & 21.5729 & \text { DF } & 390 \\ \text { Mean } & -0.3171 & \text { Prob }> & 0.6311 \\ \text { Difference } & & |\mathrm{t}| & \\ \text { Std Error } & 0.65988 & \text { Prob }>\mathrm{t} & 0.6845 \\ \text { Upper95\% } & 0.98023 & \text { Prob }<\mathrm{t} & 0.3155 \\ \text { Lower95\% } & -1.6145 & & \\ \text { N } & 391 & & \\ \text { Correlation } & 0.21311 & & \end{array}$

For Smiling cases, for Pro raters there is significant difference between Original and the Arnett. $\mathrm{P}=0.63$. 


$\begin{array}{lr}\text { Response 6E-ARN (REP) } \\ \text { Whole Model } \\ \text { Summary of Fit } \\ \text { RSquare } \\ \text { RSquare Adj } \\ \text { Root Mean Square Error } \\ \text { Mean of Response } & -0.01994 \\ \text { Observations (or Sum } & 12.0294 \\ \text { Wgts) } & 1.34375 \\ & \end{array}$

$\begin{array}{lrrrrr}\text { Parameter Estimates } & & & & \\ \text { Term } & \text { Estimate } & \text { Std Error } & \text { DFDen } & \text { t Ratio } & \text { Prob }>\mid \mathbf{t} \text { | } \\ \text { Intercept } & 1.6479291 & 0.296557 & 96.82 & 5.56 & <.0001 \\ \text { Rstatus[NONPRO] } & -0.464603 & 0.296557 & 96.82 & -1.57 & 0.1205\end{array}$

$\begin{array}{lrrrrr}\text { Fixed } & \text { Effect } & \text { Tests } & & & \\ \text { Source } & \text { Nparm } & \text { DF } & \text { DFDen } & \text { F Ratio } & \text { Prob > F } \\ \text { Rstatus } & 1 & 1 & 96.82 & 2.4544 & 0.1205\end{array}$

\section{Rstatus}

Least Squares Means Table
Level
Least Sq Mean
Std Error
NONPRO
1.1833261
0.24611800
PRO
2.1125320
0.53963833
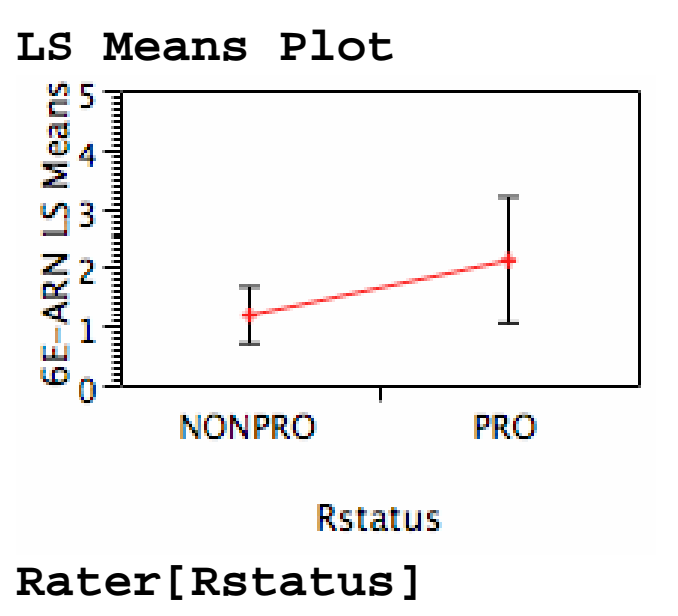

For Repose cases, there is no evidence of rater status differences. $\mathrm{P}=0.12$. For Repose cases, there is some weak evidence that Pro raters prefer 6e over Arnett, more than NonPro raters. 


\section{Response 6E-ARN (REP) \\ Summary of Fit}

$\begin{array}{lr}\text { RSquare } & -0.01863 \\ \text { RSquare Adj } & -0.01908 \\ \text { Root Mean Square Error } & 12.02935 \\ \text { Mean of Response } & 1.34375 \\ \text { Observations (or Sum } & 2272\end{array}$

Wgts )

\begin{tabular}{lrrrrr} 
Parameter & \multicolumn{2}{l}{ Estimates } & & & \\
Term & Estimate & Std Error & DFDen & t Ratio & Prob $>|t|$ \\
Intercept & 1.3411671 & 0.226758 & 97.26 & 5.91 & $<.0001$ \\
Rgender[F] & -0.071292 & 0.226758 & 97.26 & -0.31 & 0.7539
\end{tabular}

$\begin{array}{llrrr}\begin{array}{l}\text { REML Variance } \\ \text { Random Effect }\end{array} & \begin{array}{c}\text { Component } \\ \text { Var Ratio Var Component }\end{array} & \text { Std Error } & \begin{array}{r}\text { Pct of } \\ \text { Total }\end{array} \\ \text { Rater[Rgender] } & -0.008428 & -1.219598 & 0.7537073 & -0.850 \\ \text { Residual } & & 144.7053 & 4.3897571 & 100.850 \\ \text { Total } & 143.4857 & & 100.000 \\ \quad-2 \text { LogLikelihood }= & & & \\ 17729.153259 & & & \end{array}$

\section{Fixed Effect Tests}

Source Nparm DF DFDen F Ratio Prob > F

$\begin{array}{llllll}\text { Rgender } & 1 & 1 & 97.26 & 0.0988 & 0.7539\end{array}$

\section{Effect Details}

Rgender

Least Squares Means Table

Level Least Sq Mean Std Error

$\begin{array}{lll}\mathrm{F} & 1.2698752 & 0.32560673 \\ \mathrm{M} & 1.4124590 & 0.31568501\end{array}$




\section{LS Means Plot}

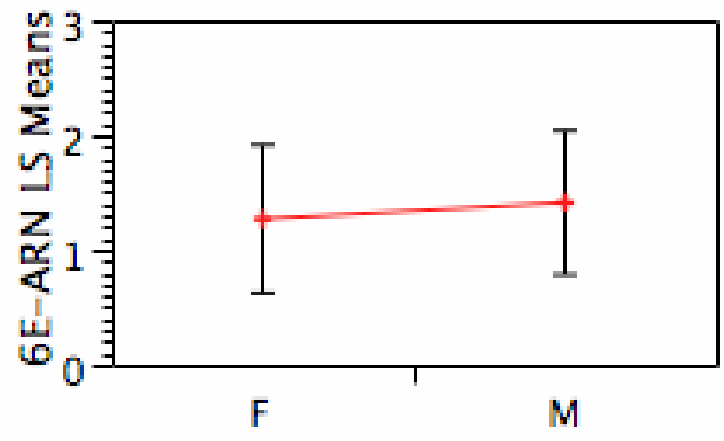

Rgender

\section{Rater [Rgender]}

For Repose cases, there is no evidence of rater gender differences. $\mathrm{P}=0.75$. For Repose cases, there is no evidence that Male raters prefer 6e over Arnett more than the Female raters 


\section{Response 6E-ARN (REP) \\ Summary of Fit}

$\begin{array}{lr}\text { RSquare } & 0.229585 \\ \text { RSquare Adj } & 0.229246 \\ \text { Root Mean Square Error } & 10.56236 \\ \text { Mean of Response } & 1.34375 \\ \text { Observations (or Sum } & 2272\end{array}$

Wgts )

$\begin{array}{lrrrrr}\text { Parameter } & \text { Estimates } & & & & \\ \text { Term } & \text { Estimate } & \text { Std Error } & \text { DFDen } & \text { t Ratio } & \text { Prob }>|\mathbf{t}| \\ \text { Intercept } & 2.3438304 & 1.467373 & 21 & 1.60 & 0.1251 \\ \text { Sgender[F] } & -1.788504 & 1.467373 & 21 & -1.22 & 0.2364\end{array}$

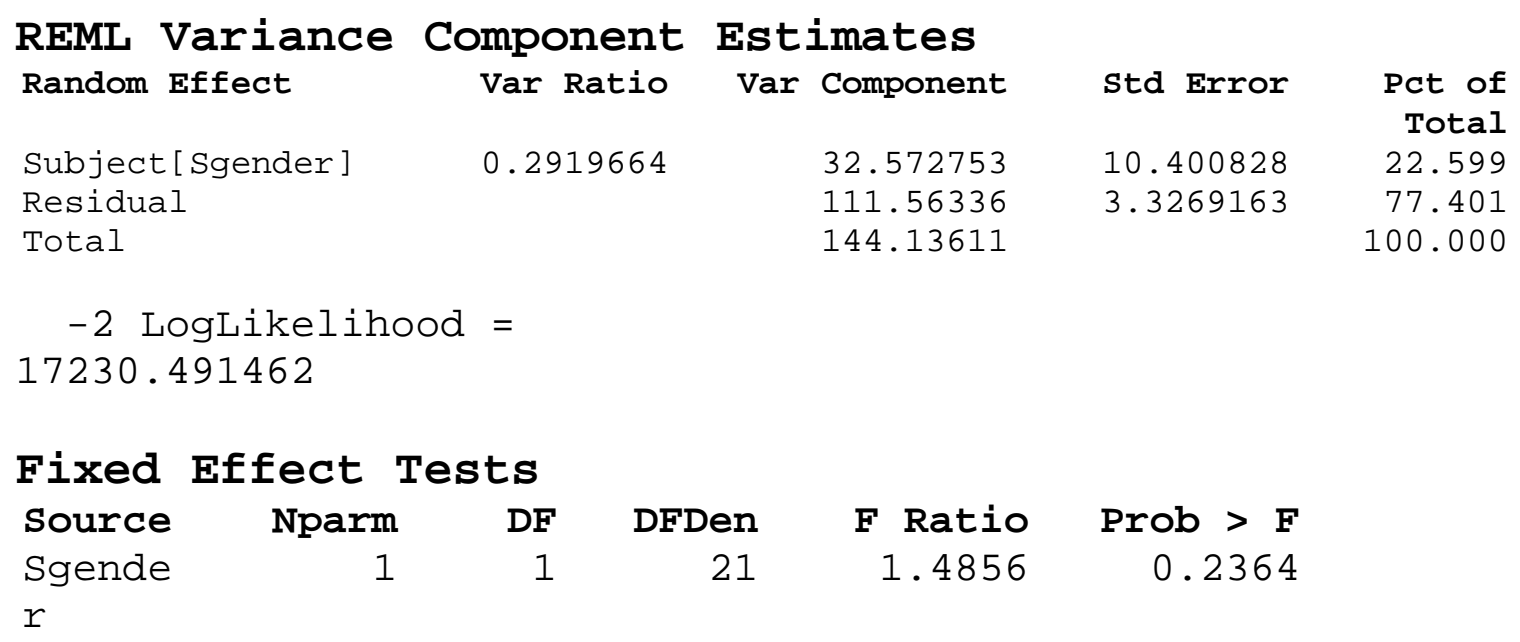

Effect Details

Sgender

Least Squares Means Table

Level Least Sq Mean Std Error

$\begin{array}{lll}\mathrm{F} & 0.5553262 & 1.3683374 \\ \mathrm{M} & 4.1323345 & 2.5962263\end{array}$


LS Means Plot

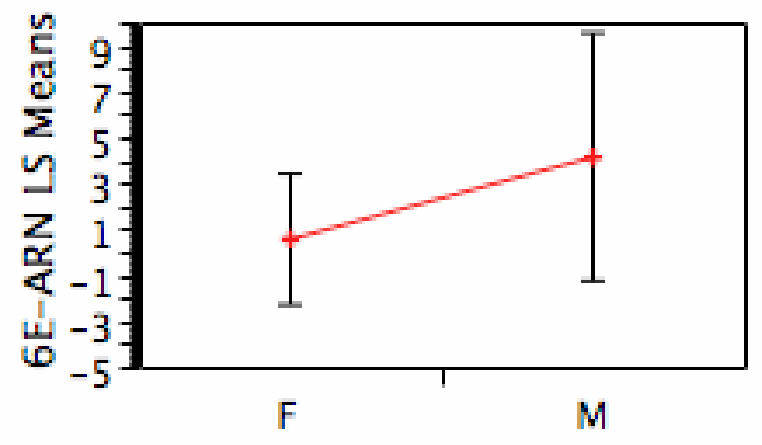

Sgender

\section{Subject [Sgender]}

For Repose cases, there is no evidence of subject gender differences. $\mathrm{P}=0.23$. 


$\begin{array}{lr}\text { Response 6E-ARN (SMIL) } \\ \text { Summary of Fit } \\ \text { RSquare } & -0.00988 \\ \text { RSquare Adj } & -0.01033 \\ \text { Root Mean Square Error } & 10.47524 \\ \text { Mean of Response } & 1.290989 \\ \text { Observations (or Sum } & 2275 \\ \text { Wgts) } & \end{array}$

\section{Parameter Estimates

Term Estimate \\ Intercept $\quad 1.428855$ \\ Rstatus[NONPRO] $\quad-0.210531$

$\begin{array}{rrrr}\text { Std Error } & \text { DFDen } & \text { t Ratio } & \text { Prob }>|t| \\ 0.274423 & 96.69 & 5.21 & <.0001 \\ 0.274423 & 96.69 & -0.77 & 0.4448\end{array}$

$\begin{array}{llrrr}\begin{array}{l}\text { REML Variance } \\ \text { Random Effect }\end{array} & \begin{array}{c}\text { Component } \\ \text { Var Ratio Var Component }\end{array} & \text { std Error } & \begin{array}{r}\text { Pct of } \\ \text { Total }\end{array} \\ \text { Rater[Rstatus] } & -0.004832 & -0.530168 & 0.627033 & -0.485 \\ \text { Residual } & & 109.73072 & 3.3268235 & 100.485 \\ \text { Total } & & 109.20055 & & 100.000 \\ \quad-2 \text { LogLikelihood }= & & & \\ 17132.59566 & & & \end{array}$

Fixed Effect Tests

$\begin{array}{lrrrrr}\text { Source } & \text { Nparm } & \text { DF } & \text { DFDen } & \text { F Ratio } & \text { Prob > F } \\ \text { Rstatu } & 1 & 1 & 96.69 & 0.5886 & 0.4448\end{array}$

$\mathrm{S}$

\section{Effect Details}

Rstatus

Least Squares Means Table

Level Least Sq Mean Std Error

$\begin{array}{lll}\text { NONPRO } & 1.2183238 & 0.22754738\end{array}$

$\begin{array}{lll}\text { PRO } & 1.6393862 & 0.49945456\end{array}$ 


\section{Rater[Rstatus]}

For Smiling cases, there is no evidence of rater status differences. $\mathrm{P}=0.44$.

For Smiling cases, there is no significant evidence that Pro raters prefer 6e over Arnett, more than Non-Pro raters 


\section{Response 6E-ARN (SMIL) \\ Summary of Fit}

$\begin{array}{lr}\text { RSquare } & -0.00964 \\ \text { RSquare Adj } & -0.01008 \\ \text { Root Mean Square Error } & 10.47522 \\ \text { Mean of Response } & 1.290989 \\ \text { Observations (or Sum } & 2275\end{array}$

Wgts )

\section{Parameter Estimates \\ Term \\ Intercept \\ Rgender [F] \\ Estimate \\ 1.2886824 \\ $-0.066903$ \\ Std Error \\ 0.20769 \\ $\odot .20769$ \\ DFDen \\ 96.85 \\ 96.85
t Ratio
6.20 \\ $-0.32$}

\section{REML Variance Component Estimates \\ Random Effect \\ Rater [Rgender] \\ Residual \\ Total \\ Var Component Std Error \\ $-0.508625 \quad 0.6299892$ \\ $109.73033 \quad 3.3268007$ \\ 109.22171

$$
\begin{array}{r}
\text { Pct of } \\
\text { Total } \\
-0.466
\end{array}
$$$$
100.466
$$ \\ 100.000 \\ - 2 LogLikelihood = \\ 17133.640989}

\section{Fixed Effect Tests}

$\begin{array}{lrrrrr}\text { Source } & \text { Nparm } & \text { DF } & \text { DFDen } & \text { F Ratio } & \text { Prob > F } \\ \text { Rgender } & 1 & 1 & 96.85 & 0.1038 & 0.7480\end{array}$

\section{Effect Details}

Rgender

Least Squares Means Table

Level Least Sq Mean

Std Error

$\mathrm{F}$

1.2217793

๑. 29813904

$M$

1. 3555855

$\odot .28922875$ 


\section{Rater [Rgender ]}

For Smiling cases, there is no significant evidence of rater gender differences in preference of $6 \mathrm{e}$ over Arnett. $\mathrm{P}=0.74$. That is, for Smiling cases, there is no significant evidence that Male raters prefer 6e over Arnett more than the Female raters. 


\section{Response 6E-ARN (SMIL) \\ Summary of Fit}

$\begin{array}{lr}\text { RSquare } & 0.163297 \\ \text { RSquare Adj } & 0.162928 \\ \text { Root Mean Square Error } & 9.602569 \\ \text { Mean of Response } & 1.290989 \\ \text { Observations (or Sum } & 2275\end{array}$

Wgts )

$\begin{array}{lrrrrr}\text { Parameter } & \text { Estimates } & & & & \\ \text { Term } & \text { Estimate } & \text { Std Error } & \text { DFDen } & \text { t Ratio } & \text { Prob }>|\mathbf{t}| \\ \text { Intercept } & 1.4186112 & 1.116525 & 21 & 1.27 & 0.2178 \\ \text { Sgender[F] } & -0.227853 & 1.116525 & 21 & -0.20 & 0.8403\end{array}$

\section{REML Variance Component Estimates}

$\begin{array}{lrrrr}\text { Random Effect } & \text { Var Ratio } & \text { Var Component } & \text { Std Error } & \begin{array}{r}\text { Pct of } \\ \text { Total }\end{array} \\ \text { Subject[Sgender] } & 0.2015067 & 18.5808 & 6.0217106 & 16.771 \\ \text { Residual } & & 92.209327 & 2.747929 & 83.229 \\ \text { Total } & & 110.79013 & & 100.000\end{array}$

-2 LogLikelihood = 16812.626913

Fixed Effect Tests

$\begin{array}{rrrrrr}\text { Source } & \text { Nparm } & \text { DF } & \text { DFDen } & \text { F Ratio } & \text { Prob > F } \\ \text { Sgende } & 1 & 1 & 21 & 0.0416 & 0.8403\end{array}$

$r$

\section{Effect Details \\ Sgender \\ Least Squares Means Table \\ Level Least Sq Mean Std Error \\ F $\quad 1.1907577 \quad 1.0411869$ \\ $\begin{array}{lll}\text { M } & 1.6464646 & 1.9754598\end{array}$}

\section{Subject [Sgender ]}

For Smiling cases, there is no evidence of subject gender differences in preference of $6 \mathrm{e}$ over Arnett. $\mathrm{P}=0.84$. 


\section{Response 6E-ARN (NPI) \\ Summary of Fit}

$\begin{array}{lr}\text { RSquare } & -0.01813 \\ \text { RSquare Adj } & -\odot .01858 \\ \text { Root Mean Square Error } & 16.95835 \\ \text { Mean of Response } & 2.575758 \\ \text { Observations (or Sum } & 2277 \\ \text { Wgts) }\end{array}$

\begin{tabular}{lrrrrr}
$\begin{array}{l}\text { Parameter Estimates } \\
\text { Term }\end{array}$ & Estimate & Std Error & DFDen & \multicolumn{2}{c}{$\begin{array}{r}\mathbf{t} \\
\text { Ratio }\end{array}$} \\
& & & & \\
Intercept & 3.0419188 & 0.421886 & 97 & 7.21 & $<.0001$ \\
Rstatus[NONPRO] & -0.709999 & 0.421886 & 97 & -1.68 & 0.0956
\end{tabular}

$\begin{array}{lrrrr}\begin{array}{l}\text { REML Variance } \\ \text { Random Effect }\end{array} & \begin{array}{c}\text { Component } \\ \text { Var Ratio }\end{array} & \begin{array}{c}\text { Estimates } \\ \text { Var Component }\end{array} & \text { std Error } & \begin{array}{r}\text { Pct of } \\ \text { Total }\end{array} \\ \text { Rater[Rstatus] } & -0.00862 & -2.478889 & 1.488515 & -0.869 \\ \text { Residual } & & 287.58574 & 8.7147194 & 100.869 \\ \text { Total } & & 285.10685 & & 100.000\end{array}$

-2 LogLikelihood = 19329.594692

$\begin{array}{lrrrrr}\text { Fixed } & \text { Effect } & \text { Tests } & & & \\ \text { Source } & \text { Nparm } & \text { DF } & \text { DFDen } & \text { F Ratio } & \text { Prob > F } \\ \text { Rstatus } & 1 & 1 & 97 & 2.8322 & 0.0956\end{array}$

\section{Effect Details}

Rstatus

Least Squares Means Table

Level Least Sq Mean Std Error

$\begin{array}{lll}\text { NONPRO } & 2.3319194 & 0.34964858\end{array}$

$\begin{array}{lll}\text { PRO } & 3.7519182 & 0.76791692\end{array}$

\section{Rater[Rstatus]}

With respect to NPI, there is no evidence of rater status differences. $\mathrm{P}=0.09$.

With respect to NPI, there is no significant evidence that Pro raters prefer 6e over Arnett, more than Non-Pro raters. 


\section{Response 6E-ARN (NPI) \\ Summary of Fit}

$\begin{array}{lr}\text { RSquare } & -0.0167 \\ \text { RSquare Adj } & -0.01715 \\ \text { Root Mean Square Error } & 16.95835 \\ \text { Mean of Response } & 2.575758 \\ \text { Observations (or Sum } & 2277\end{array}$

Wgts )

$\begin{array}{lrrrrr}\text { Parameter } & \text { Estimates } & & & & \\ \text { Term } & \text { Estimate } & \text { Std Error } & \text { DFDen } & \text { t Ratio } & \text { Prob }>|\mathbf{t}| \\ \text { Intercept } & 2.5717977 & 0.322703 & 97 & 7.97 & <.0001 \\ \text { Rgender[F] } & -0.130675 & 0.322703 & 97 & -0.40 & 0.6864\end{array}$

$\begin{array}{llrrr}\begin{array}{l}\text { REML Variance } \\ \text { Random Effect }\end{array} & \begin{array}{c}\text { Component } \\ \text { Var Ratio }\end{array} & \begin{array}{c}\text { Estimates } \\ \text { Var Component }\end{array} & \text { Std Error } & \begin{array}{r}\text { Pct of } \\ \text { Total }\end{array} \\ \text { Rater[Rgender] } & -0.007662 & -2.203595 & 1.526776 & -0.772 \\ \text { Residual } & & 287.58574 & 8.7147194 & 100.772 \\ \text { Total } & & & & 100.000 \\ \quad-2 \text { LogLikelihood }= & & & \\ 19332.785605 & & & & \end{array}$

\section{Fixed Effect Tests}

Source Nparm DF DFDen F Ratio Prob > F

$\begin{array}{llllll}\text { Rgender } & 1 & 1 & 97 & 0.1640 & 0.6864\end{array}$

\section{Effect Details}

Rgender

Least Squares Means Table

Level Least Sq Mean Std Error

$\begin{array}{lll}\mathrm{F} & 2.4411232 & 0.46323439\end{array}$

$\begin{array}{lll}M & 2.7024723 & 0.44940337\end{array}$ 


\section{Rater [Rgender ]}

With respect to NPI, there is no evidence of rater gender differences. $\mathrm{P}=0.68$.

With respect to NPI, there is no significant evidence that Male raters prefer 6e over Arnett, more than Female raters. 


\section{Response 6E-ARN (NPI) \\ Summary of Fit}

$\begin{array}{lr}\text { RSquare } & 0.261767 \\ \text { RSquare Adj } & 0.261443 \\ \text { Root Mean Square Error } & 14.5819 \\ \text { Mean of Response } & 2.575758 \\ \text { Observations (or Sum } & 2277\end{array}$

Wgts )

$\begin{array}{lrrrrr}\text { Parameter } & \text { Estimates } & & & & \\ \text { Term } & \text { Estimate } & \text { Std Error } & \text { DFDen } & \text { t Ratio } & \text { Prob }>|\mathbf{t}| \\ \text { Intercept } & 3.7356902 & 2.242093 & 21 & 1.67 & 0.1105 \\ \text { Sgender[F] } & -2.052189 & 2.242093 & 21 & -0.92 & 0.3704\end{array}$

\begin{tabular}{|c|c|c|c|c|}
\hline $\begin{array}{l}\text { REML Variance } \\
\text { Random Effect }\end{array}$ & $\begin{array}{c}\text { Component Es } \\
\text { Var Ratio }\end{array}$ & $\begin{array}{l}\text { stimates } \\
\text { var component }\end{array}$ & Std Error & $\begin{array}{l}\text { Pct of } \\
\text { Total }\end{array}$ \\
\hline Subject [Sgender] & 0.3599435 & 76.535401 & 24.282246 & 26.468 \\
\hline $\begin{array}{l}\text { Residual } \\
\text { Total }\end{array}$ & & $\begin{array}{l}212.6317 \\
289.1671\end{array}$ & 6.333825 & $\begin{array}{r}73.532 \\
100.000\end{array}$ \\
\hline \multicolumn{5}{|c|}{$\begin{array}{l}-2 \text { LogLikelihood }= \\
18739.869999\end{array}$} \\
\hline \multicolumn{5}{|c|}{ Fixed Effect Tests } \\
\hline Source Nparm & DFDen & F Ratio & Prob > F & \\
\hline $\begin{array}{l}\text { Sgende } \\
r\end{array}$ & 21 & 0.8378 & 0.3704 & \\
\hline
\end{tabular}

\section{Effect Details \\ Sgender \\ Least Squares Means Table \\ Level Least Sq Mean Std Error

F $\quad 1.6835017 \quad 2.0907627$ \\ $\begin{array}{lll}M & 5.7878788 & 3.9669433\end{array}$}

\section{Subject [Sgender]}

With respect to NPI, there is no evidence of subject gender differences in preference of 6e over Arnett. $\mathrm{P}=0.37$. 
Reliability:

\section{Pairwise Correlations}

$\begin{array}{ll}\text { Variable } & \text { by Variable } \\ \text { T2- SMIL (Original) } & \text { T1-SMIL(original) } \\ \text { T2-SMIL (Arnett) } & \text { T1-SMIL (Arnett) } \\ \text { T2-6E } & \text { T1-6E }\end{array}$
Correlation
0.4375
0.5290
0.4534
Count Signif Prob
$295<.0001$
$295<.0001$
$295<.0001$

\section{SUBJECT 1}

Pairwise Correlations

$\begin{array}{llrrr}\text { Variable } & \text { by Variable } & \text { Correlation } & \text { Count } & \text { Signif Prob } \\ \text { T2-SMIL (Original) } & \text { T1-SMIL(original) } & 0.2855 & 99 & 0.0042 \\ \text { T2-SMIL (Arnett) } & \text { T1-SMIL (Arnett) } & 0.3432 & 99 & 0.0005 \\ \text { T2-6E } & \text { T1-6E } & 0.3644 & 99 & 0.0002\end{array}$

\section{SUBJECT 11}

\section{Pairwise Correlations}

$\begin{array}{ll}\text { Variable } & \text { by Variable } \\ \text { T2-SMIL (original) } & \text { T1-SMIL(original) } \\ \text { T2-SMIL (Arnett) } & \text { T1-SMIL (Arnett) } \\ \text { T2-6E } & \text { T1-6E }\end{array}$
Correlation
0.4199
0.6215

0.4042
Count Signif Prob
$<.0001$
$<.0001$
$<.0001$

SUBJECT 20

\section{Pairwise Correlations}

variable

T2-SMIL (Original)

T2-SMIL (Arnett)

$\mathrm{T} 2-6 \mathrm{E}$

by Variable

T1-SMIL(original)

T1-SMIL (Arnett)

T1-6E

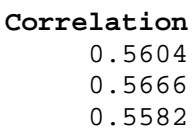

$\begin{array}{rr}\text { Count } & \text { Signif } \text { Prob } \\ 98 & <.0001 \\ 98 & <.0001 \\ 98 & <.0001\end{array}$ 


\begin{tabular}{|l|l|l|}
\hline & & Cronbach's Alpha \\
\hline Subjects 1,11,20 & Original & 0.60 \\
\hline Subjects 1,11,20 & Arnett & 0.69 \\
\hline Subjects 1,11,20 & 6e & 0.62 \\
\hline Subject 1 & Original & 0.44 \\
\hline Subject 1 & Arnett & 0.51 \\
\hline Subject 1 & 6e & 0.53 \\
\hline Subject 11 & Original & 0.59 \\
\hline Subject 11 & Arnett & 0.76 \\
\hline Subject 11 & 6e & 0.57 \\
\hline Subject 20 & Original & 0.71 \\
\hline Subject 20 & Arnett & 0.72 \\
\hline Subject 20 & 6e & 0.71 \\
\hline
\end{tabular}

The measurements are most reliable for Subject 20, followed by Subject 11 and Subject 1. Overall reliability is satisfactory. 


\section{APPENDIX E \\ CURRICULUM VITAE}




\section{Jennifer Hamilton, D.D.S.}

\section{Education}

WVU School of Dentistry

Morgantown, WV

- M.S. in Orthodontics anticipated May 2007. WVU School of Dentistry

Morgantown, WV

- Received D.D.S. in May 2004. Graduated summa cum laude as Valedictorian with a cumulative 3.94 GPA.

West Virginia University

Morgantown, WV

- Received B.S. in Animal and Veterinary Sciences in May 2000.

- Graduated summa cum laude with a cumulative 3.95 GPA in the WVU Honors Program.

Clay County High School

Clay, WV

- Graduated as Salutatorian with a cumulative 4.0 GPA in 1996.

\section{Awards and Accomplishments}

- 2004 Valedictorian WVU School of Dentistry

- 2003 National Hinman Scholar

- 2003-2004 Senior Class Secretary

- 2002-2004 Geraldine Core Willis Scholarship

- 2002-2003 Junior Class Secretary

- 2002 Omicron Kappa Upsilon Basic Health Sciences Award for highest GPA

- 2001 WVU School of Dentistry Alumni Association Instrument Award

- 2000-2004 WVU School of Dentistry Tuition Scholarship

- WVU President's List for 4.0 GPA for Fall 1996, Spring 1997, Spring 1999, Fall 1999, and Spring 2000 semesters

- WVU Dean's List for 3.5 GPA and above for Fall 1997 and Fall 1998 semesters

- Honored by Phi Kappa Phi for being in top $1 \%$ of WVU class during both freshman and sophomore years

\section{Memberships}

- American Association of Orthodontists

- American Dental Association

- Golden Key National Honor Society

- Gamma Beta Phi National Society

\section{Research Experience}

- "Individual preferences for profile attractiveness comparing Arnett and Andrews soft tissue diagnostic techniques," thesis completed March 2007.

- "Growth treatment response vector analysis to predict excessive mandibular growth in Class III patients," Peter Ngan, DMD, Jennifer Hamilton and Jamie Day, 2002-03.

- "A microbiological study of dental unit water lines," 2000.

- Research seminar: "The microbiological aspects of dental caries," 1999. 